University of Rhode Island

DigitalCommons@URI

Open Access Master's Theses

2014

\title{
A RESPONSIVE PARTICLE COATING FOR EMULSION FORMATION AT THE OIL-WATER INTERFACE
}

Sarah Beaton Fields

University of Rhode Island, sarah2988@gmail.com

Follow this and additional works at: https://digitalcommons.uri.edu/theses

\section{Recommended Citation}

Fields, Sarah Beaton, "A RESPONSIVE PARTICLE COATING FOR EMULSION FORMATION AT THE OILWATER INTERFACE" (2014). Open Access Master's Theses. Paper 350.

https://digitalcommons.uri.edu/theses/350

This Thesis is brought to you for free and open access by DigitalCommons@URI. It has been accepted for inclusion in Open Access Master's Theses by an authorized administrator of DigitalCommons@URI. For more information, please contact digitalcommons-group@uri.edu. 
A RESPONSIVE PARTICLE COATING FOR EMULSION FORMATION AT THE OIL-WATER INTERFACE

BY

SARAH BEATON FIELDS

A THESIS SUMITTED IN PARTIAL FULFILLMENT OF THE REQUIREMENTS FOR THE DEGREE OF MASTER OF SCIENCE IN CHEMICAL ENGINEERING

UNIVERSITY OF RHODE ISLAND

2014 


\section{MASTER OF SCIENCE THESIS}

OF

SARAH BEATON FIELDS

\section{APPROVED:}

Thesis Committee:

Major Professor: Geoffrey D. Bothun

Arijit Bose

Vinka Oyanedel-Craver

Nasser H. Zawia

DEAN OF THE GRADUATE SCHOOL

UNIVERSITY OF RHODE ISLAND

2014 


\begin{abstract}
Emulsions were prepared using lipid-coated silica nanoparticles as a stabilizer, and the effects of type of lipid coating, lipid tail structure, type of oil, and concentration of lipid-coated silica nanoparticle on the stability, morphology and size of these emulsions were investigated. Three different methods for coating silica nanoparticles were used, resulting in three different particle types: partial bilayer/monolayer-coated silica particles (PBC SNPs), bilayer-coated silica particles (BC SNPs), and monolayer-coated silica particles (MC SNPs), which were evaluated for their efficacy in dispersing different types of oil. Dipalmitoylphosphatidylcholine (DPPC) and dioleoylphosphatidylcholine (DOPC) were used as lipid coatings to examine the effect of lipid tail structure on particulate dispersant performance. It was observed that PBC SNPs foster emulsions that mirror the characteristics of emulsions stabilized by liposomes, and cause an inverse of the phase behavior of emulsions stabilized by silica only. When concentrations of DOPC and DPPC are adjusted such that no free vesicles are present, both characteristics of the emulsions stabilized by silica and characteristics of the emulsions stabilized by vesicles only are observed.
\end{abstract}




\section{ACKNOWLEDGEMENTS}

A big thank you to all who helped me along the way - in particular my advisor Geoff Bothun, for making this possible and coaching me through the program, as well as professors Arijit Bose and Michael Greenfield. I acknowledge and thank C-MEDS and the Gulf of Mexico Research Initiative for funding this research. Thank you to all the other professors and grad students in the department for being so friendly and making Crawford such a welcoming place.

A sincere thank you to Peng Wang for writing me a recommendation letter for entrance to the program and reinforcing my confidence in engineering at the start of the program by being enthusiastic about my biochemistry background.

Thank you to the members of the Bothun lab who helped me throughout this project, Anju, Matt, and Yaser, but especially Max.

Thank you Mom, Dad, Angie, Rob, Henry, and Esmé. Love you so much! Thank you Poppy and John for being inspiration for this path and taking particular interest in my work. 


\section{TABLE OF CONTENTS}

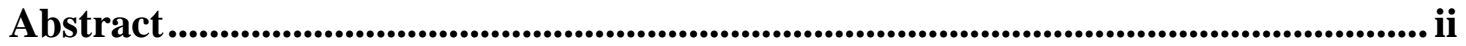

Acknowledgements................................................................................................................... iii

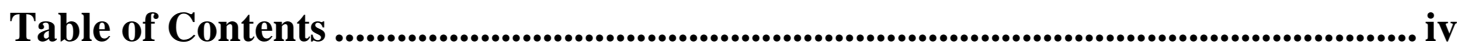

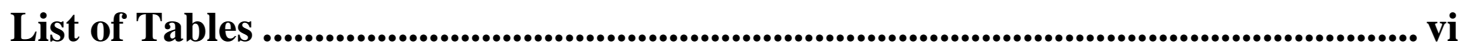

List of Figures.................................................................................................................... ix

1. Introduction ......................................................................................................... 1

2. Review of Literature ......................................................................................... 4

2.1. Oil Spills and Dispersants ................................................................ 4

2.1.1. Oil in the Marine Environment .................................................. 4

2.1.2. Dispersant Use .................................................................. 7

2.1.3. Oil Weathering......................................................................... 11

2.2. Emulsion Science and Pickering Emulsions ........................................... 11

2.2.1. Classical emulsions vs. Pickering emulsions ............................ 11

2.2.2. Pickering Emulsion Theory ……………………................... 12

2.2.3. Factors that Affect PEs ....................................................... 14

2.3. Novel Dispersant Systems ………………………………………..... 14

2.3.1. Bioengineered microbes ........................................................ 14

2.3.2. Nutrient enhanced biodegradation of oil ................................. 15

2.3.3. Materials of interest for novel dispersant systems .................... 16

2.4. Literature precedence for technique of coating silica particles with lipid

3. Methodology ............................................................................................................... 18

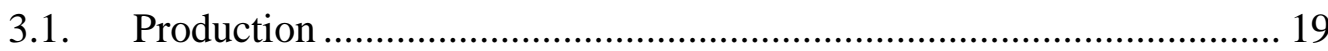

3.1.1. Partial mono/bilayer coated silica particles ............................. 19

3.1.2. Lipid bilayer-coated silica nanoparticles ................................. 23

3.1.3. Lipid monolayer-coated silica nanoparticles ............................ 25

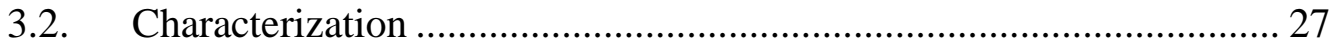

3.2.1. Confirmation of Particle Size (Dynamic Light Scattering) ..... 27 
3.2.2. Confirmation of Adsorbed Lipid (Zeta potential measurements) 27

3.2.3. Quantification of Adsorbed Lipid (Bartlett Assay) ............... 28

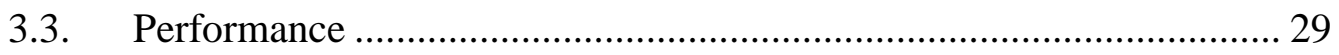

3.3.1. Preparation of emulsions .................................................. 29

3.3.2. Evaluation of dispersant performance .............................. 29

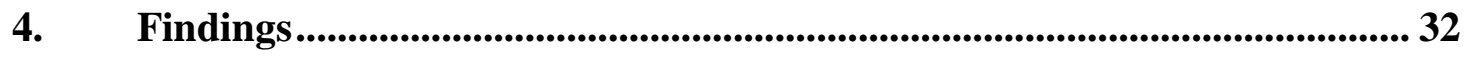

4.1. Production of PBC SNPs .......................................................... 32

4.1.1. Characterization ................................................................ 32

4.1.2. Performance of PBC SNPs as emulsifying agents................. 36

4.2. Lipid bilayer-coated silica nanoparticles (BC SNPs)........................ 46

4.2.1. Characterization of BC SNPs ............................................ 47

4.2.2. Performance of BC SNPs ............................................. 48

4.3. Lipid monolayer-coated silica nanoparticles (MC SNPs)................. 51

4.3.1. Characterization of MC SNPs............................................ 51

4.3.2. Performance of MC SNPs............................................ 52

4.4. A Comparison of emulsions stabilized with PBC SNPs, BC SNPs and

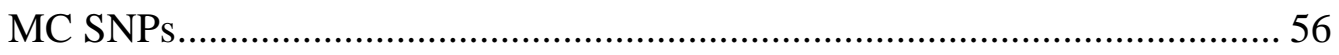

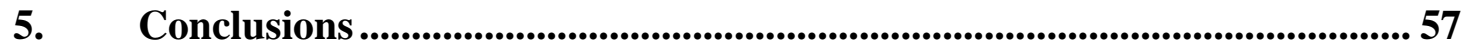

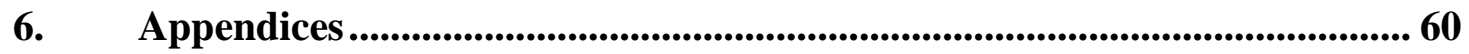

6.1. Lipid-coated silica nanoparticles............................................... 60

6.1.1. Characterization of lipid-coated silica nanoparticles .............. 60

6.1.2. Performance of lipid-coated silica particles........................... 63

6.2. Lipid bilayer-coated silica particles .......................................... 79

6.3. Lipid monolayer-coated silica particles (MC SNPs) ........................ 81

6.3.1. Characterization of MC SNPs............................................ 81

6.3.2. Performance of MC SNPs............................................... 84

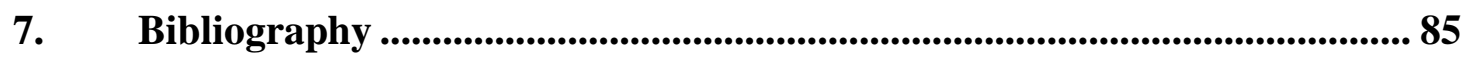




\section{LIST OF TABLES}

TABLE 3.1: MATERIALS USED IN PRODUCTION OF LIPID-COATED SILICA NANOPARTICLES. 23

TABLE 3.2: OVERVIEW OF MATERIALS USED FOR BARTLETT ASSAY 28

TABLE 3.3: OVERVIEW OF MATERIALS USED IN EVALUATION OF EFFICACY OF PARTICULATE DISPERSANTS 31

TABLE 4.1: OCTANE-DI WATER EMULSIONS STABILIZED WITH DOPC AND DPPC PBC SNPS COMPARED WITH EMULSIONS STABILIZED WITH VESICLES ONLY AND SILICA ONLY. IMAGED 72 HOURS AFTER VORTEX (N=2). . .37

TABLE 4.2: OCTANE-DI WATER EMULSIONS (1:1 VOLUMETRIC RATIO) STABILIZED WITH INCREASING CONCENTRATIONS OF DPPC PBC SNPS. IMAGE TAKEN IMMEDIATELY AFTER VORTEX. NO FREE LIPID REMOVAL STEP (N=2). . .40

TABLE 4.3: OCTANE-DI WATER EMULSIONS (1:1 VOLUMETRIC RATIOS) STABILIZED WITH INCREASING CONCENTRATIONS OF DOPC PBC SNPS. IMAGES TAKEN 24 HOURS AFTER VORTEX. NO FREE LIPID REMOVAL STEP (N=2). . .41

TABLE 4.4: EMULSIFICATION OF OCTANE AND CRUDE OIL WITH DOPC PBC SNPS. (QUANTITY OF LIPID PRESENT IS THAT CALCULATED TO COMPLETELY COVER SURFACE SURFACE AREA OF SILICA PARTICLES. NO FREE LIPID REMOVAL STEP. $\mathrm{N}=2$ )

TABLE 4.5: OPTICAL MICROSCOPY IMAGE OF CRUDE OIL-DI WATER EMULSION STABILIZED BY DOPC PBC SNPS . .44

TABLE 4.6: OCTANE-DI WATER EMULSION STABILIZED WITH PBC SNPS WITH AN OIL PHASE DYE (SUDAN IV). IMAGED IMMEDIATELY AFTER VORTEX (N=2). . .45

TABLE 4.7: EFFECT OF LIPID TAIL STRUCTURE AND OIL TYPE ON EMULSIONS (1:1 VOLUMETRIC RATIO) STABILIZED BY 0.1 WT\% DOPC AND DPPC BC SNPS W.R.T THE 
AQUEOUS PHASE $(\mathrm{A}=$ BROMOHEXADECANE, $\mathrm{B}=$ PENNSYLVANIA CRUDE OIL, $\mathrm{C}=$

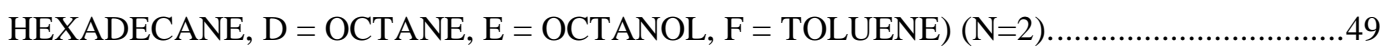

TABLE 4.8: EFFECT OF LIPID TAIL STRUCTURE AND OIL TYPE ON EMULSIONS STABILIZED BY DPPC AND DOPC MC SNPS. SAMPLES CONTAIN 1 WT\% PARTICLE WITH RESPECT TO THE AQUEOUS PHASE, VOLUME OF SAMPLE IS 2 ML AND VOLUMETRIC RATIO OF OIL:WATER IS 1:1. (A = BROMOHEXADECANE, $\mathrm{B}=$ BUTANOL, $\mathrm{C}=$ PENNSYLVANIA CRUDE OIL, $\mathrm{D}=$ HEXADECANE, $\mathrm{E}=$ OCTANE, $\mathrm{F}=$ OCTANOL). .52

TABLE 4.9: BROMOHEXADECANE-DI WATER EMULSION STABILIZED WITH MC SNPS. (1 WT\%, 30 MIN AFTER VORTEX, EMULSION PHASE IMAGED, AND SCALE BAR $=100$ $\mathrm{MM})$ . .54

TABLE 4.10: A COMPARISON OF OCTANE-DI WATER EMULSIONS STABILIZED WITH DPPC AND DOPC PBC SNPS AND BC SNPS (0.1 WT\% PARTICLE) .56

TABLE 6.1: EMULSIFICATION OF OCTANE AND DI WATER BY DPPC PBC SNP AT VARIOUS PARTICLE CONCENTRATIONS W.R.T THE AQUEOUS PHASE. NO OILPHASE DYE (SUDAN IV) USED. . .66

TABLE 6.2: EMULSIFICATION OF OCTANE AND DI WATER BY DOPC PBC SNPS AT VARIOUS PARTICLE CONCENTRATIONS W.R.T THE AQUEOUS PHASE. NO OILPHASE DYE (SUDAN IV) USED.

TABLE 6.3: EMULSIFICATION OF OCTANE AND DI WATER BY DPPC LIPOSOMES. NO OILPHASE DYE (SUDAN IV) USED. . .69

TABLE 6.4: EMULSIFICATION OF OCTANE AND DI WATER BY DOPC LIPOSOMES. NO OILPHASE DYE USED. . .70

TABLE 6.5: EMULSIFICATION OF OCTANE AND DI WATER BY SNPS. NO OIL-PHASE DYE USED. . .72 
TABLE 6.6: EMULSIFICATION OF OCTANE AND DI WATER BY DOPC PBC SNPS AT VARIOUS PARTICLE CONCENTRATIONS W.R.T THE AQUEOUS PHASE. OIL-PHASE DYE (SUDAN IV) USED . .74

TABLE 6.7: EMULSIFICATION OF OCTANE AND DI WATER BY DPPC PBC SNPS AT VARIOUS PARTICLE CONCENTRATIONS W.R.T. THE AQUEOUS PHASE. OIL-PHASE DYE (SUDAN IV) USED . .75

TABLE 6.8: EMULSIFICATION OF OCTANE AND DI WATER BY DPPC LIPOSOMES AT VARIOUS CONCENTRATIONS W.R.T. THE AQUEOUS PHASE. OIL-PHASE DYE (SUDAN IV) USED. NO REMOVAL OF FREE LIPID . .76

TABLE 6.9: EMULSIFICATION OF OCTANE AND DI WATER BY DOPC LIPOSOMES AT VARIOUS CONCENTRATIONS W.R.T. THE AQUEOUS PHASE. OIL-PHASE DYE (SUDAN IV) USED. NO REMOVAL OF FREE LIPID. . .77

TABLE 6.10: EMULSIFICATION OF OCTANE AND DI WATER BY SNPS. OIL-PHASE DYE (SUDAN IV) USED. . .78

TABLE 6.11: EMULSIFICATION OF OCTANE AND DI WATER WITH LOW CONCENTRATIONS OF DPPC AND DOPC PBC SNPS. NO FREE LIPID REMOVAL STEP. 


\section{LIST OF FIGURES}

FIGURE 2.1: CLASSICAL EMULSION VS. PICKERING EMULSION; A DROPLET OF OIL STABILIZED WITH CLASSICAL SURFACTANT MOLECULES (LEFT) AND A DROPLET OF OIL STABILIZED WITH SOLID PARTICLES (RIGHT). . .12

FIGURE 2.2: CONTACT ANGLE OF SOLID PARTICLES WITH OIL PHASE AND OIL DROPLET.

FIGURE 3.1: OVERVIEW OF PROCESS USED TO EVALUATE PARTICLES AS STABILIZERS OF OIL-WATER EMULSIONS. . .18

FIGURE 3.2: OVERVIEW OF EMULSION STABILIZERS EXAMINED IN THIS RESEARCH. ....19 FIGURE 3.3: OVERVIEW OF THE EMULSION STABILIZERS PREPARED IN THIS SECTION. 20 FIGURE 3.4: SCHEMATIC OF CALCULATIONS FOR LIPID NEEDED TO COVER SILICA PARTICLES IN SOLUTION.

FIGURE 3.5: OVERVIEW OF THE EMULSION STABILIZERS PREPARED IN THIS SECTION. 23 FIGURE 3.6: SURFACE HYDROXYLATION OF A SILICA PARTICLE BY PIRANHA SOLUTION.

FIGURE 3.7: OVERVIEW OF THE EMULSION STABILIZERS PREPARED IN THIS SECTION. 25 FIGURE 3.8: SILATION REACTION . .26

FIGURE 3.9: SILATION REACTION SET UP. .26

FIGURE 4.1: ADSORBED LIPID TO 0.5 WT\% SILICA PARTICLES (10 ML SAMPLE, 1 MM DIAMETER SILICA PARTICLES) AS A FUNCTION OF AVAILABLE LIPID. ERROR BARS BASED ON AVERAGE STANDARD DEVIATION (DPPC STANDARD DEVIATION: 0.312; DOPC STANDARD DEVIATION: 1.303). N=3. . .34

FIGURE 4.2: STERIC DIFFERENCES BETWEEN DOPC AND DPPC DUE TO AN ALKENE IN EACH TAIL OF DOPC. . .35

FIGURE 4.4: LIPID COATED SILICA FORMATION AND LIPID RESTRUCTURING AT THE OIL-WATER INTERFACE. . .38 
FIGURE 4.5: EMULSION VOLUME/TOTAL SAMPLE VOLUME AS A FUNCTION OF PARTICLE CONCENTRATION (OCTANE-DI WATER EMULSION STABILIZED BY DPPC PBC SNP) 41

FIGURE 4.6: STABILITY OF CRUDE OIL AND DI WATER EMULSION (DEPICTED IN TABLE 4.1.4) OVER TIME. ( $\mathrm{N}=2)$ . .44

FIGURE 4.7: BROMOHEXADECANE-DI WATER EMULSION STABILIZED BY DPPC MC SNPS $(1 \mathrm{WT} \%$, SCALE BAR $=5 \mathrm{MM})$ . .55

FIGURE 6.1: CALIBRATION CURVE FOR BARTLETT ASSAY DISCUSSED IN METHODOLOGY 3.2.3 AND FINDINGS 4.1.1.4. .60

FIGURE 6.2: SIZE DISTRIBUTION OF DOPC PBC SNPS AFTER REMOVAL OF FREE LIPID...60 FIGURE 6.3: SIZE DISTRIBUTION OF DPPC PBC SNPS AFTER REMOVAL OF FREE LIPID. ..61 FIGURE 6.4: SIZE DISTRIBUTION OF NON-ADSORBED DOPC (LIPOSOME FORM) AND DOPC PBC SNP IN THE SUPERNATANT AFTER CENTRIFUGATION STEP FOR THE REMOVAL OF FREE LIPID. 61

FIGURE 6.5: SIZE DISTRIBUTION OF NON-ADSORBED DPPC (LIPOSOME FORM) AND DPPC PBC SNP IN THE SUPERNATANT AFTER CENTRIFUGATION STEP FOR THE REMOVAL OF FREE LIPID. . .62

FIGURE 6.6: SIZE (DLS OUTPUT) OF NON-SURFACE MODIFIED SILICA PARTICLES (PARTICLES AS RECEIVED) IN DEIONIZED WATER, PH = 6.5. 62

FIGURE 6.7: STABILITY OF CRUDE OIL - DI WATER EMULSION STABILIZED WITH DOPC LIPOSOMES (0.1 WT\% EQUIVALENT DOPC; $7.52 \mu \mathrm{MOL}$ W.R.T AQUEOUS PHASE). .63 FIGURE 6.8: STABILITY OF CRUDE OIL - DI WATER EMULSION STABILIZED WITH DPPC LIPOSOMES (0.1 WT\% EQUIVALENT; $7.52 \mu$ MOL W.R.T. AQUEOUS PHASE). .63

FIGURE 6.9: STABILITY OF CRUDE OIL - DI WATER EMULSION STABILIZED WITH SNP $(0.1 \mathrm{WT} \%)$ .64

FIGURE 6.10: CRYO-SEM IMAGE OF OCTANE IN DI WATER DROPLETS STABILIZED BY SNPS ONLY (1 WT\%). $10 \mu \mathrm{M}$ SCALE BAR. MAGNIFICATION 15.17 KX. .64 
FIGURE 6.11: STABILITY OF CRUDE OIL - DI WATER EMULSION STABILIZED WITH DPPC $\operatorname{PBC}$ SNP $(0.1 \mathrm{WT} \%)$.

FIGURE 6.12: STABILITY OF CRUDE OIL - DI WATER EMULSION STABILIZED WITH DPPC $\operatorname{PBC}$ SNP $(0.1 \mathrm{WT} \%)$

FIGURE 6.13: STABILITY OF CRUDE OIL - DI WATER EMULSION STABILIZED WITH DPPC $\operatorname{BC} \operatorname{SNP}(0.1 \mathrm{WT} \%)$ . .79

FIGURE 6.14: STABILITY OF CRUDE OIL - DI WATER EMULSION STABILIZED WITH DOPC $\operatorname{BC~SNP}(0.1 \mathrm{WT} \%)$ . .80

FIGURE 6.15: STABILITY OF CRUDE OIL - DI WATER EMULSION STABILIZED WITH SNPS AS RECEIVED (0.1 WT\%). . .80

FIGURE 6.16: SIZE DISTRIBUTION OF HYDROPHILIC SILICA PARTICLES IN TOLUENE BEFORE GRAFTING OF SILANE GROUPS (DLS OUTPUT). . .81

FIGURE 6.17: SIZE DISTRIBUTION OF HYDROPHOBIC SILICA PARTICLES IN TOLUENE BEFORE ADSORPTION OF LIPID. . .81

FIGURE 6.18: SIZE DISTRIBUTION OF DOPC LIPOSOMES BEFORE ADSORPTION TO HYDROPHOBIC SILICA PARTICLES. . .82

FIGURE 6.19: SIZE DISTRIBUTION OF DOPC MC SNPS IN DI WATER . .82

FIGURE 6.20 SIZE DISTRIBUTION OF DPPC MC SNPS IN DI WATER. . .83

FIGURE 6.21: STABILITY OF CRUDE OIL - DI WATER EMULSION STABILIZED WITH DPPC MC SNPS (0.1 WT\%) .84

FIGURE 6.22: STABILITY OF CRUDE OIL - DI WATER EMULSION STABILIZED WITH DOPC MC SNPS (0.1 WT\%) . .84 


\section{INTRODUCTION}

As oil use and enhanced oil recovery continues, and the possibility of another oil spill is high, it is important to understand the chemistry and toxicology of oil spills and have technologies available to mediate environmental damage. A variety of remediation strategies were employed after the Deepwater Horizon (DWH) oil spill in the Gulf of Mexico in April of 2010, from mechanical efforts, such as booming, skimming and cementing the wellhead, to chemical methods, such as burning and dispersant application, both at the ocean surface and at the wellhead.

Corexit ${ }^{\circledR} 9527$ and Corexit ${ }^{\circledR}$ 9500, products made by Nalco®, were the commercial dispersants used in this case. It was reported that the toxicity of Corexit $9500 \AA$ and Corexit@ 9527 is relatively low for many aquatic species (George-Ares \& Clark, 2000). However, there is room for improvement upon these products, as toxicity is still observed (Goodbody-Gringley et al., 2013). It would be advantageous to have an environmental benign dispersant readily available for use in the event of another oil pollution event.

There is much interest in fine particles as a replacement for classical surfactant molecules. The use of fine particles potentially allows for the elimination of the more environmentally taxing solvents in which classical surfactants are dissolved. When particles are used instead of classical surfactants for forming emulsions, the emulsion is called a 'Pickering emulsion,' named after S.U. Pickering who documented the effect in his 1907 paper (Pickering, 1907). To date, an extensive array of materials have been used as stabilizers for Pickering emulsions, including organic and inorganic particles, and biological macromolecules such as proteins (He et al., 2013). An effective stabilizer of an oil-water Pickering emulsion is both hydrophobic and 
hydrophilic such that the particle makes contact with both the oil phase and water phase and preferentially resides at the interface.

It has been shown that increasing localized nutrient concentration improves the rate of microbial colonization and biodegradation (Bragg et al., 1994). From this, the concept of combining the nutrient with the dispersant arose in the Bothun lab at URI so that the nutrient is localized at the oil-water interface with the dispersant. One approach to combine the nutrient with the dispersant is to coat the silica nanoparticle with a lipid bilayer, which provides phosphorus, nitrogen, and fatty acids. This approach had not been employed previously.

Previous studies have established that it is possible to tune the hydrophobicity of silica nanoparticles (Chevalier \& Bolzinger, 2013; Frelichowska et al., 2009). By varying the hydrophobicity of the silica nanoparticle, it is possible to vary the effectiveness of the particle as a Pickering emulsion stabilizer. Furthermore, as silica is ubiquitous in the marine environment, it is possible to circumvent much of the environmental concern that arises with the use of classical surfactants in response to oil spills.

The properties of the solid particles such as wettability, shape and size, the type of oil used in the emulsion, and the concentrations of solid particle greatly affect the characteristics of the Pickering emulsions formed (Binks \& Lumsdon, 2000). The hydrophobicity of the particles predicts whether oil in water $(\mathrm{o} / \mathrm{w})$ emulsions (stabilized by hydrophilic particles) or water in oil (w/o) emulsions (stabilized by hydrophobic particles) are formed. Multiple emulsions, such as oil-in-water-in-oil (o/w/o) emulsions or water-in-oil-in-water (w/o/w) emulsions, can be formed with a 
mixture of two or more types of particles or surfactants. Multiple emulsions be formed by silica particles of two slightly distinct hydrophobicities; with one particle type, but differences in the wetting behavior across particles; and with particles of non uniform shapes (He et al., 2013).

This research merges the tunable, environmentally benign nature of silica with amphiphilic and nutrient-containing lipids to create a novel stabilizer of oil-water emulsions. The behavior of Pickering emulsions stabilized by these lipid-coated silica nanoparticles (LC SNPs) was characterized. The effect of type of lipid-coating (monolayer or bilayer), hydrophobicity of silica particle used, lipid tail structure, particle concentration, and type of oil on the characteristics of the Pickering emulsions formed are investigated. The optimal conditions for Pickering emulsions stabilized by LC SNPs is recommended, which provides guidance for future applications of Pickering emulsions stabilized by LC SNPs. 


\section{REVIEW OF LITERATURE}

This chapter provides a short introduction into the science of oil dispersants for promoting emulsification and enhancing microbial biodegradation. The concepts of Pickering emulsions and the use of particulate dispersant systems are emphasized, as well as the use of nutrients for enhancing microbial biodegradation. For a more detailed description of Pickering emulsions, see Emulsions stabilized with solid nanoparticles: Pickering emulsions (Chevalier \& Bolzinger, 2013).

\subsection{Oil Spills and Dispersants}

\subsubsection{Oil in the Marine Environment}

\subsubsection{Oil Pollution}

Oil input to the marine environment due to human activity constitutes a major threat to marine life and economic viability of impacted coastal regions, and will continue to be a challenge as oil use, transportation, and recovery continue. The Deepwater Horizon (DWH) spill released nearly 584 million liters (4.9 million barrels) of oil into the Gulf of Mexico after the Maconda well blowout on April 20, 2010, resulting in locally unprecedented damage to marine ecosystems and coastal communities. In 1989, the Exxon Valdex, an oil tanker on track to Long Beach, California, struck Prince William Sound's Bligh Reef, and spilled approximately 42 million liters $(\sim 352,000$ barrels $)$ resulting in contamination of $\sim 2000 \mathrm{~km}$ of shoreline (Bragg et al., 1994). In 1991, an airstrike during the Gulf War resulted in damage of two oil tankers, which discharged $\sim 500$ million liters (4 to 6 million barrels) into the Persian Gulf. As oil exploration and enhanced oil recovery continues, and the 
likelihood that another marine pollution event will occur is high, it is important to have technologies available for the mitigation of the next marine oil spill.

\subsubsection{Composition of Crude Oil}

The composition and characteristics of crude oil varies greatly, from flammable light liquids, to heavy tar-like materials, between regions and even among samples from the same geologic source (EPA, 2011). Oil released from a deep-water well is a complex mixture of natural gas and heavier oils, and is known as "live oil" for its high vapor pressure. Oil released from a damaged oil tanker generally consists solely of heavier oils, and is known as "dead oil" for its relatively low vapor pressure (Reddy et al., 2012).

Sampling of the contents spewing from the Maconda well in June of 2010 yielded a gas to oil ratio (GOR, defined as standard cubic feet per petroleum barrel at $15.6^{\circ} \mathrm{C}$ and 1 bar) of 1,600 (Reddy et al., 2012). Gas components from a sample

obtained from the near the wellhead included methane (82.5\%), ethane $(8.3 \%)$, propane $(5.3 \%)$, isobutane $(0.97 \%), n$-butane $(1.9 \%)$, isopentane $(0.52 \%)$, and $n$ pentane $(0.52 \%)$. Oil analyzed within this sample had a density of $820 \mathrm{~g} / \mathrm{L}$, and contained $74 \%$ saturated hydrocarbons, $16 \%$ aromatic hydrocarbons and 10\% polar hydrocarbons by volume (Reddy et al., 2012). Generally dispersants are applied to break up slicks of larger molecular weight hydrocarbons (NRC, 2005).

\subsubsection{Environmental and Economic Impact}

Oil can cause serious devastation to the marine environment, most clearly to mammalian marine life and fish, but also to microscopic organisms that provide the base of the marine ecosystem. The effect on microscopic organisms varies depending 
on type and size of the species, and the time scale and concentration of oil exposure that the organism experiences (González et al., 2009). Furthermore, species that reside in coastal habitats can be threatened. As a result of the Deepwater Horizon oil spill, approximately 1,100 linear miles of coastal wetland were compromised (Mayer et al., 2013).

Oil in the ocean will degrade by natural processes even without human intervention as bacteria, algae, protozoa, and marine fungi will degrade most hydrocarbons in the oil released to the marine environment. In some cases, this choice is preferable to active countermeasures (NRC, 1989, 2005). However, in most cases, this process is not fast enough to negate the environmental, economic and societal impacts of an oil spill. Dispersants, when used effectively, will accelerate microbial biodegradation of oil (Lessard \& Demarco, 2000).

Oil spills cause serious economic damage in addition to ecological damage. Oil spills affect everything from fishing and shellfish industries, to tourism, as oiled shores deter tourists (NRC, 1989). BP states on its website that the cost of the Gulf Coast recovery after the Deepwater Horizon oil spill has been in excess of 26 billion dollars thus far, which includes response and clean-up; claims and settlements; funding for the natural resource damage assessment process; early restoration projects; and state-led tourism campaigns, seafood marketing programs, and seafood testing (BP, 2014). 


\subsubsection{Dispersant Use}

\subsubsection{Response to Oil Spills}

Dispersants are one part of a larger contingency plan for response to oil spills in the United States (EPA, 2014). Mechanical methods, which are the primary response tactic in the United States against oil spills (EPA, 2014), include the use of booms to contain or divert oil, and skimmers or absorbent materials to remove oil from surface of the ocean (NRC, 1989, 2005). Non-mechanical countermeasures, which may be used in conjunction with mechanical methods (EPA, 2014), include burning the oil, the use of "herder" chemicals, gelling agents, water jets, air jets, and air bubble barriers to contain or divert oil (Mayer et al., 2013; NRC, 1989).

The use of dispersants is an attractive option to oil spill response crews for several reasons. Microbial degradation of oil is enhanced by dispersion of oil due to the increase in surface area of the oil, which allows for enhanced access by the bacteria (NRC, 1989). Dispersion of oil at sea makes the oil spill less visible, and greatly reduces coastal clean up costs (Mayer et al., 2013; NRC, 2005). In weighing oil spill remediation costs, it is more expensive to clean oil off shorelines than the cost of additional dispersants to promote microbial biodegradation offshore (NRC, 2005). The use of dispersants offshore also has the potential to lower ecological impact, given that the water column into which the oil is dispersed is sufficiently large (Lessard \& Demarco, 2000).

Predicting whether addition of a dispersant will increase or lower the overall toxicity of the spill is complicated, and studies suggesting varying levels of toxicity to Corexit®9500 and Corexit@9527 have been published (George-Ares \& Clark, 2000; 
Goodbody-Gringley et al., 2013; Zahed et al., 2011), depending on the species studied, the route of exposure, the organ or organelle of the species analyzed, and the concentration of dispersant. Toxicity is dependent upon concentration of pollutant as well as the sensitivity of the organism to the components present.

\subsubsection{Industrial Dispersants}

Dispersants work by lowering interfacial tension between oil and water phases, thereby stabilizing oil-water emulsions (Kujawinski et al., 2011). Commonly used oil dispersants such as Corexit ${ }^{\circledR} 9527$ and Corexit ${ }^{\circledR} 9500$ contain three types of chemicals: solvents, additives and surfactants (Gong et al., 2014). Solvents are used to alter the viscosity of the dispersant and allow for increased solubility in the spilled oil. Additives serve to enhance the solubility of the surfactant in the spilled oil and to improve the stability of the dispersant while in storage. Most commercial surfactants, including Corexit ${ }^{\circledR}$ products, contain more than one surfactant, which increases overall effectiveness (Gong et al., 2014). The components of Corexit ${ }^{\circ} 9500$ are publically available, though the proportions of each component remains proprietary (Nalco, 2014).

Above the critical micelle concentration of a surfactant in water, it is possible for an emulsion to form (Kujawinski et al., 2011). The dispersion of oil droplets into the water column is increased by the use of dispersants (Gong et al., 2014). Generally, aerial spraying of dispersants directly into the oil phase is the most effective way to deliver dispersants to the oil spill (NRC, 1989). There is recent interest in using fine particles in conjunction with or as an alternative to classical surfactants (Gupta et al., 2014; Li et al., 2007; W. Wang et al., 2013). 


\subsubsection{Historical Use of Dispersants}

The use of oil dispersants has been a critical response measure to mitigate the impacts of marine oil spills since the 1960's, during which one of the first instances of dispersant use was recorded (Franklin \& Warner, 2011). Controversy accompanied their years of use, as the efficacy and safety of the dispersant products were unclear (NRC, 1989). Although initial motive for dispersant use was to respond to public concern for damage to birds, fish, marine mammals, and costly damage to coastlines (Lessard \& Demarco, 2000; NRC, 1989), the result of the addition of dispersants in one of the first instances of use was negative (Franklin \& Warner, 2011).

The addition of dispersants after the Torrey Canyon tanker spill in 1967 resulted in environmental disaster, as it soon proved that the dispersants worsened the situation (Franklin \& Warner, 2011). Three years after this spill, amendments to the Clean Water Act provided a clarification of US policy towards dispersants, which can be summarized as a "trust but verify" approach (NRC, 1989, 2005). This called for a national contingency plan for future releases of hazardous substances and that the US EPA work with states to establish safety standards for dispersants, regulations which emerged in 1975 (Franklin \& Warner, 2011).

After the Exxon Valdez oil spill of 1989, Congress passed the Oil Pollution Act of 1990 to attempt to address shortcomings in the existing oil spill response contingency plan (Franklin \& Warner, 2011; NRC, 2005). Dispersants were not a major focus in this legislation, due to the fact that they were not stockpiled as part of a contingency plan before this event (Franklin \& Warner, 2011). In response to the 1989 Exxon Valdez oil spill off the shores of Alaska, only approximately $21 \mathrm{~m}^{3}(\sim 5500$ 
gallons) of Corexit@9527 were applied to the oil slick, a relatively small amount (Jensen, 2009).

Dispersants continued to be used well into the $21^{\text {st }}$ century and continue to be part of the US contingency plan for oil spill response today. Examples of dispersant use in this time include two instances in the Gulf of Mexico. In 1999, following the M/V Blue Master Spill, $55 \mathrm{~km}$ south of Galveston, Texas, approximately $2.6 \mathrm{~m}^{3}$ of Corexit@9500 were applied (NRC, 2005). In the year $2000,11 \mathrm{~m}^{3}$ of Corexit $® 9527$ were used after a release of $\sim 238 \mathrm{~m}^{3}$ of South Louisiana crude oil into the Gulf of Mexico 65 miles south of Houma, Louisiana (NRC, 2005). In response to the 2010 Deepwater Horizon leak, a locally unprecedented quantity of dispersants were used (Goodbody-Gringley et al., 2013).

\subsubsection{Use of Dispersants in Response to Deepwater Horizon Spill}

Dispersants arguably can be credited with reducing the on-shore impact of the Gulf Spill substantially (Franklin \& Warner, 2011). While the effect of the DWH oil spill was catastrophic, it was expected that hydrocarbons would be detectable in the marine environment for a longer period of time than they were (Hazen, 2011). The 2010 Deepwater Horizon oil spill released approximately 584,278 $\mathrm{m}^{3}$ (4.9 million barrels) of South Louisiana sweet crude oil into the Gulf of Mexico, resulting in the largest oil spill in U.S. history and the second largest in the world, after the first Gulf War oil spill from Kuwait (Hemmer et al., 2011). Approximately $7.949 \mathrm{~m}^{3}(2.1$ million gallons) of oil dispersants Corexit ${ }^{\circ} 9500$ and 9527 were used, of which 5,300

$\mathrm{m}^{3}$ (1.4 million gallons) were applied at the surface and $2,914 \mathrm{~m}^{3}(0.77$ million gallons) at the wellhead (Kujawinski et al., 2011). 


\subsubsection{Oil Weathering}

After oil is released to the marine environment, the overall composition of the released material undergoes dynamic changes due to physical, biological and chemical processes (Michel \& Hayes, 1999; Reddy et al., 2012; Rial et al., 2013). These processes include spreading, drifting, dispersion, stranding and weathering. Chemical change to the oil may include evaporation, dissolution, biodegradation, emulsification, and photo-oxidation (NRC, 2005). The nature of the compound dictates its future location. Whole oil droplets may be dispersed into the water column while monocyclic compounds such as benzene and alkyl-substituted benzenes, (with partitioning coefficients expressed as a logarithmic scale, $\log \mathrm{K}_{\mathrm{ow}}$, between 2.1 and 3.7) and 2-3 ring polycyclic and aromatic hydrocarbons (with $\log \mathrm{K}_{\mathrm{ow}}$ values between 3.7 and 4.8) are more likely to undergo dissolution (Gong et al., 2014; Reddy et al., 2012). Dispersants affect the different components of crude oil to varying extents.

\subsection{Emulsion Science and Pickering Emulsions}

\subsubsection{Classical emulsions vs. Pickering emulsions}

There is recent interest in using fine particles as a replacement or in conjunction with classical surfactants (Li et al., 2007; W. Wang et al., 2013). In 1907, S.U. Pickering (Pickering, 1907) observed that small colloidal particles at the oilwater interface are able to stabilize oil-water emulsions effectively, much like traditional amphiphilic molecules (Refer to Figure 2.1). These colloids-stabilized-

emulsions are referred to as Pickering emulsions (PEs). One advantage to using particles rather than traditional surfactants in oil spill remediation is their potential to be dispersed in water rather than a more environmentally taxing organic solvent. 
Applications of PE research extend beyond environmental research to cosmetics, food science and pharmacy fields, particularly where the use of classical surfactants is not ideal (He et al., 2013). PEs have been stabilized with a wide range of particles including: biological molecules, such as proteins (Liang \& Tang, 2014); polymer coated particles; and nanoparticles, both inorganic and organic (Frelichowska et al., 2009; Saha et al., 2013).

Figure 2.1: Classical emulsion vs. Pickering emulsion; a droplet of oil stabilized with classical surfactant molecules (left) and a droplet of oil stabilized with solid particles (right).

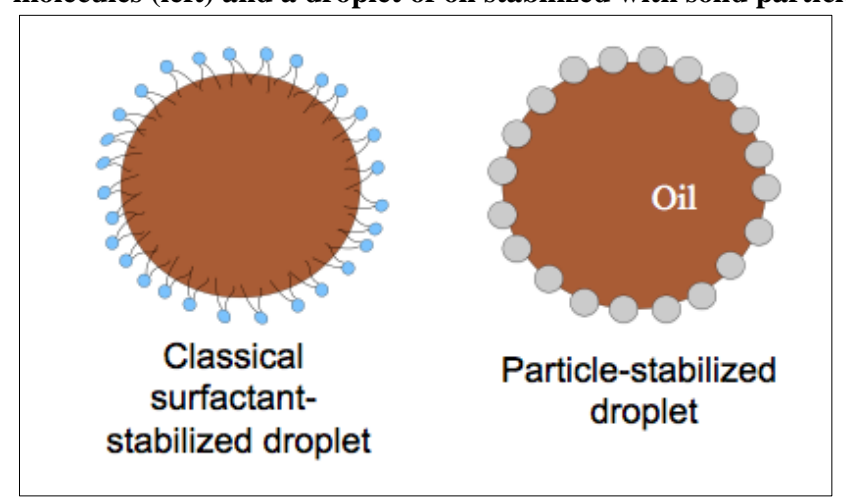

\subsubsection{Pickering Emulsion Theory}

Whether a water-in-oil (w/o) or oil-in-water $(\mathrm{o} / \mathrm{w})$ emulsion is formed is determined by the three-phase contact angle, $\theta$, (depicted in Figure 2.2) of the particle at the oil-water interface (Binks \& Lumsdon, 2000; Chevalier \& Bolzinger, 2013). For an ideal, spherical particle at an oil-water interface, the stabilization energy (i.e., the energy of attachment for particles adsorbed at the interface) $\mathrm{E}_{\gamma}$ is given by:

$$
E_{\gamma}=\pi r^{2} \gamma(1-|\cos \theta|)^{2}
$$

Here, $\gamma$ is interfacial tension, $\theta$ is the contact angle, and $r$ is the particle radius. Optimal stabilization occurs when there is a contact angle (Refer to Figure 2.2) of $90^{\circ}$, when the particles are wet by both the water and oil phases equally (Chevalier \& Bolzinger, 2013). Researchers Melle et al. (2005) estimated the energy of adsorption 
for a nearly irreversible adsorbance to the interface to be $10^{7} k_{B} T$ for a micrometer sized particle with a contact angle close to $90^{\circ}$ and interfacial tension of approximately $50 \mathrm{mN} / \mathrm{m}$. Here, $k_{B}$ is the Boltzmann's constant and $\mathrm{T}$ is room temperature (Melle et al., 2005).

Hydrophobicity, size, and shape of the particles impact the characteristics and stability of the emulsion formed (Chevalier \& Bolzinger, 2013; Gong et al., 2014). Hydrophobic particles generally have a contact angle greater than $90^{\circ}$ and tend to be oil-wetted, while hydrophilic particles have a contact angle less than $90^{\circ}$ and tend to foster oil in water emulsions. Binks showed emulsions stabilized by particles of intermediate hydrophobicity were sub-micrometer and resistant to both sedimentation and coalescence (Binks \& Lumsdon, 2000). Extremely hydrophilic or hydrophobic particles do not foster stable emulsions and are completely wetted by either phase.

Figure 2.2: Contact angle of solid particles with oil phase and oil droplet.

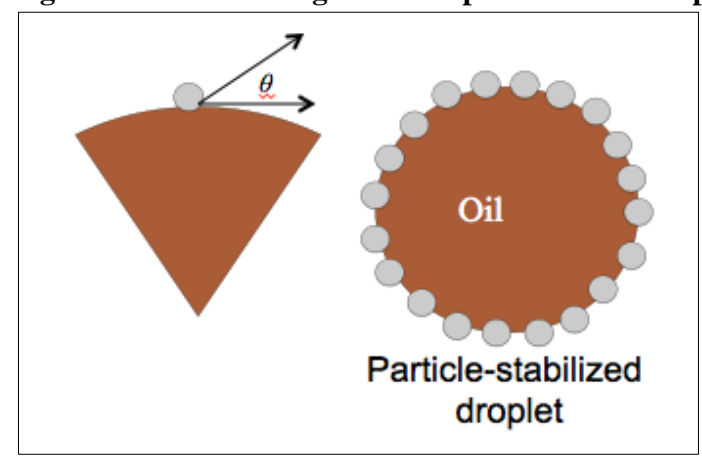

Multiple emulsions, such as oil-in-water-in-oil (o/w/o) emulsions or water-inoil-in-water (w/o/w) emulsions, can be formed with a mixture of two or more types of particles or surfactants. Multiple emulsions can be formed by silica particles of two slightly distinct hydrophobicities; with one particle type, but differences in the wetting behavior across particles; and with particles of non uniform shapes (He et al., 2013). 


\subsubsection{Factors that Affect PEs}

Many factors affect the properties of PEs. The properties of particles used as stabilizers, such as their concentration, shape, size, and hydrophobicity, as well as the interactions between particles play a large role in determining the characteristics of PEs formed. Crude oil consists of many different compounds, each of which undergoes different phenomena once introduced into the marine environment (Reddy et al., 2012; Rial et al., 2013). Each component of crude oil is affected by the addition of dispersants to a different extent. As a general trend, polar oils form more stable emulsions with water than nonpolar oils (Frelichowska et al., 2009). Polar oils include short chain mono or diesters, either ethyl, isopropyl or isobutyl esters. Non-polar oils that resist formation of oil-water emulsions include 2-ethylhexyl esters, silicone oil, and mineral oil (Frelichowska et al., 2009).

\subsection{Novel Dispersant Systems}

The Corexit ${ }^{\circledR}$ dispersants were found by the EPA (2010) to be sufficiently environmentally sound for application after the DWH leak. However, toxicity is still observed, so there is room for improvement in the development of novel dispersant systems (Goodbody-Gringley et al., 2013). Many researchers are exploring different approaches to emulsify hydrocarbons in the marine environment (Bragg et al., 1994; He et al., 2013; Saha et al., 2013).

\subsubsection{Bioengineered microbes}

The enhancement of microbial biodegradation of oil by introducing additional bioengineered oil-degrading microbes into the environment has been proposed (IGEM, 2010; NG, 2011). However, as bacteria capable of degrading oil are 
ubiquitous in the marine environment, with the single exception of colder arctic marine environments (NRC, 1989), this does not seem to be necessary.

\subsubsection{Nutrient enhanced biodegradation of oil}

In most marine environments, microbial growth is halted by the limitation of one or more key nutrients. In some marine environments, phosphorus availability is considered the key nutrient that limits photosynthesis, while in other systems, iron may be the limiting nutrient (Howarth \& Marino, 2006; Howarth, 1988; Smith, 1984). Phosphorus plays a key role in ocean photosynthesis, and the governing chemical equation can be written as:

$$
\begin{gathered}
106 \mathrm{CO}_{2}+16 \mathrm{HNO}_{3}+\mathrm{H}_{3} \mathrm{PO}_{4}+122 \mathrm{H}_{2} \mathrm{O}+\text { trace elements and vitamins } \\
\stackrel{\text { light }}{\longrightarrow} \mathrm{C}_{106} \mathrm{H}_{263} \mathrm{O}_{110} \mathrm{~N}_{16} \mathrm{P}+138 \mathrm{O}_{2}
\end{gathered}
$$

(Paytan \& McLaughlin, 2007)

Unlike nitrogen, phosphorus cannot be fixed from the atmosphere. Biologically important phosphorus compounds in soils and sediments include orthophosphate monoesters and diesters, phosphonates and phosphorus anhydrides, such as ATP (Rogers \& Bennett, 2004). Phosphorus is delivered to the ocean by way of continental weathering and through atmospheric deposition, which includes volcanic ash and mineral dust. Transport of phosphorus from anthropogenic sources, such as from wastewater discharge, is also significant (Rogers \& Bennett, 2004). Despite these inputs, phosphorus still may be a limiting nutrient (Yang et al., 2009).

Increasing the concentration of nutrients in the water surrounding an oil spill has been utilized as a way to hasten biodegradation of the oil via already present oilconsuming microbes (Filler et al., 2008; Yang et al., 2009). Studies have demonstrated 
the effectiveness of augmenting microbial colonization of oil via the addition of nutrients (Rogers \& Bennett, 2004; Röling et al., 2002). In one preliminary experiment, field experiments from a petroleum-contaminated environment, where silicate weathering was accelerated, revealed that phosphorous $(\mathrm{P})$ and iron $(\mathrm{Fe})$ bearing silicate glasses were preferentially colonized and weathered while glasses without these elements were typically barren of colonizing microorganisms (Rogers \& Bennett, 2004). In another research group, it was found that the increased concentration of key nutrients leads to enhanced biodegradation of oil (Röling et al., 2002). The addition of inorganic nutrients, but not the quantity, was most important in practice (Röling et al., 2002). This suggests that a small amount of a limiting nutrient could go a long way to enhance microbial biodegradation of oil. Existing nutrient conditions should be probed before deciding to pursue this method of treatment of an oil spill, as it is important to assess which nutrients are limiting.

\subsubsection{Materials of interest for novel dispersant systems}

Silica is an inert and environmentally sound material for potential use in dispersant systems. Due to the ubiquitous nature of silica in natural environments, much of the controversy that surrounds the use of classical dispersants in response to oil spills could be circumvented. Microorganisms have mechanisms to regulate the natural level of silicates found in ocean environments (Rogers \& Bennett, 2004) and as such, an increase in silicates would not adversely affect the growth of oilconsuming microbes in the ocean. Additionally, there is much research precedent for modifying the surface of silica, which allows for flexibility in the development of a novel particulate dispersant system (Frelichowska et al., 2009). 
Lipids such as DOPC and DPPC are of interest for use in environmentally sound dispersant systems due to their biological origin (Zhao et al., 2007), low toxicity, and their inherent amphiphilic nature. These compounds can be degraded and reincorporated into the marine ecosystem more easily than a compound that has functional groups that cause the molecule to persist in the aquatic environment (Place et al., 2014).

\subsection{Literature precedence for technique of coating silica particles with lipid}

The coating of silica particles with lipid has been explored and is documented in many published studies (Bayerl \& Bloom, 1990; Liu et al., 2009; Mager \& Melosh, 2007; Mornet et al., 2005; Tamm \& McConnell, 1985). However, these studies were not attempting to engineer particles for Pickering emulsion formation. The procedure used for coating silica nanoparticles was adapted from several of these studies. In most cases (Bayerl \& Bloom, 1990; Liu et al., 2009; Mornet et al., 2005; Tamm \& McConnell, 1985), a lipid suspension is poured over silica beads, and the mixture is vortex mixed for 60 seconds. Excess vesicles not adsorbed to the surface are removed by centrifugation and removing the supernatant, due to the size difference between the silica particles and the vesicles (Bayerl \& Bloom, 1990; Mornet et al., 2005). 


\section{METHODOLOGY}

In the research described by this chapter, DPPC (1,2-dipalmitoyl-sn-glycero-3phosphocholine) and DOPC (1,2-dioleoyl-sn-glycero-3-phosphocholine) -coated silica nanoparticles are produced and then used to foster Pickering emulsions in varying aqueous conditions and with various oils. Error! Reference source not found. gives an overview of the overall process used to evaluate the particles as stabilizers of oilwater emulsions.

Figure 3.1: Overview of process used to evaluate particles as stabilizers of oil-water emulsions.

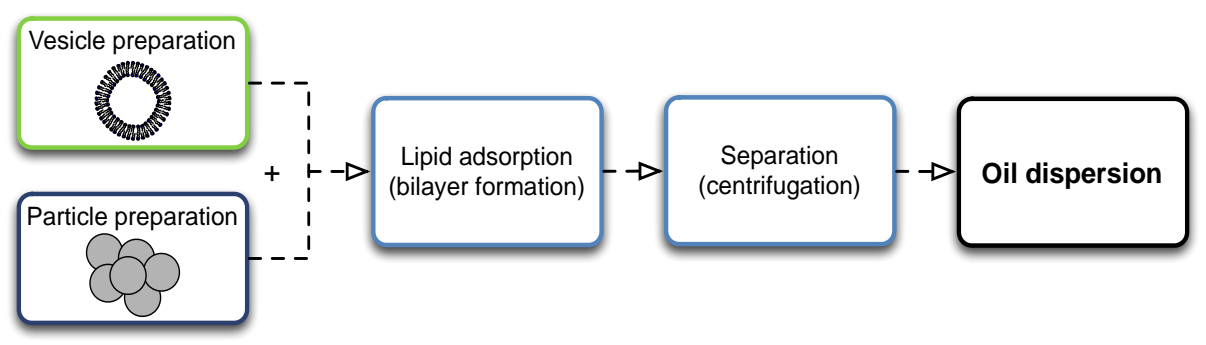

The goal of this research was to create a particle dispersible in water, which would rearrange and become hydrophobic at the oil-water interface. Three different lipid-coating procedures were explored to test this concept, which yielded three different particle coatings: a partial mono/bilayer (PBC SNPs), a lipid bilayer (BC SNPs) and a lipid monolayer coating (MC SNPs), which are depicted in Figure 3.2. These procedures are described in Sections 3.1.1, 3.1.2, and 3.1.3 respectively. 
Figure 3.2: Overview of emulsion stabilizers examined in this research.

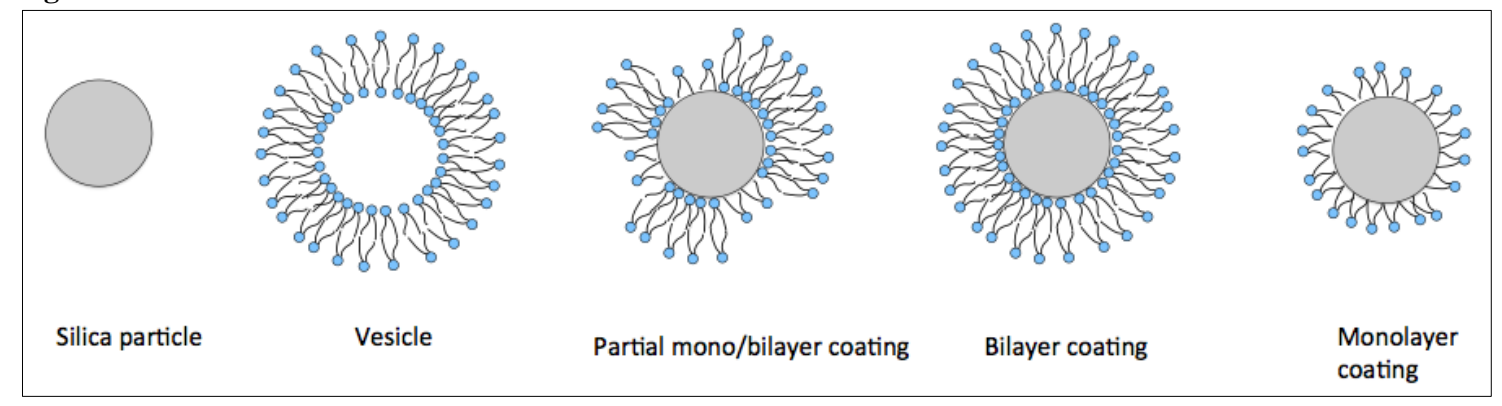

The particle coatings that result by way of the first procedure, described as partial mono/bilayer coatings, (Section 3.1.1), are such due to the intermediate hydrophobicity of the silica particles. The lipids self-assemble to a configuration of the lowest possible energy in which hydrophobic tail groups are oriented toward hydrophobic parts of the silica particle or toward other hydrophobic tail groups. Hydrophilic ends of lipid molecules are oriented towards the aqueous medium or hydrophilic bits of the silica particle.

The second procedure (detailed in Section 3.1.2) yields bilayer coatings, due to the complete hydroxylation of the silica particles. In this case, hydrophilic head groups of the lipid completely line the silica particles, such that there are no hydrophobic patches. Lastly, the third procedure (detailed in Section 3.1.3) was designed to yield monolayer-coated particles.

\subsection{Production}

\subsubsection{Partial mono/bilayer coated silica particles}

This section details the first procedure used to develop lipid-coated silica nanoparticles, which results in partial mono/bilayer coated silica particles. It also details the comparison of these lipid-coated silica particles with vesicles only and silica only for evaluation of the lipid-coated silica particle performance. 
Figure 3.3: Overview of the emulsion stabilizers prepared in this section.

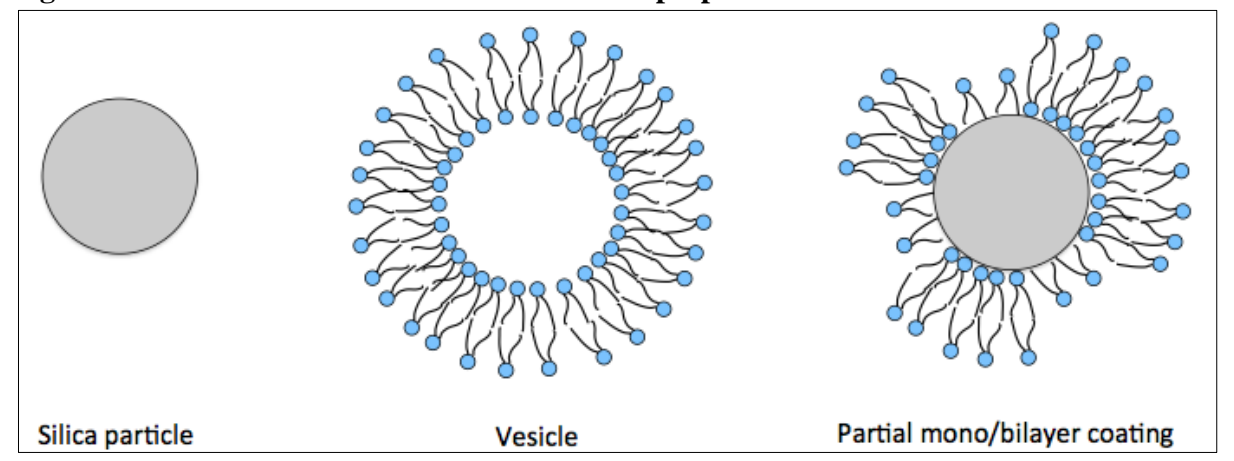

The production of lipid-coated silica nanoparticle dispersants is adopted from several procedures established by previous studies [Escher et al; Kwon et al., 2006; Bayerl et al., 1990; Baksh et al., 2004].

First the thin film hydration method [Liposomes, $2^{\text {nd }}$ Edition, 2000] is used to prepare suspensions of liposomes consisting of DPPC (1,2-dipalmitoyl-sn-glycero-3phosphocholine) and DOPC (1,2-dioleoyl-sn-glycero-3-phosphocholine) respectively. This method is described in detail in Section 3.1.1.1. In separate vials, deionized water is added to dry non-porous silicon dioxide nanoparticles to create suspensions of silicon dioxide of various concentrations (Described in Section 2.1.1.2).

Suspensions of DPPC or DOPC liposomes are poured over the silica bead solution (detailed in Section 3.1.1.3). Excess vesicles not adsorbed to the silica particles are removed by way of centrifugation (Described in Section 3.1.1.4).

To determine the quantity of lipid to add to the silica suspensions, the particles were assumed to be $1 \mu \mathrm{m}$ and spherical. One DPPC molecule was assumed to require $0.5 \mathrm{~nm}^{2}$ of surface area [53], [54], and one DOPC molecule was assumed to require $0.7 \mathrm{~nm}^{2}$ of surface area on a silica particle [55]. Total lipid needed to cover the silica particles in suspension was determined according to Figure 3.1.2. This calculation was 
consistent across all three methods used in this research, which are represented in Sections 3.1.1, 3.1.2, and 3.1.3.

Figure 3.4: Schematic of calculations for lipid needed to cover silica particles in solution.

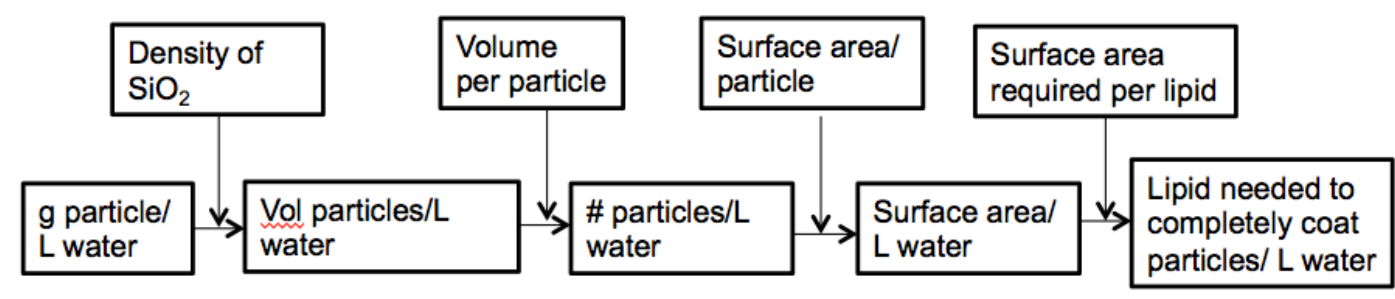

\subsubsection{Thin Film Hydration Method}

Lipids (DPPC, DOPC) are received in a chloroform solvent. First the solvent is removed using a rotary evaporator (Model: Buchi V-850 Vacuum Controller Rotovapor), leaving a thin film. Then deionized water is added to the thin film and the lipids are hydrated, resulting in the formation of liposomes. Bath sonication (Model: Branson 1510) for two hours is then used to decrease the liposome size. Liposome size is determined by way of dynamic light scattering (Model: Malvern Instruments Zetasizer Nano).

Dynamic light scattering (DLS) measures Brownian motion of the particles in suspension and outputs the size distribution of the particles (Malvern 2014). The Brownian motion of the particle is measured by way of a laser and software that converts the pattern of scattered light to Brownian motion (Malvern 2014). The Stokes-Einstein equation relates speed of a particle to its size.

$$
d(H)=\frac{k T}{3 \pi \eta D}
$$

where:

$\mathrm{d}(\mathrm{H})=$ hydrodynamic diameter

$\mathrm{D}=$ translational diffusion coefficient 


$$
\begin{aligned}
& \mathrm{k}=\text { Boltzmann's constant } \\
& \mathrm{T}=\text { absolute temperature } \\
& \eta=\text { viscosity }
\end{aligned}
$$

From the rate of intensity fluctuation, the Zetasizer Nano system outputs the size of the particles. Number, volume, and intensity outputs were taken into consideration in the analysis of the samples described in this document. For further information regarding the dynamic light scattering system, the Zetasizer Nano Manual and associated education materials (Malvern 2014) and Dynamic Light Scattering: With Applications to Chemistry, Biology and Physics (Berne, 2000) are recommended.

To determine the amount of lipid needed to cover the surface area of the silica particles in solution, a calculation is made. Size of the particle, total surface area of the particle and size of the lipid molecules are taken into consideration when determining how much lipid is necessary to completely coat the silica particles.

\subsubsection{Preparation of silica suspensions}

Dry, nonporous silicon dioxide particles (SkySpring Nanomaterials) of approximately $20 \mathrm{~nm}$ in size are combined with deionized water (from Millipore DirectQ®-3 with pump) to make aqueous solutions of silicon dioxide of varying concentrations. In solution, the particles aggregate to agglomerates of approximately 1 $\mu \mathrm{m}$ (Refer to Appendix for size distribution output from DLS).

\subsubsection{Lipid suspension added to silica suspension}

After the liposomes are determined to be between $80-100 \mathrm{~nm}$ in diameter by dynamic light scattering, the liposome suspension is added to the silica suspension. The resultant suspension is vortexed for one minute, then left to sit for one hour to 
facilitate vesicle rupture and lipid adsorption on the particle surface.

Table 3.1: Materials used in production of lipid-coated silica nanoparticles.

\begin{tabular}{|c|c|c|c|}
\hline Name & Chemical structure & $\begin{array}{l}\text { Gel phase/ } \\
\text { melting } \\
\text { point }\end{array}$ & Source \\
\hline $\begin{array}{l}\text { 1,2-dipalmitoyl- } \\
s n \text {-glycero-3- } \\
\text { phosphocholine } \\
\text { (DPPC) }\end{array}$ & & $42{ }^{\circ} \mathrm{C}-52^{\circ} \mathrm{C}$ & $\begin{array}{l}\text { Avanti Polar } \\
\text { Lipids }{ }^{\circledR}\end{array}$ \\
\hline $\begin{array}{l}\text { 1,2-dioleoyl-sn- } \\
\text { glycero-3- } \\
\text { phosphocholine } \\
\text { (DOPC) }\end{array}$ & & $-17^{\circ} \mathrm{C}$ & $\begin{array}{l}\text { Avanti Polar } \\
\text { Lipids }{ }^{\circledR}\end{array}$ \\
\hline $\begin{array}{l}\text { Silicon dioxide } \\
(20 \mathrm{~nm}, 99.5 \%)\end{array}$ & $\mathrm{SiO}_{2}$, amorphous & $1,600^{\circ} \mathrm{C}$ & $\begin{array}{l}\text { SkySpring } \\
\text { Nanoparticle } \\
\text { s Inc. }\end{array}$ \\
\hline
\end{tabular}

Phase transition data obtained from (Leonenko et al., 2004).

\subsubsection{Lipid bilayer-coated silica nanoparticles}

This section details the preparation of lipid bilayer-coated silica nanoparticles, which are formed by way of vesicle rupture and adsorption onto completely hydrophilic silica particles.

Figure 3.5: Overview of the emulsion stabilizers prepared in this section.

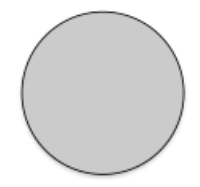

Silica particle

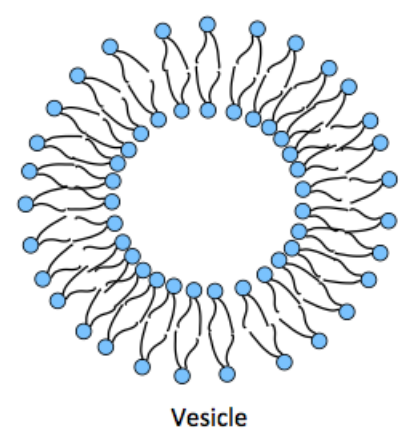

Vesicle

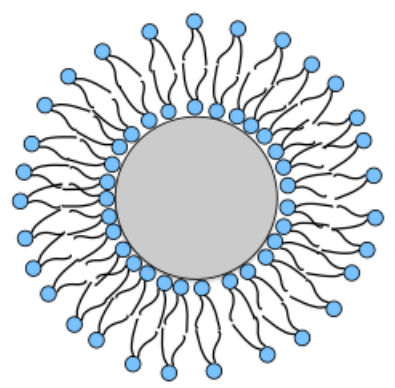

Bilayer-coated silica particle

The preparation of lipid bilayer-coated silica nanoparticles is similar to the methods described in Section 3.1.1, only for the preparation of the silica suspension, 
Section 3.1.1.2, which is replaced with Section 3.1.2.1, below. Furthermore, excess lipid not adsorbed to silica particles was removed, which is described in Section 3.1.2.2.

\subsubsection{Preparation of silica suspensions}

Piranha solution is used to fully hydroxylate nonporous silica nanoparticles. To fully hydroxylate 5 grams of silica nanoparticles, $80 \mathrm{~mL}$ of concentrated sulfuric acid and approximately $20 \mathrm{~mL}$ of hydrogen peroxide $(30 \% \mathrm{v} / \mathrm{v})$ were used. The particles were added to a $250 \mathrm{~mL}$ Pyrex ${ }^{\circledR}$ container, to which the sulfuric acid was added. The sulfuric acid-particle mixture was heated to $90^{\circ} \mathrm{C}$, at which point the hydrogen peroxide was added drop by drop, to prevent the reaction from accelerating out of control. For more information of the safety procedures required when using piranha solution, refer to the Standard Operating Procedure for Piranha Solution (UMD 2003). Figure 3.6: Surface hydroxylation of a silica particle by piranha solution.

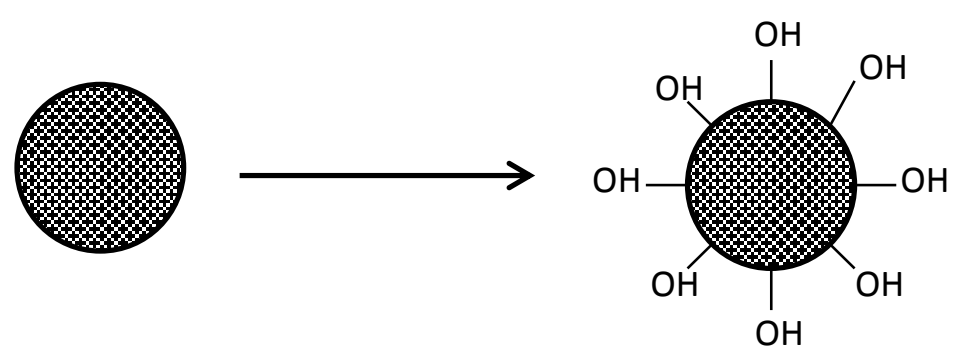

Confirmation of hydroxylation was confirmed by thermogravimetric analysis (TGA) and reported in a submitted manuscript (Gupta et al., 2014).

\subsubsection{Removal of non-adsorbed liposomes}

Preparation of lipid bilayer-coated silica nanoparticles is according to sections 3.1.1.1 and 3.1.1.3 above with the substitution of section 3.1.2.1 for 3.1.1.2. After the liposome-silica suspension is left to sit for one hour, the suspension is centrifuged for 
four minutes at $400 \mathrm{rpm}$. (Note: This centrifugation speed was determined by an iterative process of centrifugation at various speeds and checking via dynamic light scattering whether all free lipid was removed.) After centrifugation at the appropriate speed, the supernatant is removed. Dynamic light scattering confirms the removal of non-adsorbed liposomes due to the size difference between the lipid-coated silica and the free liposomes.

\subsubsection{Lipid monolayer-coated silica nanoparticles}

This section describes the preparation of lipid monolayer-coated silica nanoparticles (MC SNPs). Figure 3.6 gives an overview of the emulsion stabilizers prepared in this section.

Figure 3.7: Overview of the emulsion stabilizers prepared in this section.

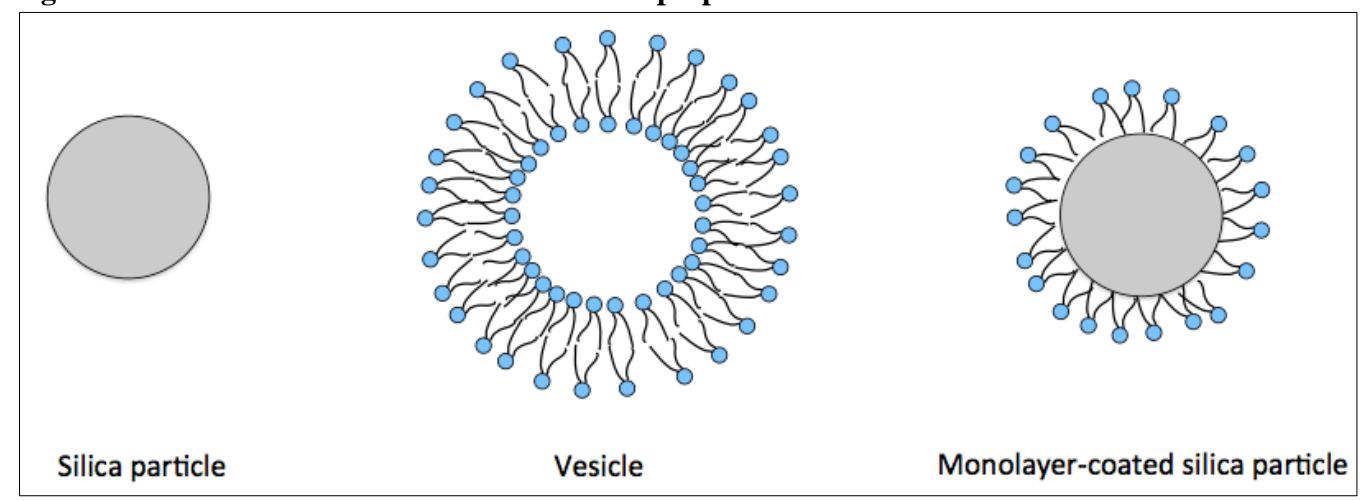

\subsubsection{Preparation of the silica suspension}

Piranha solution is used to fully hydroxylate nonporous silica nanoparticles. Then silane groups, specifically n-Octyltriethoxysilane (Sigma Aldrich®), are grafted to the hydroxylated silica nanoparticles. The hydroxylated silica particles (5 g) are placed in a $200 \mathrm{~mL}$ flask containing $80 \mathrm{~mL}$ of anhydrous toluene and $0.2 \mathrm{M}$ octyltriethoxysilane. The flask was stirred under a nitrogen atmosphere and heated to $80^{\circ} \mathrm{C}$ for 12 hours. 
Figure 3.8: Silation reaction

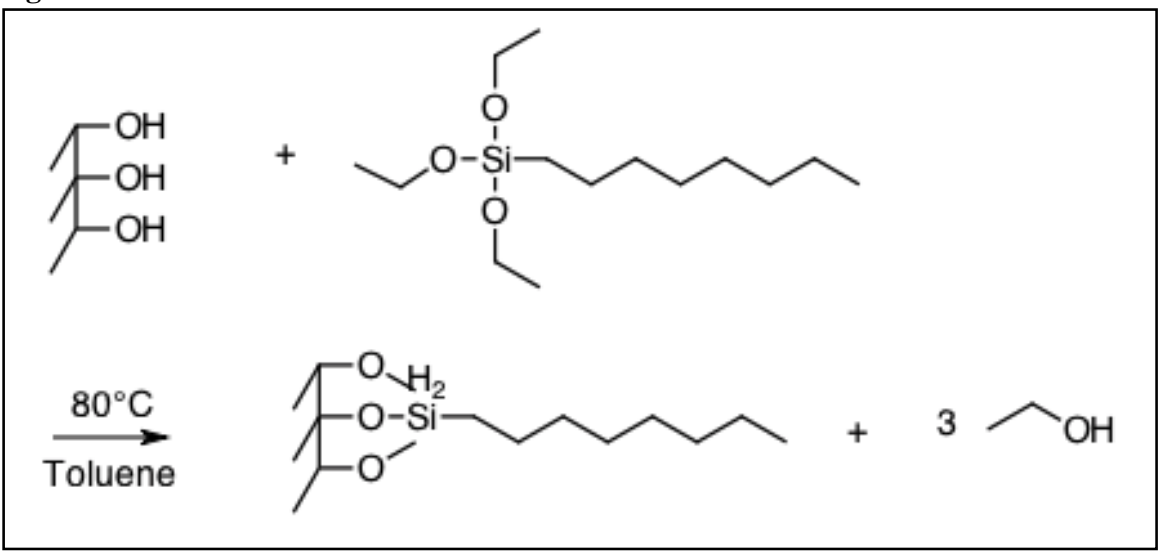

Figure 3.9: Silation reaction set up.

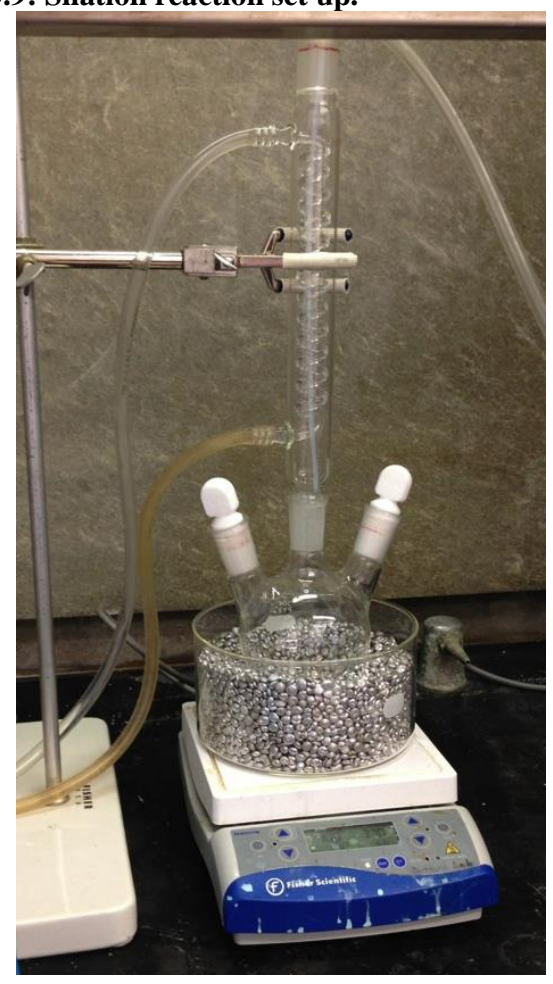

\subsubsection{Other preparation}

Lipid in chloroform sufficient to cover surface area of the silica particles was added to the aqueous suspension of hydrophobic silica particles. The suspension was agitated using a vortex mixer (described previously) for 1 minute. Chloroform was removed with a rotovap (Buchi V-850 vacuum controller rotovapor). Probe sonication for 5 minutes total time on, at $75 \%$ power, 30 seconds on, 15 seconds off (Model: 
Fisher Scientific Sonic Dismembrator, Part No. FB-120) was used to reduce aggregation in the aqueous suspension of MC SNPs.

\subsection{Characterization}

It is necessary to characterize lipid-coated silica nanoparticles to ensure that the correct product has been made, as particle size and hydrophobicity greatly affect the emulsions stabilized by these particles. Characterization techniques were used to confirm particle size, to determine whether lipid adsorbed to the silica nanoparticles, and to determine the quantity of lipid adsorbed to the particles. This is accomplished with techniques described below.

\subsubsection{Confirmation of Particle Size (Dynamic Light Scattering)}

Dynamic light scattering is used to determine the size of particles in suspension, and whether excess non-adsorbed vesicles were still present. For more detail on analysis of dynamic light scattering, see Section 3.1.1.1.

\subsubsection{Confirmation of Adsorbed Lipid (Zeta potential measurements)}

Zeta potential measurements (Malvern 2014b) are used to confirm the presence of a surface coating on the silica nanoparticles. The Zetasizer Nano calculates an approximation of the zeta potential by first determining electrophoretic mobility, the motion of the dispersed particles relative to the fluid in the presence of an electric field, and then using Henry's equation, below, to calculate zeta potential.

$$
U_{e}=\frac{2 \varepsilon z f(\kappa \alpha)}{3 \eta}
$$

where $U_{e}=$ electrophoretic mobility, $\mathrm{z}=$ zeta potential, $\varepsilon=$ dielectric constant, $\eta=$ viscosity, and $f(\kappa \alpha)=$ Henry's function (Malvern 2014b). 
The electrophoretic mobility is calculated from an electrophoresis experiment on the sample and Laser Doppler Velocimetry (LDV) (Malvern 2014b). The zeta potential is the potential that exists at the surface of hydrodynamic shear or slipping plane, the boundary between the Stern layer, an inner region where the ions are strongly bound, and the outer layer, where the ions are less firmly attached (Malvern 2014b). The zeta potential can be an indicator of stability of the system. Generally a magnitude greater than $+/-30 \mathrm{mV}$ is taken to be stable and a magnitude less than $+/$ $30 \mathrm{mV}$ is considered unstable (Malvern 2014b).

\subsubsection{Quantification of Adsorbed Lipid (Bartlett Assay)}

To quantify lipid adsorbed to a particle, a Bartlett Assay is used (Torchilin and Weissig, 2003). This assay is used to quantify inorganic phosphate, which in turn is used to quantify lipid, by way of a colorimetric product. First, the phospholipid is disconnected from the lipid tails with perchloric acid to result in inorganic phosphate. The inorganic phosphate is converted to phosphor-molybdic acid by the reagent ammonium molybdate. This is then converted to a blue-colored complex by 4-amino2-napthyl-4-sulfonic acid with heat added (Torchilin and Weissig, 2003). The quantity of blue-colored compound is determined using a spectrophotometer at $830 \mathrm{~nm}$. Refer to Appendix Figure 6.1 for curve used for colorimetric quantification.

Table 3.2: Overview of materials used for Bartlett Assay

\begin{tabular}{|l|l|l|}
\hline \multicolumn{1}{|c|}{ Name } & \multicolumn{1}{c|}{ Function } & \multicolumn{1}{c|}{ Source } \\
\hline $\begin{array}{l}0.65 \mathrm{mM} \\
\text { phosphorous } \\
\text { standard solution }\end{array}$ & Control solutions. & Sigma Aldrich \\
\hline $70 \%$ perchloric acid & $\begin{array}{l}\text { Removes } \\
\text { phosphorous from } \\
\text { lipid tails }\end{array}$ & Sigma Aldrich® \\
\hline
\end{tabular}




\begin{tabular}{|l|l|l|}
\hline $\begin{array}{l}\text { 4-amino-2-napthyl- } \\
\text { 4-sulfonic acid }\end{array}$ & $\begin{array}{l}\text { Reduces phosphor- } \\
\text { molybdic acid to a } \\
\text { colorimetric } \\
\text { complex. }\end{array}$ & Sigma Aldrich® \\
\hline $\begin{array}{l}\text { 5\% (w/w) } \\
\text { ammonium } \\
\text { molybdate solution }\end{array}$ & $\begin{array}{l}\text { Converts inorganic } \\
\text { phosphate to } \\
\text { phosphor-molybdic } \\
\text { acid. }\end{array}$ & Sigma Aldrich® \\
\hline
\end{tabular}

\subsection{Performance}

To evaluate the efficacy of the lipid-coated silica particles formed in fostering oil-water emulsions, emulsions are formed between an aqueous suspension of the dispersant and various oils. Emulsions are then analyzed with complementary techniques, described below.

\subsubsection{Preparation of emulsions}

Samples containing an aqueous suspension and a set amount of oil are vortex mixed (Fisher ${ }^{\mathrm{TM}}$ Scientific Mini Vortex Mixer) at $2800 \mathrm{rpm}$ and an orbit of $4.5 \mathrm{~mm}$ for 1 minute and set aside for a specified amount of time. Emulsions are then evaluated with a variety of techniques described in the following sections.

\subsubsection{Evaluation of dispersant performance}

\subsubsection{Macroscopic emulsion size measurements}

Macroscopic images using a digital camera are taken of the samples. Heights of the emulsions are measured and the approximate volume of the emulsion in the particular sample is determined.

\subsubsection{Stability analysis (Ultraviolet visible spectroscopy)}

Ultraviolet visible spectroscopy (UV-vis) is used to analyze the stability of emulsions. Aqueous solutions of DPPC and DOPC, bilayer-coated and monolayer- 
coated silica particles are formed with $0.1 \%(\mathrm{wt} / \mathrm{wt})$ silica. A 1:4 oil:water volumetric ratio was used and the vials were vortex mixed for 1 minute at 30,000 rpm. UV-vis was used at intervals to measure the emulsion: once the droplets have coalesced, the $\mathrm{UV}$-vis reading returns to the baseline of the aqueous solution measured prior to the time-course experiment.

\subsubsection{Droplet Size Microscopic Measurement (Optical microscopy)}

The emulsion phases were imaged using optical microscopy with a $20 \mathrm{X}$ objective (Instrument: Fisher Scientific Micromaster®, Software: Micron). The droplets were imaged in a concave lens without a cover slip.

\subsubsection{Cryogenic Scanning Electron Microscopy (cryo-SEM)}

In using cryo-SEM, approximately $5 \mu \mathrm{L}$ of the emulsion is placed on a sample holder. The sample and sample holder are then plunged into liquid nitrogen, which rapidly solidifies the emulsion. The sample is fractured with a flat-edge knife at $130^{\circ} \mathrm{C}$, sputtered with a gold-palladium composite, then moved from the preparation chamber to the imaging stage. A Hitachi S-4800 field-emission SEM operated at $3 \mathrm{kV}$ and $20 \mu \mathrm{A}$ is used for imaging. The entire process takes place under a high vacuum. The sample is maintained at $-130^{\circ}$ during fracturing, moving, and imaging. Energy Dispersive Microanalysis (EDS/EDX), made by Oxford Instruments, is used to characterize chemical composition of the cryo-SEM images obtained. 
Table 3.3: Overview of materials used in evaluation of efficacy of particulate dispersants

\begin{tabular}{|c|c|c|c|c|}
\hline Name & $\begin{array}{l}\text { Chemical } \\
\text { structure }\end{array}$ & $\begin{array}{l}\text { Density } \\
\text { (g/mL) }\end{array}$ & $\begin{array}{l}\text { Dipole } \\
\text { moment }\end{array}$ & Source \\
\hline $\begin{array}{l}\text { Synthetic Seawater, } \\
\text { ASTM D 1141-52 } \\
\text { Formula a, Table 1, } \\
\text { Sec. } 4\end{array}$ & N/A & N/A & N/A & $\begin{array}{l}\text { Fisher } \\
\text { Scientific } ₫\end{array}$ \\
\hline Bromohexadecane & $\mathrm{C}_{16} \mathrm{H}_{33} \mathrm{Br}$ & 0.999 & $\sim 2$ & $\begin{array}{l}\text { Fisher } \\
\text { Scientific } ₫\end{array}$ \\
\hline Butanol & $\mathrm{C}_{4} \mathrm{H}_{9} \mathrm{OH}$ & 0.81 & $\begin{array}{l}1.66{ }^{+/-} \\
0.03\end{array}$ & $\begin{array}{l}\text { Fisher } \\
\text { Scientific }{ }^{\circ}\end{array}$ \\
\hline $\begin{array}{l}\text { Crude Oil } \\
\text { (Pennsylvania) }\end{array}$ & Uncharacterized & uncharacterized & N/A & Onta, Inc. \\
\hline Hexadecane & $\mathrm{C}_{16} \mathrm{H}_{34}$ & 0.77 & 0 & $\begin{array}{l}\text { Fisher } \\
\text { Scientific }{ }^{\circledR}\end{array}$ \\
\hline Octane & $\mathrm{C}_{8} \mathrm{H}_{18}$ & 0.703 & 0 & $\begin{array}{l}\text { Fisher } \\
\text { Scientific }{ }^{\circledR}\end{array}$ \\
\hline Octanol & $\mathrm{CH}_{3}\left(\mathrm{CH}_{2}\right)_{7} \mathrm{OH}$ & 0.824 & 1.76 & $\begin{array}{l}\text { Fisher } \\
\text { Scientific }{ }^{\circledR}\end{array}$ \\
\hline Toluene & $\mathrm{C}_{7} \mathrm{H}_{8}$ & 0.867 & $\begin{array}{l}0.375+/- \\
0.01\end{array}$ & $\begin{array}{l}\text { Fisher } \\
\text { Scientific® }\end{array}$ \\
\hline
\end{tabular}

Dipole moments obtained from (Lide \& Haynes, 2010). 


\section{FINDINGS}

Three variations of lipid-coated silica nanoparticles, PBC SNPs, BC SNPs, and MC SNPs, were produced according to Methodology sections 3.1.1, 3.1.2, and 3.1.3. The methods were developed with insight from the publications by [Escher et al., 2000; Kwon et al., 2006; Bayerl et al., 1990; Baksh et al., 2004]. These lipid-coated nanoparticles are used to form emulsions with oils of varying polarity and size to evaluate their efficacy as emulsion stabilizers.

\subsection{Production of PBC SNPs}

PBC SNPs were produced with the method described in Methodology section 3.1.1. These lipid-coated nanoparticles were used to form emulsions with octane, crude oil and hexadecane. These emulsions were compared to the emulsions formed by vesicles and silica respectively at comparable concentrations.

\subsubsection{Characterization}

Characterization was done on the starting materials and the end result to ensure that the desired product had been made. The characterization methods include dynamic light scattering and zeta potential measurements as well as a Bartlett assay to quantify the amount of lipid adsorbed to the silica particles.

\subsubsection{Vesicle properties before adsorption to SNPS}

The approximate size of the vesicles (both DPPC and DOPC respectively) before adsorption to the silica particles is $80 \mathrm{~nm}$. Sonication in a water bath is used to achieve the desired liposome size. The zeta potentials of liposomes DPPC and DOPC in suspension were determined to both be approximately $0 \mathrm{mV}$, consistent with that of 
a net neutral charge (Chibowski et al., 2010a), which was to be expected from zwitterionic lipids $(\mathrm{pH}=6.5)$.

\subsubsection{SNP properties}

The approximate size of the silica particles once in solution is $1 \mu \mathrm{m}$. Probe sonication was used to achieve the desired particle size. The zeta potential of silica (at $\mathrm{pH}$ 6.5) was determined to be $-26 \mathrm{mV}$. Hydrophobicity of silica particles was quantified in manuscript recently accepted to Marine Pollution Bulletin (Gupta et al, 2014). Details of quantification of hydrophobicity of silica particles are described in Section 3.1.1.

\subsubsection{PBC SNP properties}

It was determined from the size distribution obtained from dynamic light scattering that all free liposomes not adhered to silica were removed. The zeta potential of the DPPC and DOPC PBC SNPs mirrored that of silica only, approximately $-26 \mathrm{mV}$ at $\mathrm{pH}=6.5$. This mirrors the results of studies by other researchers who coated silica particles with DPPC (Chibowski et al., 2010b). This is explained due to the net neutral charge of the zwitterionic lipid, which does not alter the zeta potential of silica to a large extent (Chibowski et al., 2010b). However, other researchers noted a slight reduction of the negative zeta potential of $\mathrm{SiO}_{2}$ upon coating with lipid (Chibowski et al., 2010b). This was not observed in this case. 


\subsubsection{Quantification of adsorbed lipid: Bartlett assay}

A Bartlett assay was used to quantify the lipid that adsorbed to the silica nanoparticles. This was done to quantify how much lipid was in the emulsion system, such that the emulsions could be compared to emulsion systems with lipid only and silica only.

The expected quantity of lipid required to completely cover the silica particles was calculated by determining the surface area of the silica particles in suspension and then the quantity of lipid needed to coat the silica particles completely. The calibration curve used to quantify lipid is provided in Figure 6.1 of the Appendix. For this calculation, the particles were assumed to be $1 \mu \mathrm{m}$ and spherical. One DPPC molecule was assumed to require $0.5 \mathrm{~nm}^{2}$ of surface area (Gruner et al., 1988; Marsh, 1990), and one DOPC molecule was assumed to require $0.7 \mathrm{~nm}^{2}$ of surface area on a silica particle (MacDonald et al., 1999).

Figure 4.1: Adsorbed lipid to $0.5 \mathrm{wt} \%$ silica particles (10 $\mathrm{mL}$ sample, $\sim 1 \mu \mathrm{m}$ diameter silica particles) as a function of available lipid. Error bars based on average standard deviation (DPPC standard deviation: 0.312; DOPC standard deviation: 1.303). $n=3$.

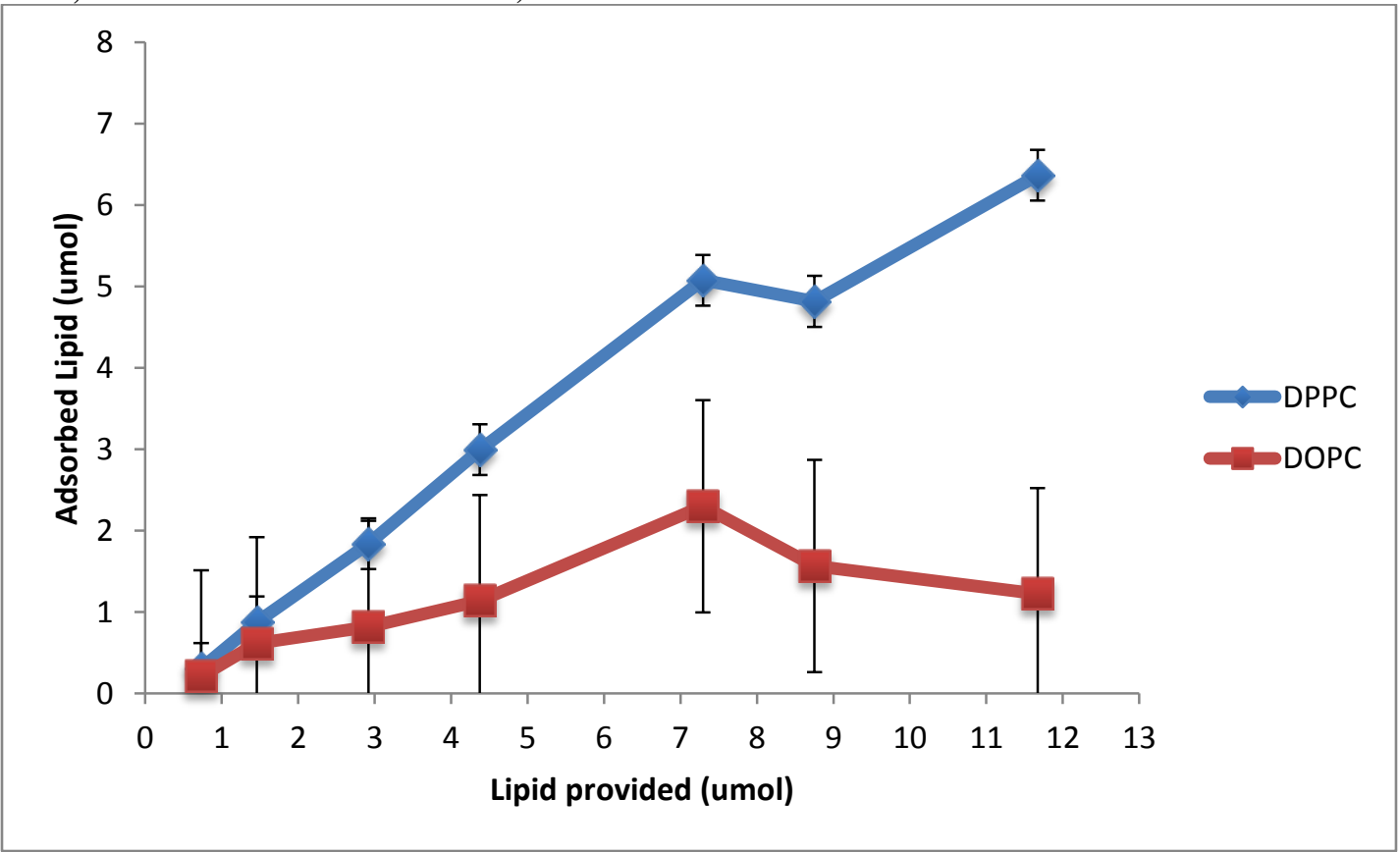


Figure 4.1.1 shows the quantity of lipid that adsorbed to the silica particles as a function of total available lipid. From Figures 4.1.1, it is clear that more DPPC adsorbed to the silica particles than DOPC. This was expected due to steric differences between DPPC and DOPC, with the presence of an alkene in the lipid tails of DOPC, which is not present in the lipid tails of DPPC. This is shown below in Figure 4.1.3:

Figure 4.2: Steric differences between DOPC and DPPC due to an alkene in each tail of DOPC.

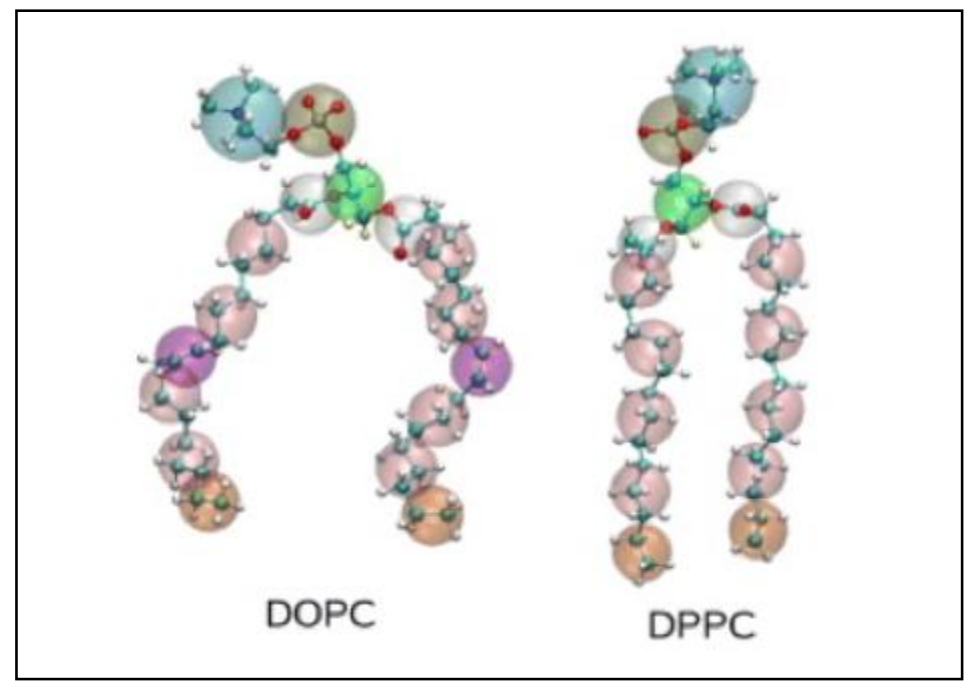

Figure 4.1.3 credit: (Z.-J. Wang \& Deserno, 2010)

Figure 4.1.3: DPPC and DOPC lipid coatings on silica particle. Due to the presence of an alkene in the lipid tail of DOPC, DOPC occupies more surface area than DPPC.
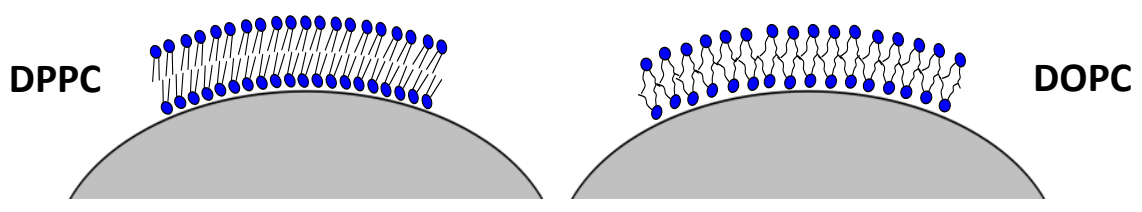

As is clear from Figure 4.1.3, due to the larger amount of space DOPC occupies, less DOPC molecules adsorb to the surface of the silica particles than DPPC. Upon a review of recent literature, this is the first time that the amount of lipid that adsorbed 
to silica particles has been quantified via a Bartlett assay. The Bartlett assay is an effective tool for quantifying the amount of lipid that adsorbs to silica particles.

\subsubsection{Performance of PBC SNPs as emulsifying agents}

PBC SNPs were evaluated for their effectiveness in fostering emulsions between octane and DI water at varying concentrations. The $\mathrm{pH}$ value of the aqueous phase, total agitation time, oil type and concentration of particle all affect the characteristics of the emulsion formed. In the first experiments presented here, vortex time and speed (1 min at $2800 \mathrm{rpm}), \mathrm{pH}(6.5)$, are kept constant, and variables explored include concentration of particle, lipid tail structure, and type of oil. The $\mathrm{pH}$ was chosen to minimize an effect due to added ions, as a $\mathrm{pH}$ of 6.5 is close to the $\mathrm{pH}$ of DI water available. PBC SNPs are compared to emulsions formed with equivalent amounts of lipid and equivalent amounts of silica to evaluate the performance of lipidcoated silica nanoparticles.

\subsubsection{Emulsions Stabilized by PBC SNPs}

Emulsions stabilized by PBC SNPs were prepared by way of vortex mixing. The emulsions were stable for at least one month with crude oil $(0.5 \mathrm{wt} \%)$ without removing free lipid, although some sedimentation occurs. Characterization of the particles was done before the emulsion samples were prepared, which confirmed lipidcoated silica nanoparticles of approximately $1 \mu \mathrm{m}$. 
Table 4.1: Octane-DI water emulsions stabilized with DOPC and DPPC PBC SNPs compared with emulsions stabilized with vesicles only and silica only. Imaged 72 hours after vortex $(n=2)$. Lipid provided is $3.76 \mathrm{umol} / \mathrm{mL}$ w.r.t the aqueous phase.

\begin{tabular}{|l|l|l|l|l|}
\hline $\begin{array}{l}\text { DOPC PBC } \\
\text { SNP } \\
(1 \mathrm{wt} \%)\end{array}$ & $\begin{array}{l}\text { DPPC PBC } \\
\text { SNP } \\
(1 \mathrm{wt} \%)\end{array}$ & $\begin{array}{l}\text { DOPC } \\
(1 \mathrm{wt} \% \text { equiv })\end{array}$ & $\begin{array}{l}\text { DPPC } \\
(1 \mathrm{wt} \% \text { equiv })\end{array}$ & $\begin{array}{l}\text { Silica } \\
(1 \mathrm{wt} \%)\end{array}$ \\
\hline a. & b. & c. & d. & e. \\
\hline
\end{tabular}

Within the time frame that the emulsions in Table 4.1 were monitored (3 days), the stability of the emulsions are comparable. DOPC PBC SNP-stabilized emulsions (a) appear have the most opaque emulsion phase, which reflects an increased number of particles in the emulsion phase at the oil-water interface which scatter light, and also an increased quantity of droplets in the emulsion phase, with disrupt the path of light through the sample. The emulsion phase is less transparent in the emulsion stabilized with DOPC (c) or with silica (e) than in the emulsion stabilized by DOPC PBC SNPs (a), which suggests a smaller droplet size in the emulsion phase or simply more particles localized to the oil-water interface.

An oil-in-water $(\mathrm{o} / \mathrm{w})$ emulsion is observed in the emulsion stabilized by PBC SNPs (a) and (b). The emulsion phase is larger in the emulsion stabilized by DOPC PBC SNPs (a) than the emulsion phase in the emulsion stabilized by DPPC PBC SNPs (b). It is clear that it is an o/w emulsion due to the presence of the oil phase. Because most of the oil phase is not emulsified, it is clear that the emulsion phase is primarily 
water. This reasoning can be extended to describe the emulsions stabilized by DOPC and DPPC liposomes (c) and (d): the emulsion phases are primarily water. The emulsion stabilized by silica only is a w/o emulsion, due to the presence of the largely non-emulsified water phase.

Significant sedimentation is observed in the emulsion stabilized by silica only (e), which is not observed in the emulsion stabilized by DOPC PBC SNP (a) or DPPC PBC SNP (b). To confirm the absence of sedimentation in (a) and (b), the emulsion was slowly inverted after the time window (72 hours) elapsed.

PBC SNPs cause the phase behavior that is observed in emulsions stabilized by vesicles only. W/o emulsions are observed for emulsions stabilized with silica only, but o/w emulsions are observed for DOPC PBC SNPs, DPPC PBC SNPs, DOPC liposomes, and DPPC liposomes. This suggests that any restructuring of vesicles occurring in (c) or (d) at the oil water interface is happening in a similar manner in (a) and (b). This also suggests that the lipid coating dictates the phase behavior that will be observed. Figure 4.4 gives a possible mechanism for the observed phase behavior. Figure 4.4: Lipid coated silica formation and lipid restructuring at the oil-water interface.

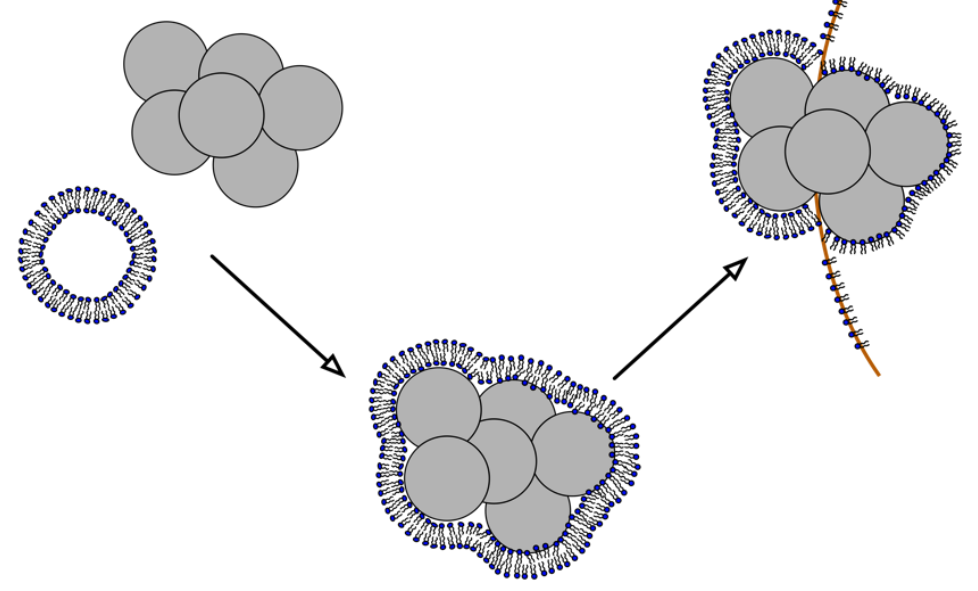


The silica nanoparticle agglomerates are completely coated with lipid, such that the characteristics of the agglomerates do not dictate the type of emulsion formed, as with PBC SNPs as in (a), (b), (c) and (d) of Table 4.1.1. as some vesicles are still suspended in the aqueous phase and some have restructured at the oil-water interface.

\subsubsection{Effect of Lipid Tail Structure on Emulsions Stabilized by PBC SNPs}

DOPC and DPPC were used as lipid coatings to evaluate the effect of lipid tail structure on emulsions stabilized by PBC SNPs. It is important to note that excess lipid that did not adsorb to the silica particles was not removed in this experiment. A calculation was made, described in Methodology section 3.1.1, for the quantity of lipid necessary to completely cover the surface area of the silica particles.

It was observed in the results presented in Table 4.1.1, that both DOPC and DOPC PBC SNPs fostered emulsions that were larger in volume and more stable than both DPPC liposomes and DPPC PBC SNPs. This likely is due to the difference between structures of DPPC and DOPC (Figure 4.2). One explanation is that the same quantity of DOPC molecules occupy more space at the oil-water interface than DPPC, thus lending increased stability to the emulsion within a certain range. This was the case in the results presented in Table 4.1.1. The oil-water interface completely saturated with particle or lipid represents the upper boundary, at which maximum stability is achieved.

\subsubsection{Effect of Particle Concentration on Emulsions Stabilized by PBC} SNPS

Particle concentration is an important parameter that affects the formation of Pickering emulsions. It has a critical influence on the emulsion stability and on the 
average droplet size (Aveyard et al., 2003). With the particles at the oil-water interface, the surface energy of the system is reduced, resulting in a more stable system (Chevalier \& Bolzinger, 2013). Within a certain range, an increased concentration of particles will lower the surface energy of the system, as the particles localize to the oil-water interface, and contribute to a more stable Pickering emulsion. The oil-water interface completely saturated with particles represents the upper boundary.

In the results presented here, with increasing concentration of particle, the size and stability of the emulsion increases. This trend is noted most clearly in emulsion systems without Sudan IV, and is consistent across all particle systems examined (DPPC PBC SNP, DOPC PBC SNP, DPPC, DOPC, and SNP). Table 4.2 and Table 4.3 depict images of the emulsions formed and Figure 4.1.5 is a quantitative representation of Table 4.2.

Table 4.2: Octane-DI water emulsions (1:1 volumetric ratio) stabilized with increasing concentrations of DPPC PBC SNPs. Image taken immediately after vortex. No free lipid removal step $(n=2)$. Lipid concentration is $0.188(0.05 \mathrm{wt} \%), 0.376(0.1 \mathrm{wt} \%), 3.76(1 \mathrm{wt} \%)$, and $7.52 \mathrm{umol} / \mathrm{mL}(2 \mathrm{wt} \%)$.

\begin{tabular}{|l|l|l|l|}
\hline $\begin{array}{l}\text { DPPC PBC } \\
\text { SNPs } \\
(0.05 \mathrm{wt} \%)\end{array}$ & $\begin{array}{l}\text { DPPC PBC } \\
\text { SNPs } \\
(0.1 \mathrm{wt} \%)\end{array}$ & $\begin{array}{l}\text { DPPC PBC } \\
\text { SNPs } \\
(1 \mathrm{wt} \%)\end{array}$ & $\begin{array}{l}\text { DPPC PBC } \\
\text { SNPs } \\
(2 \mathrm{wt} \%)\end{array}$ \\
\hline & & & \\
\hline & & & \\
\hline
\end{tabular}


Figure 4.5: Emulsion volume/total sample volume as a function of particle concentration (Octane-DI water emulsion stabilized by DPPC PBC SNP)

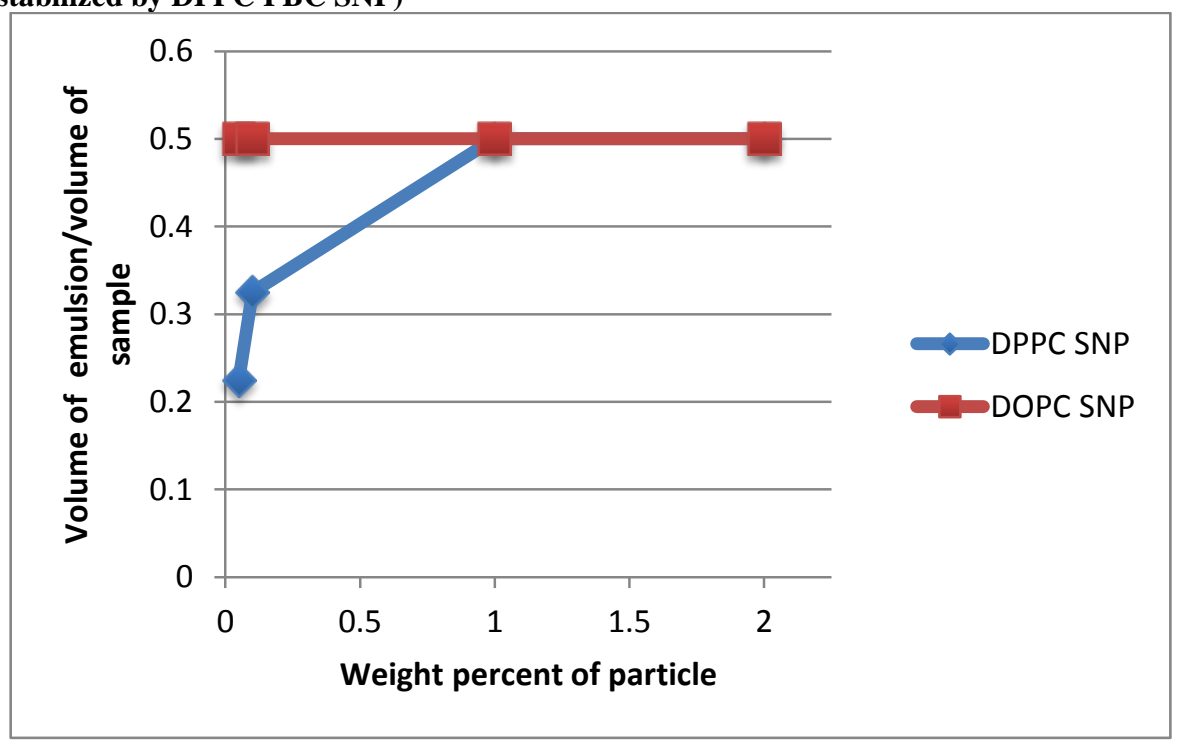

Table 4.3: Octane-DI water emulsions (1:1 volumetric ratios) stabilized with increasing concentrations of DOPC PBC SNPs. Images taken 24 hours after vortex. No free lipid removal step $(n=2)$. Lipid concentration is $0.188(0.05 w t \%), 0.376(0.1 \mathrm{wt} \%), 3.76(1 \mathrm{wt} \%)$, and $7.52 \mathrm{umol} / \mathrm{mL}(2 \mathrm{wt} \%)$.

\begin{tabular}{|l|l|l|l|}
\hline $\begin{array}{l}\text { DOPC PBC } \\
\text { SNPs } \\
(0.05 \mathrm{wt} \%)\end{array}$ & $\begin{array}{l}\text { DOPC PBC } \\
\text { SNPs } \\
(0.1 \mathrm{wt} \%)\end{array}$ & $\begin{array}{l}\text { DOPC PBC } \\
\text { SNPs } \\
(1 \mathrm{wt} \%)\end{array}$ & $\begin{array}{l}\text { DOPC PBC } \\
\text { SNPs } \\
(2 \mathrm{wt} \%)\end{array}$ \\
\hline & & & \\
\hline & & & \\
\hline & & & \\
\hline & & & \\
\hline
\end{tabular}

The emulsion in the water phase of the octane-DI water emulsion fostered by DOPC PBC SNPs has a constant height, but it is clear that the emulsion phase is less transparent as the particle concentration is increased. This is due to an increased number of particles in the emulsion phase at the oil-water interface which scatter light, 
and also an increased quantity of droplets in the emulsion phase, with disrupt the path of light through the sample. The emulsion phase is in the lowest phase in cases of emulsions stabilized with DOPC PBC SNPs and DPPC PBC SNPs (Table 4.1.2, Table 4.1.3) because the emulsion in these cases is primarily water.

\subsubsection{Effect of Oil Type on Emulsions Stabilized with PBC SNP}

Pickering emulsions are affected by factors such as particle concentration, $\mathrm{pH}$ of the aqueous phase, oil:water ratio, vortex time, and the properties of the oil phase. Crude oil and octane were chosen to evaluate the effect of different oils on emulsions stabilized by LC SNP. By maintaining $\mathrm{pH}$ of the aqueous phase (6.5), the vortex speed and time $(2800 \mathrm{rpm}$ for $1 \mathrm{~min})$, the oil:water volumetric ratio (1:1), and particle concentration constant, and varying the type of oil used, it was noted the emulsions stabilized by LC SNP were similar for oils octane and Pennsylvania crude oil. LC SNPs appear to emulsify octane and Pennsylvania crude oil to a similar extent. This is likely due to the high alkane content of Pennsylvania crude oil. 
Table 4.4: Emulsification of octane and crude oil with DOPC PBC SNPs. (Quantity of lipid present is that calculated to completely cover surface surface area of silica particles. No free lipid removal step. Lipid concentration is $1.88 \mathrm{umol} / \mathrm{mL}$. $\mathrm{n}=2$ )

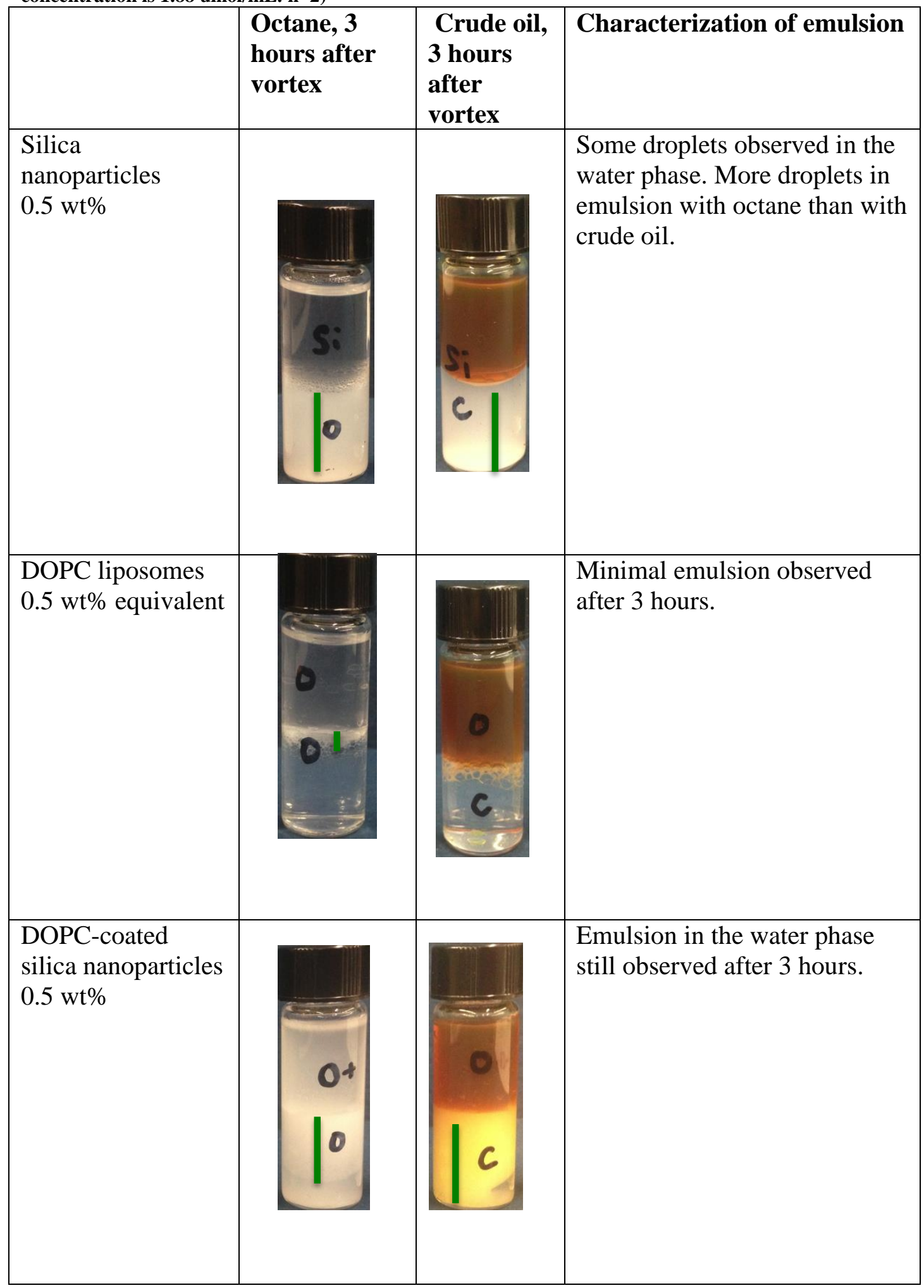


Table 4.5: Optical microscopy image of crude oil-DI water emulsion stabilized by DOPC PBC SNPs

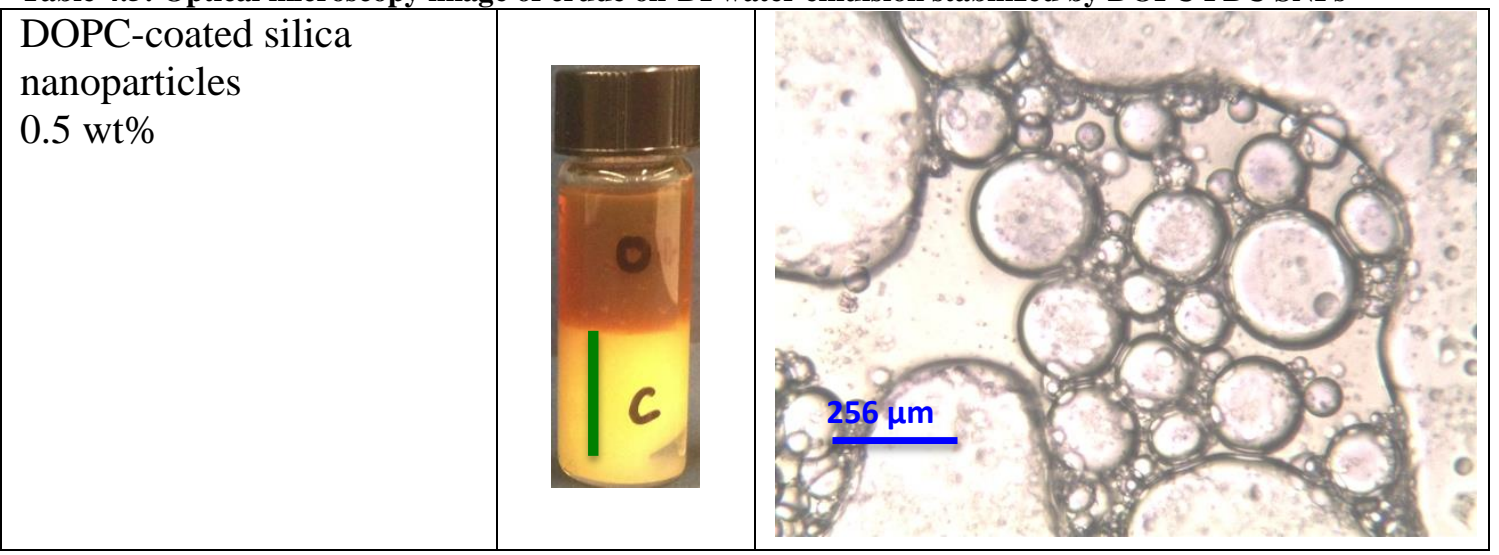

From Table 4.1.5, it is clear that in crude oil-DI water emulsions stabilized with DOPC PBC SNPs, droplet structure is complex, and droplets within droplets are observed. From the UV vis results obtained (Figure 6.7), the emulsion is primarily water and oil in water droplets are present.

Figure 4.6: Stability of crude oil and DI water emulsion (depicted in Table 4.1.4) over time. $(\mathrm{n}=2)$

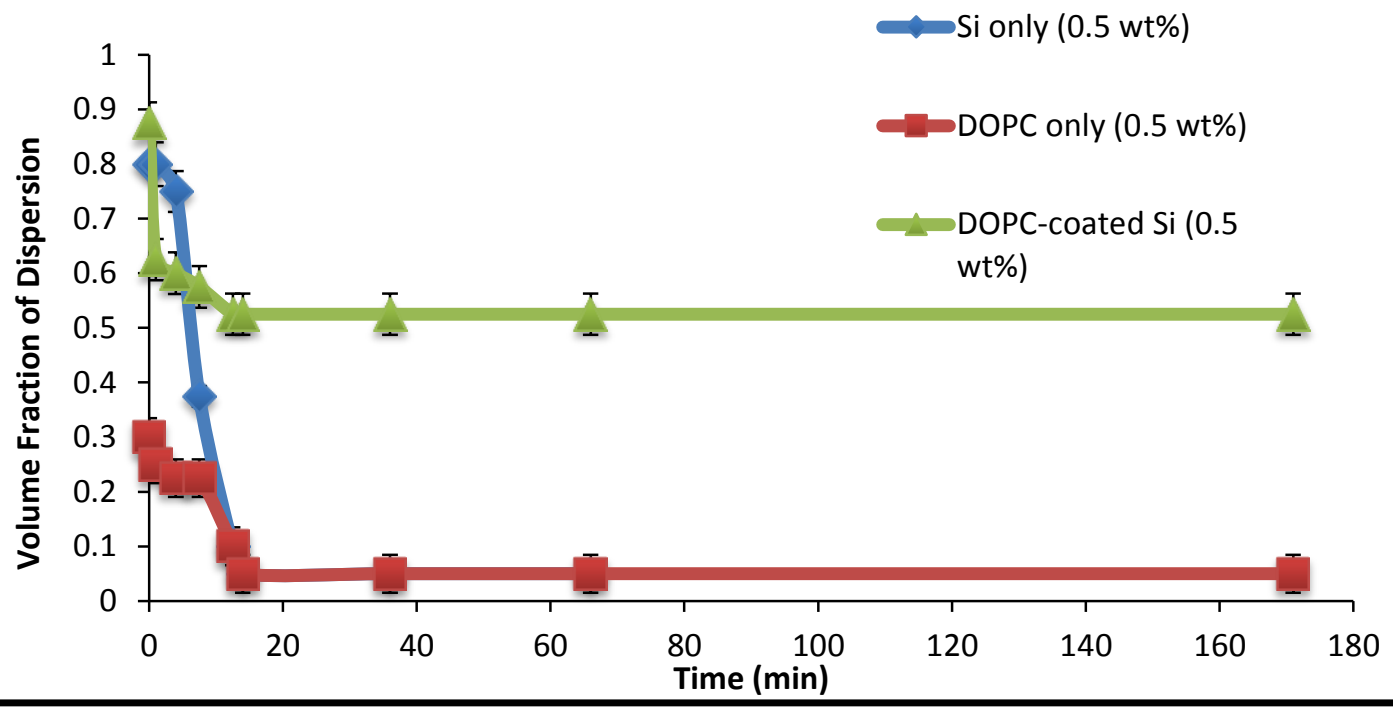




\subsubsection{Effect of Oil-Phase Dye on Emulsion Stabilized by PBC SNPs.}

In this next set of results, factors such as particle concentration, $\mathrm{pH}$ of the aqueous phase (6.5), oil:water volumetric ratio (1:1), vortex speed and duration (2800 rpm and $1 \mathrm{~min}$ ), and the oil used (octane) were kept constant but an oil-phase dye was not used. It was observed that the presence of oil-phase dye Sudan IV alters phase behavior in certain cases.

Table 4.6: Octane-DI water emulsion stabilized with PBC SNPs with an oil phase dye (Sudan IV). Imaged immediately after vortex $(\mathrm{n}=2)$. Lipid concentration is $7.52 \mathrm{umol} / \mathrm{mL}$.

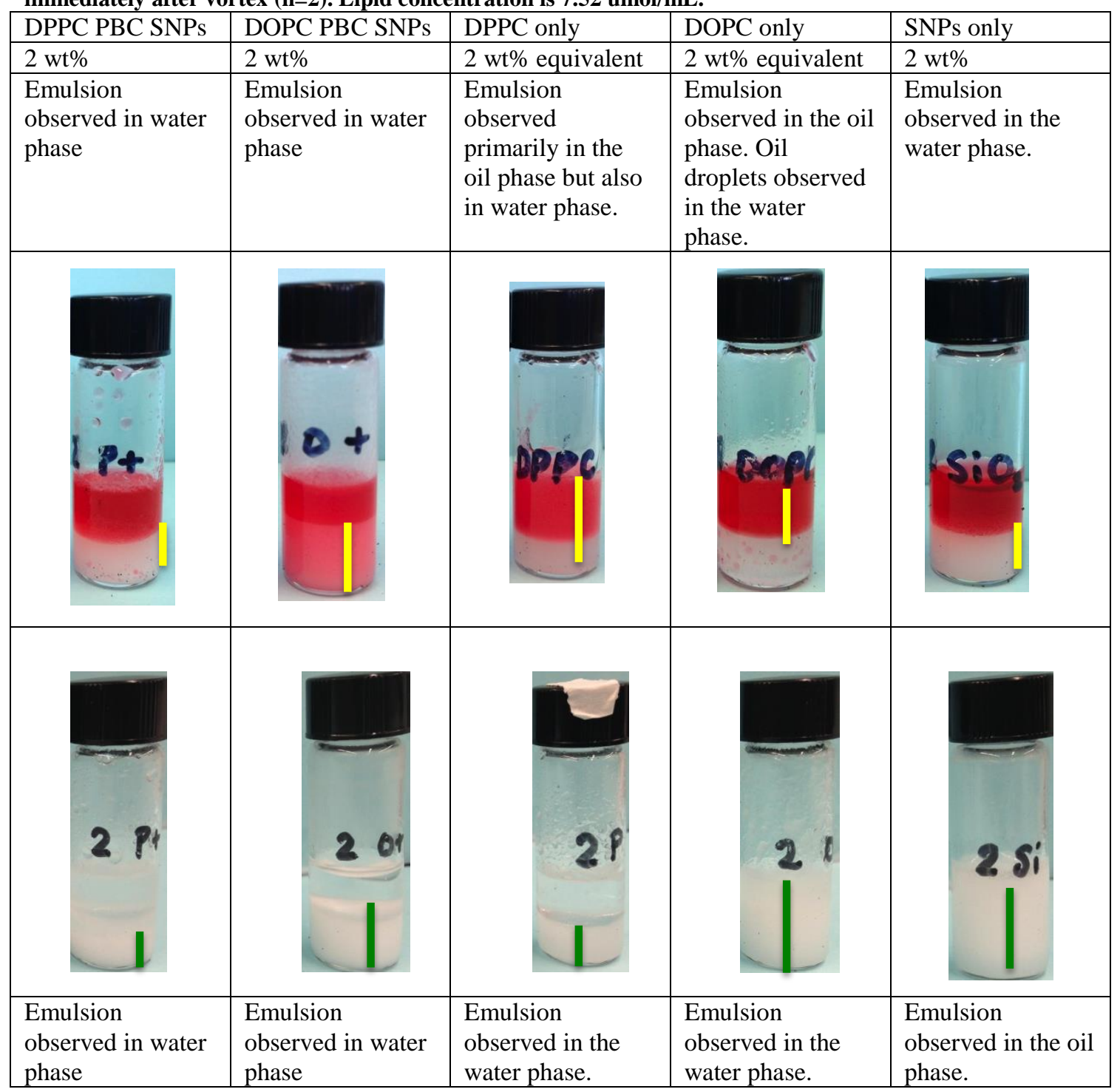


Interestingly, as seen in Table 4.6, when Sudan IV is used to dye the oil phase, different phase behavior is observed. Without Sudan IV, DOPC and DPPC liposomes foster octane-DI water emulsions in the water phase, while silica fosters an emulsion in the oil phase, the inverse of what was observed with DOPC, DPPC and silica with the oil phase dye Sudan IV. Lipid-coated silica nanoparticles follow the same trend as observed with Sudan IV: an emulsion is observed in the water phase.

In the case of the emulsion stabilized by silica $(a, b)$ in Table 4.1.6, an emulsion is observed in the aqueous phase in the presence of Sudan IV, while an emulsion is observed in the oil phase in the absence of Sudan IV. In the case of the emulsion stabilized by DPPC (c, d), an emulsion is observed in the water phase without Sudan IV, while an emulsion is observed in the oil phase and the water phase in the presence of Sudan IV. In the case of an enhanced emulsion, this is likely due to Sudan IV the oil-water interface, which contributes to a decrease of surface tension between the two phases. In the case where different phase behavior is observed, this is likely because Sudan IV dominates the oil-water interface, more so than silica, and so dictates the emulsion characteristics. Interference of Sudan IV with studies of interfacial phenomena has been noted previously, when researchers observed that Sudan IV was surface active (Tuck, 1999). It is important to note this variability since many studies of interfacial phenomena enlist a colored dye to better image the oil phase.

\subsection{Lipid bilayer-coated silica nanoparticles (BC SNPs)}

BC SNPs were prepared according to section 3.1.2. The effect of type of oil and the effect of lipid tail structure was explored, while vortex speed and time, $\mathrm{pH}$ of 
the aqueous phase, particle concentration and the oil-water volumetric ratio were kept constant.

\subsubsection{Characterization of BC SNPs}

DPPC and DOPC vesicles, SNPs before lipid adsorption, and BC SNPs were characterized by DLS and zeta potential measurements before being used to stabilize emulsions.

\subsubsection{Characterization of liposomes before adsorptions to SNPs}

DPPC and DOPC liposomes were determined to be approximately $80 \mathrm{~nm}$ from dynamic light scattering. A net neutral zeta potential of approximately $0 \mathrm{mV}$ was recorded at $\mathrm{pH}=6.5$.

\subsubsection{Characterization of silica before adsorption to SNPS}

Fully hydroxylated silica particles were determined to be approximately $1 \mu \mathrm{m}$ in aqueous suspension, from DLS. Confirmation of fully hydroxylated silica particles is documented in a paper pending submission to Marine Pollution Bulletin (Gupta et al., 2014). The zeta potential at $\mathrm{pH}$ of 6.5 was approximately $-20 \mathrm{mV}$.

\subsubsection{Characterization of BC SNPs}

DOPC and DPPC BC SNPs were determined to be approximately $1 \mu \mathrm{m}$ in aqueous suspension, from dynamic light scattering. DOPC and DPPC BC SNPs were observed to have a zeta potential of approximately $-25 \mathrm{mV}+/-3 \mathrm{mV}$. This is similar to the results seen with PBC SNPs, and to the results observed by previous researchers who coated silica particles with DPPC (Chibowski et al., 2010a). As the zwitterionic lipids used have a net neutral charge, they do not impact the zeta potential of the silica 
particles to a large extent and the recorded zeta potential is similar to that of silica only at the same concentration.

\subsubsection{Performance of BC SNPs}

\subsubsection{Effect of Lipid Tail Structure on Emulsions Stabilized with BC SNP}

The effect of lipid-tail structure on emulsions stabilized with BC SNPs was examined. In the results presented in Table 4.7, no significant difference between the emulsions stabilized with DPPC BC SNPs and DOPC BC SNPs was observed. This is because in the results presented here, just enough lipid is on the SNPs to coat the complete surface of the SNPs, due to the free lipid removal step. In results presented in section 4.1, excess lipid is present.

\subsubsection{Effect of Oil Type on Emulsions Stabilized with BC SNPS}

In this section, the effect of different oil types on emulsions stabilized by $\mathrm{BC}$ SNPs was explored. Non-aromatic organic solvents and an aromatic organic solvent are used as the oil phase to examine the effect of aromaticity on emulsions stabilized with BC SNPs, as well as oils of varying polarity to explore the influence of polarity of the oil on emulsion stability. The emulsions with a polar oil, octanol, were significantly larger in volume and more stable than the emulsions with non-polar oils, such as hexadecane and octane.

Interfaces between liquids that are close in polarity have a lower interfacial tension and lower surface energy than interfaces between liquids with very different molecular polarities, which contributes to more stable emulsions. Results (Table 4.2.1) 
show that BC SNPs foster more stable emulsions between DI water and more polar oils than with more nonpolar oils.

Emulsions with toluene stabilized by BC SNPs exhibited approximately the same emulsion size and stability as emulsions with octane. No noticeable effect was observed due to aromaticity.

Table 4.7: Effect of lipid tail structure and oil type on emulsions (1:1 volumetric ratio) stabilized by 0.1 wt $\%$ DOPC and DPPC BC SNPs w.r.t the aqueous phase $(\mathrm{A}=$ bromohexadecane, $\mathrm{B}=$ Pennsylvania crude oil, $\mathrm{C}=$ hexadecane, $\mathrm{D}=$ octane, $\mathrm{E}=$ octanol, $\mathrm{F}=$ toluene $)(\mathrm{n}=2)$. Free lipid was removed in these samples.

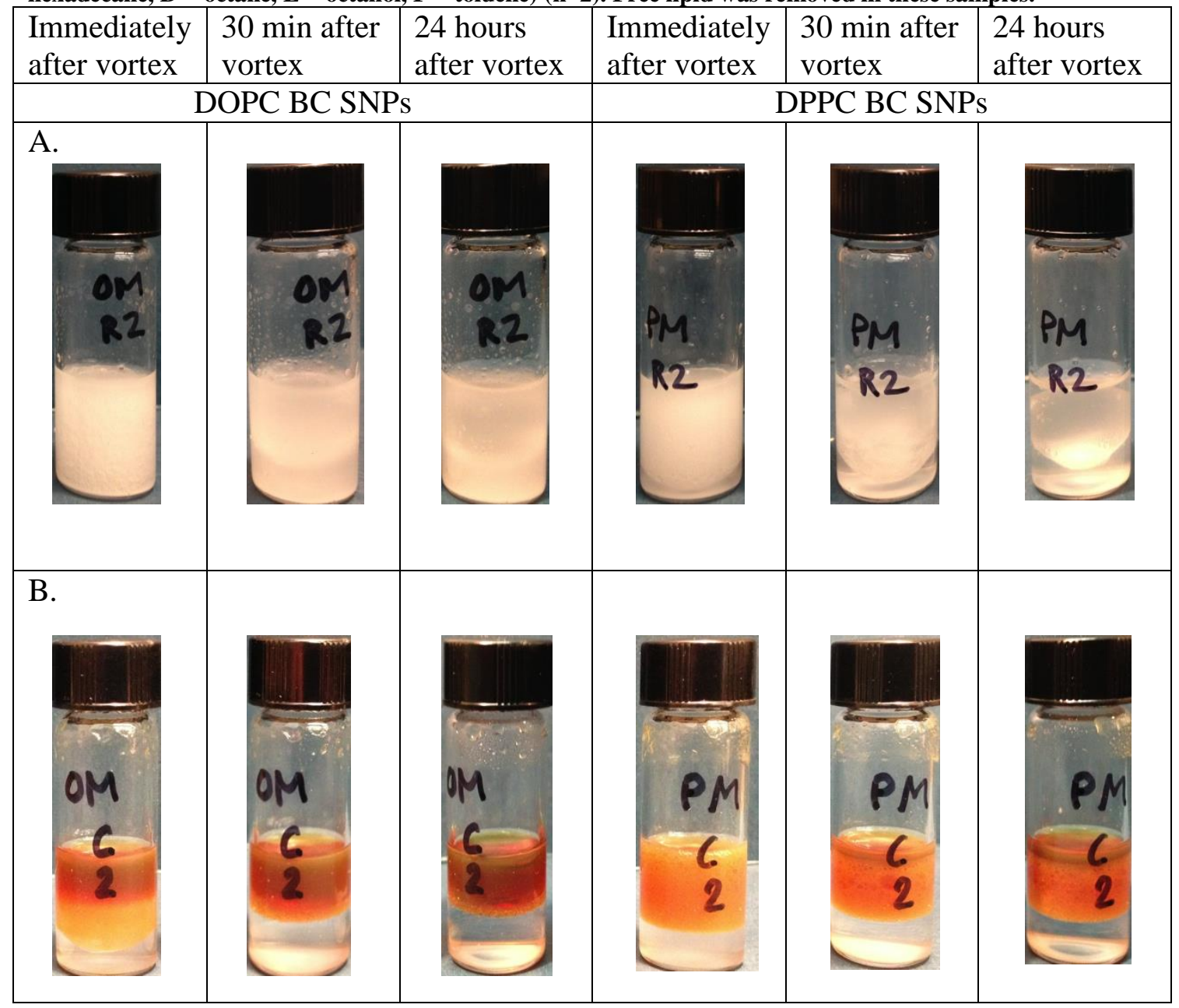




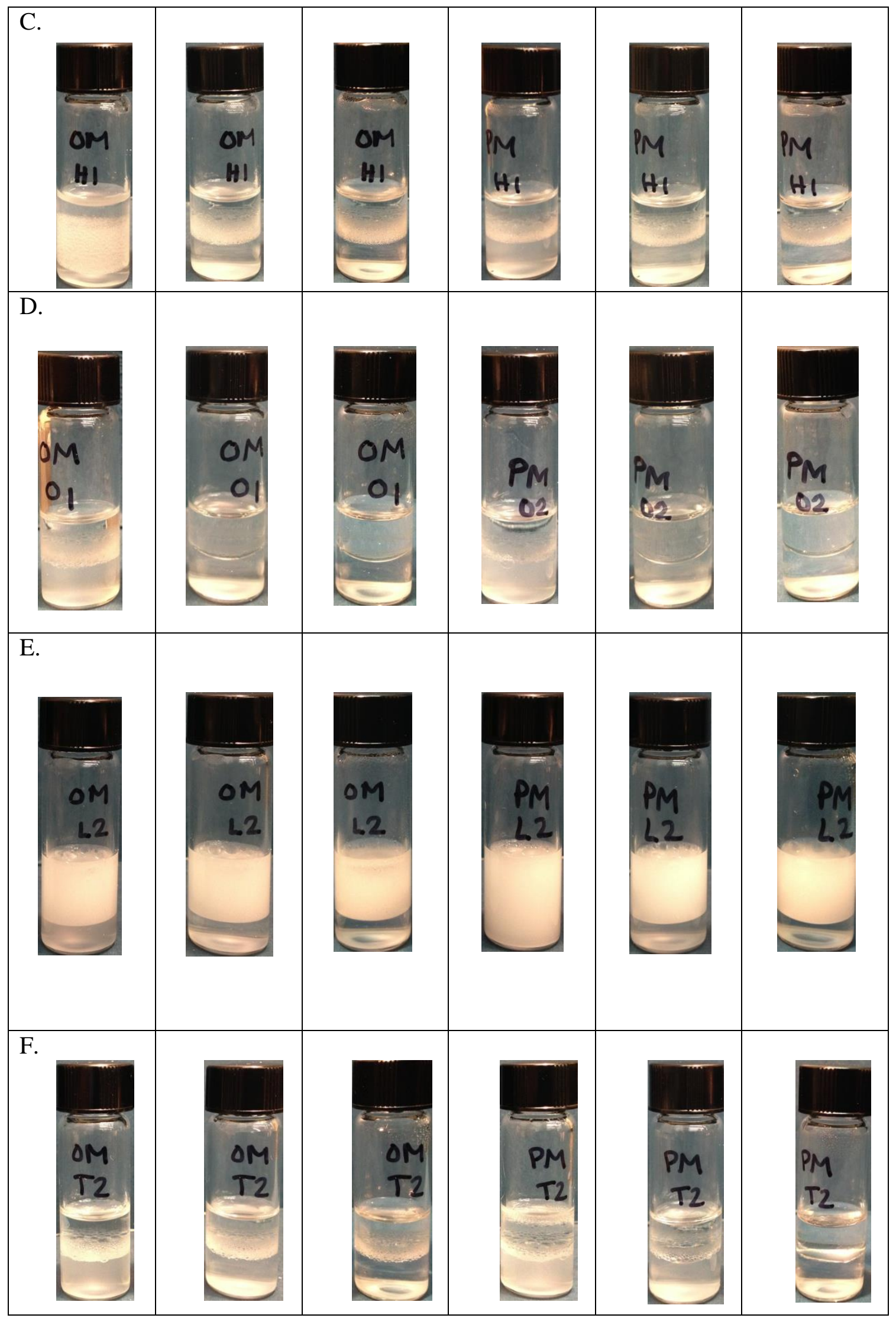




\subsection{Lipid monolayer-coated silica nanoparticles (MC SNPs)}

MC SNPs were prepared according to Methodology section 3.1.3. The effect of type of oil and the effect of lipid tail structure was examined, while vortex speed and time, $\mathrm{pH}$ of the aqueous phase, particle concentration and the oil-water volumetric ratio were kept constant.

\subsubsection{Characterization of MC SNPs}

DPPC and DOPC MC SNPs were characterized by DLS and zeta potential measurements before being used to stabilize emulsions.

\subsubsection{Characterization of lipid before adsorption to SNPs}

Lipid in chloroform (both DPPC and DOPC) was determined to be approximately $5 \mathrm{~nm}$ from dynamic light scattering (DLS).

\subsubsection{Characterization of SNPs before coating with lipid}

Hydrophobized silica particles were approximately $1 \mu \mathrm{m}$ in size before being coated with lipid. Completely hydrophobic silica nanoparticles in toluene were characterized before grafting of silane groups, and also were approximately $1 \mu \mathrm{m}$ in size in toluene and water. The zeta potential was observed to be approximately -10 $\mathrm{mV}$ at $\mathrm{pH}$ of 6.5 .

\subsubsection{Characterization of MC SNPs}

Severe aggregation was observed with MC SNPs. However, aggregation was reversed using probe sonication (Refer to Methodology Section 3.1.3), and the average of the zeta potential observed was approximately $0 \mathrm{mV}$ for DPPC monolayers, and -29 $\mathrm{mV}$ for DOPC monolayers at a $\mathrm{pH}$ of $6.5 \mathrm{mV}$. The zeta potential readings were not in 
agreement with values published in literature (Chibowski et al., 2010a) and the disagreement between zeta potentials of DPPC MC SNP and DOPC MC SNP coatings was also not expected.

\subsubsection{Performance of MC SNPs}

Oil type is an important factor in the formation of Pickering emulsions. In this section the effect of lipid tail structure and oil type on emulsions stabilized by MC SNPs are examined.

Table 4.8: Effect of lipid tail structure and oil type on emulsions stabilized by DPPC and DOPC MC SNPs. Samples contain $1 \mathrm{wt} \%$ particle with respect to the aqueous phase, volume of sample is $2 \mathrm{~mL}$ and volumetric ratio of oil:water is 1:1. (A = bromohexadecane, $\mathrm{B}=$ butanol, $\mathrm{C}=$ Pennsylvania crude oil, $\mathrm{D}=$ hexadecane, $\mathrm{E}$ $=$ octane, $\mathbf{F}=$ octanol). Lipid concentration is $3.76 \mathrm{umol} / \mathrm{mL}$, though aggregation introduced variability.

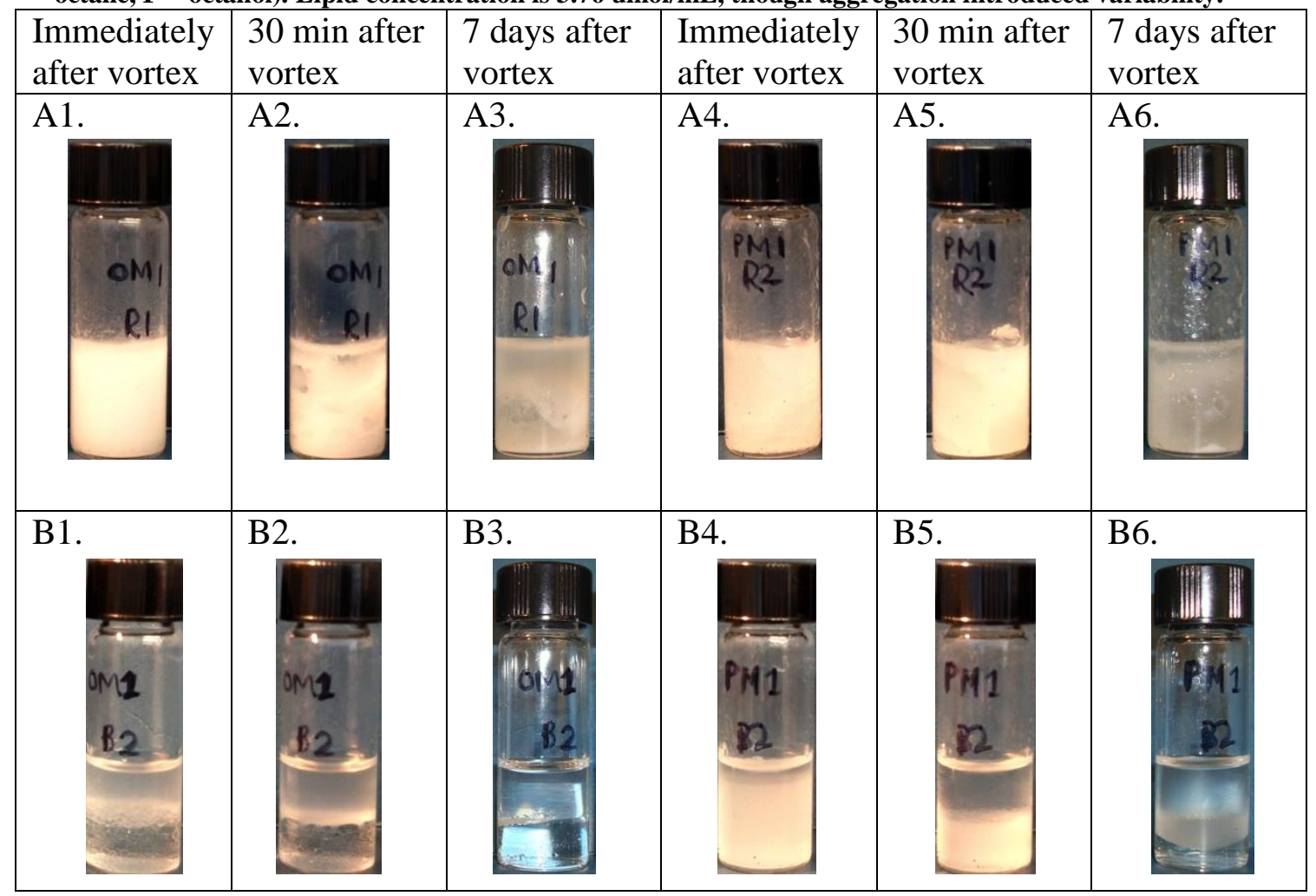




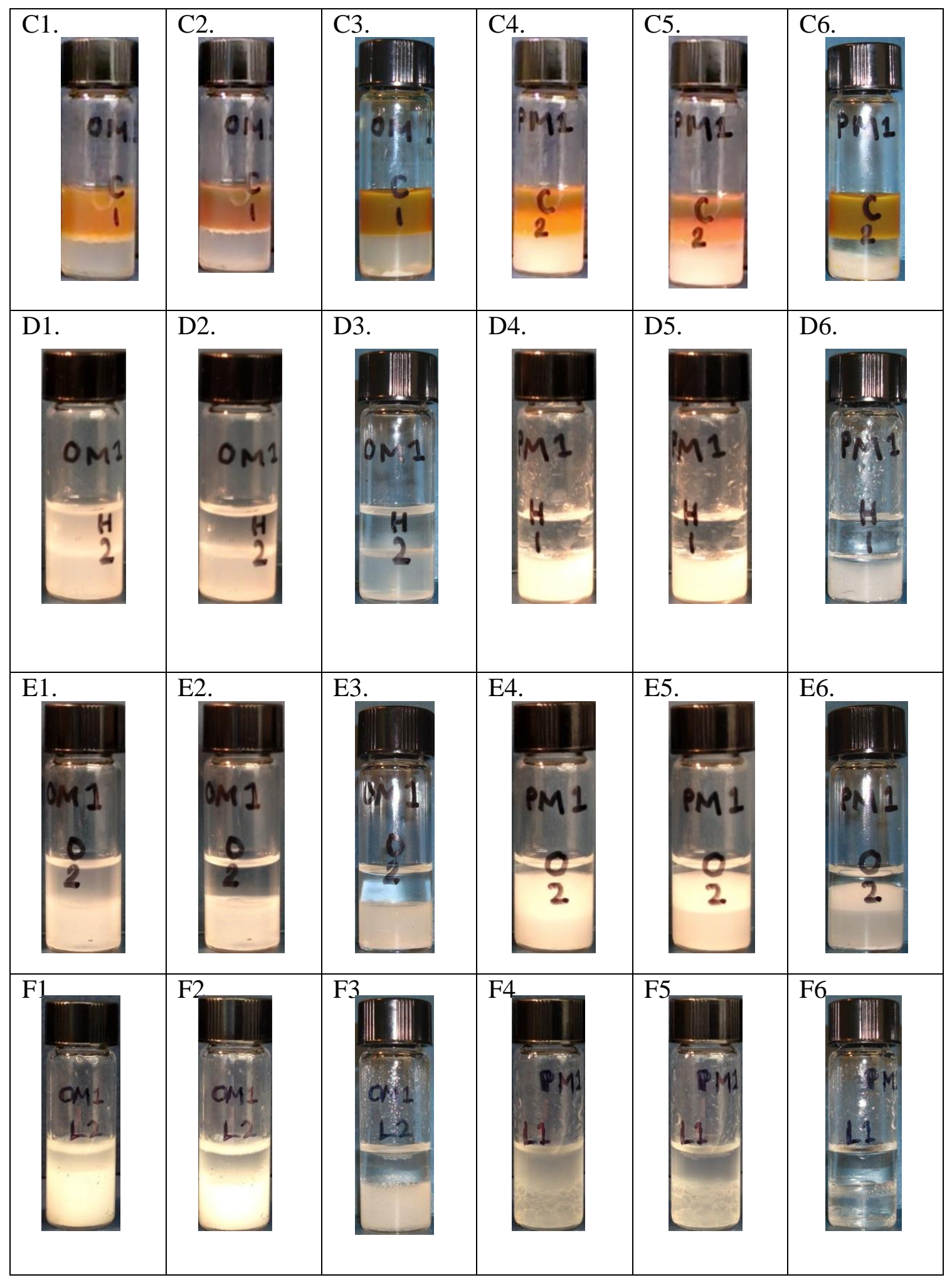




\subsubsection{Effect of Lipid Tail Structure on Emulsions Stabilized with MC SNPS}

The effect of lipid-tail structure on emulsions stabilized with MC SNPs was examined. In the results presented in Table 4.8, no significant difference between the emulsions stabilized with DPPC BC SNPs and DOPC BC SNPs was observed. DI water-bromohexadecane emulsions stabilized by DPPC MC SNPs were approximately the same size and stability as DI water-bromohexadecane emulsions stabilized by DOPC MC SNPs.

Table 4.9: Bromohexadecane-DI water emulsion stabilized with MC SNPs. (1 wt \%, 30 min after vortex, emulsion phase imaged, and scale bar $=100 \mu \mathrm{m}$ ) Lipid concentration is $3.76 \mathrm{umol} / \mathrm{mL}$.

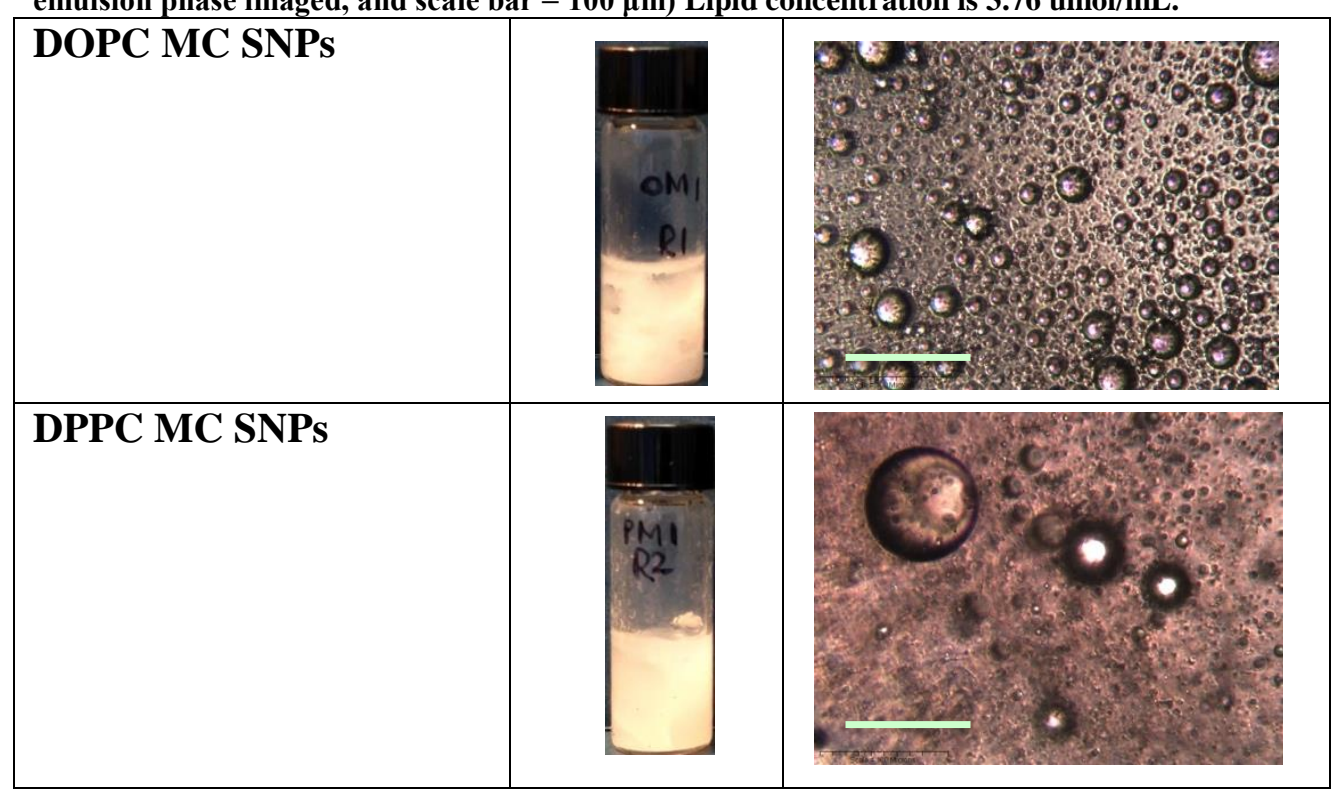


Figure 4.7: Bromohexadecane-DI water emulsion stabilized by DPPC MC SNPs $(1 \mathrm{wt} \%$, scale bar $=5 \mu \mathrm{m})$

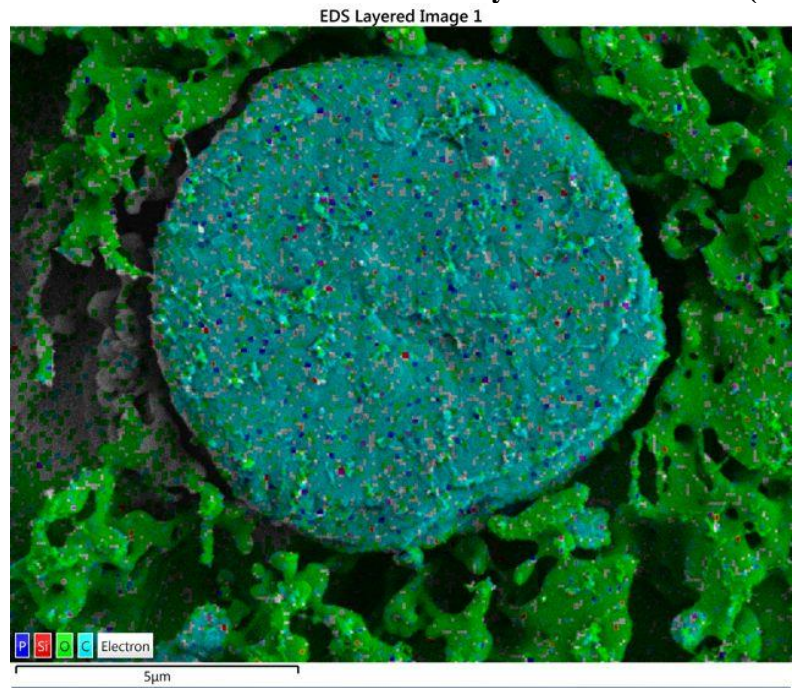

From Table 4.3.2, it is clear that in bromohexadecane-DI water emulsions stabilized with MC SNPs, droplet structure is complex, and droplets within droplets are observed. It is likely that multiple emulsions are present due to some free lipid. Figure 4.3.1 confirms the presence of oil droplets in water, though does not preclude the existence of water droplets in oil.

\subsubsection{Effect of Oil Type on MC SNPs}

Due to the aggregation that occurred in the preparation of MC SNPs, the effects of non-uniformity of the samples are present in the results displayed in Table 4.3.1. The non-homogeneity of the samples precludes sweeping conclusions about the effect of different oils on the characteristics of the Pickering emulsions. 


\subsection{A Comparison of emulsions stabilized with PBC SNPs, BC SNPs and MC SNPs}

Tables 4.10 compares the octane-DI water emulsions stabilized with PBC SNPs and BC SNPs. Due to aggregation, the MC SNPs display variability and are not recommended without significant changes to the process that would result in colloidal stability, rather than the aggregation that was observed here. BC SNPs display consistency from sample to sample. However, PBC SNPs outperform BC SNPs up to the conditions evaluated in this research, $7.52 \mathrm{mM}$ lipid and $2 \mathrm{wt} \%$ silica particle. In the application of oil spills, PBC SNPs represent the particle with the least number of production steps, and the largest emulsion height of the samples tested. In the application of oil spill remediation, given sufficient evaluation of the oil spill site such that nutrient enhancement would be beneficial, PBC SNPs are recommended.

Table 4.10: A Comparison of octane-DI water emulsions stabilized with DPPC and DOPC PBC SNPs and BC SNPs (0.1 wt \% particle, $0.376 \mathrm{umol} / \mathrm{mL}$ w.r.t. aqueous phase)

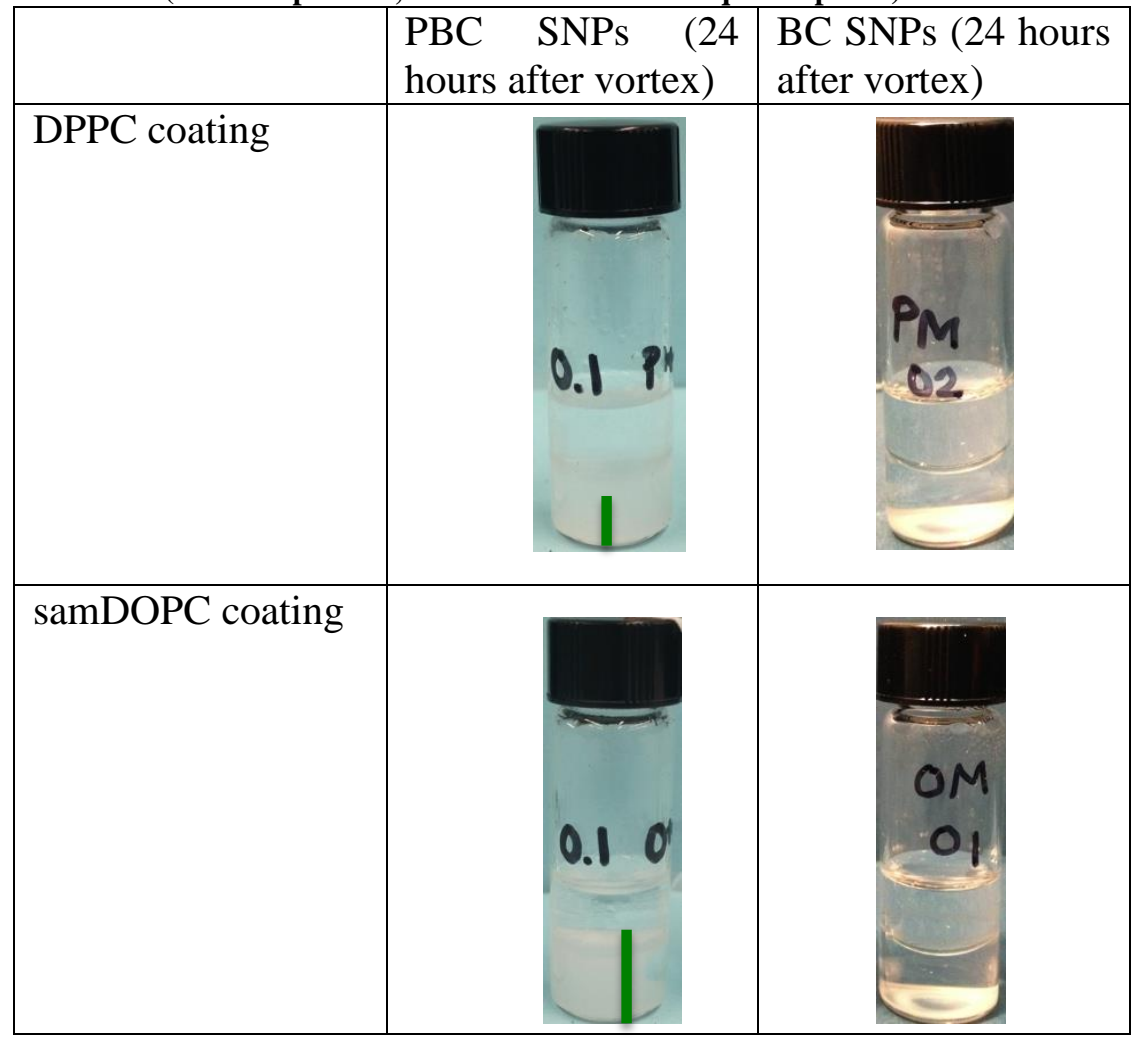




\section{CONCLUSIONS}

Three different methods were used to coat silica particles with a responsive lipid coating. These methods produced: partial bilayer-coated silica nanoparticles (PBC SNPs), bilayer-coated silica nanoparticles (BC SNPs) and monolayer-coated silica nanoparticles (MC SNPs). For each of these methods, two different lipids were used for the coating to evaluate the effect of lipid tail structure on the emulsion stabilized by these particles. Furthermore, the effects of particle concentration and oil type on emulsion stability were examined.

More DPPC adsorbed to the silica particles than DOPC. This is likely due to their slightly different surface area required per lipid molecule on the silica particle. Furthermore, as DOPC occupies more space on the oil water interface, given equal molarities of DOPC and DPPC, DOPC fosters stronger emulsions at the conditions examined in the research presented in this document, up to $7.52 \mathrm{mM}$ lipid with respect to the aqueous phase only. As predicted, when DOPC and DPPC are used to coat silica particles, excess lipid is removed, and the particles are used to foster Pickering emulsions, the emulsion size and stability is approximately equivalent.

PBC SNP concentration and oil type greatly influenced the characteristics of the emulsion formed. Within the conditions tested, increasing the particle concentration resulted in a more stable emulsion. The largest and most stable of the emulsions stabilized with BC SNPs were the emulsions with oil types octanol and Pennsylvania crude oil, due to the polarity of octanol, and the asphaltenes of Pennsylvania crude oil, which contribute to the stability of the emulsions. Also, in 
experimentation, an oil phase dye used (Sudan IV) was determined to be surface active.

BC SNPs were prepared similarly to PBC SNPs, except that the surface of the silica particles is completely hydrophilic, and excess lipid vesicles not adsorbed to silica particles were removed by way of centrifugation. This removal of excess lipid vesicles had a profound effect on the emulsions formed, compared to PBC SNPs. As some lipid adsorbs to the oil-water interface, and there is no excess lipid present, as a result of the addition of oil and the emulsification process, some bare silica is exposed to the oil-water interface. Vesicles only foster oil in water emulsions, and this is seen in emulsions fostered by PBC SNPs also, when excess lipid is present. However, when no excess lipid is present, and bare silica is exposed to the oil-water interface, a change in phase behavior is seen. This exposed bare silica is observed to influence emulsion type in Table 4.8, as the inverse emulsion (w/o instead of o/w) is observed in cases with crude oil and hexadecane.

Previous researchers have noted multiple emulsion formation when two different stabilizers are present (He et al., 2013). As lipid adsorbing and desorbing to silica particles is a dynamic process, two distinct surface-active stabilizers are readily available to adsorb to the oil-water interface, which contribute to multiple emulsions, observed in the case of DI water-crude oil emulsions stabilized by PBC SNPs. Despite the presence of multiple emulsions, it is always possible to tell if the emulsion is primarily in the water phase or the oil phase. In BC SNPs, an oil phase emulsion is observed with crude oil, distinct from the water phase emulsion observed with PBC SNPs, and is attributed to patches of non-lipid-coated silica particle at the interface. 
In the case of MC SNPs, excess lipid was not removed. Also, phase behavior is drastically different across emulsions stabilized with particles coated with different lipids, an effect that was not observed in emulsions stabilized by BC SNPs. This suggests that aggregation compromised monodispersity.

In summary, of the lipid-coated silica nanoparticles prepared in this research, the lipid bilayer-coated silica nanoparticles is recommended over lipid monolayer silica nanoparticles, due to their stability and uniformity. PBC SNPs foster emulsions that mirror the characteristics of emulsions stabilized by liposomes, and cause an inverse of the phase behavior of emulsions stabilized by silica only. When concentrations of DOPC and DPPC are adjusted such that no free vesicles are present, both characteristics of the emulsions stabilized by silica and characteristics of the emulsions stabilized by vesicles only are observed.

In the application of this concept to oil-spill remediation, it is important first to consider the nutrient concentration and particle concentration at the site of interest before the addition of a particulate dispersant. Secondly, the economics of dispersant production are important: it is important to use materials that are inexpensive enough for large-scale production. It is recommended that a less expensive lipid, such as lecithin, a lipid already mass-produced for food applications, be investigated for this purpose before this approach is attempted on a large scale. As discussed in section 4.4, PBC SNPs are recommended over BC SNPs and MC SNPs in the event that the oil spill site meets the criteria for nutrient supplementation. 


\section{APPENDICES}

\subsection{Lipid-coated silica nanoparticles}

\subsubsection{Characterization of lipid-coated silica nanoparticles}

Figure 6.1: Calibration curve for Bartlett assay discussed in Methodology 3.2.3 and Findings 4.1.1.4.

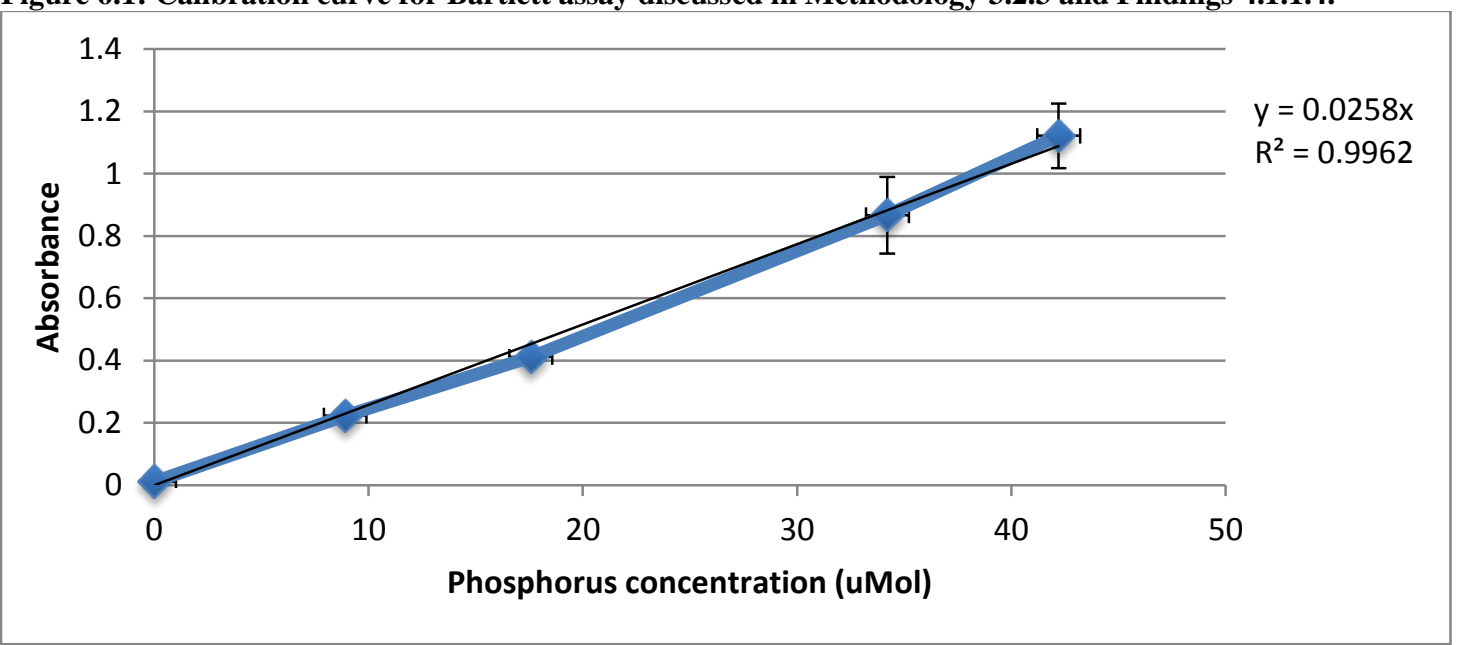

Figure 6.2: Size distribution of DOPC PBC SNPs after removal of free lipid.

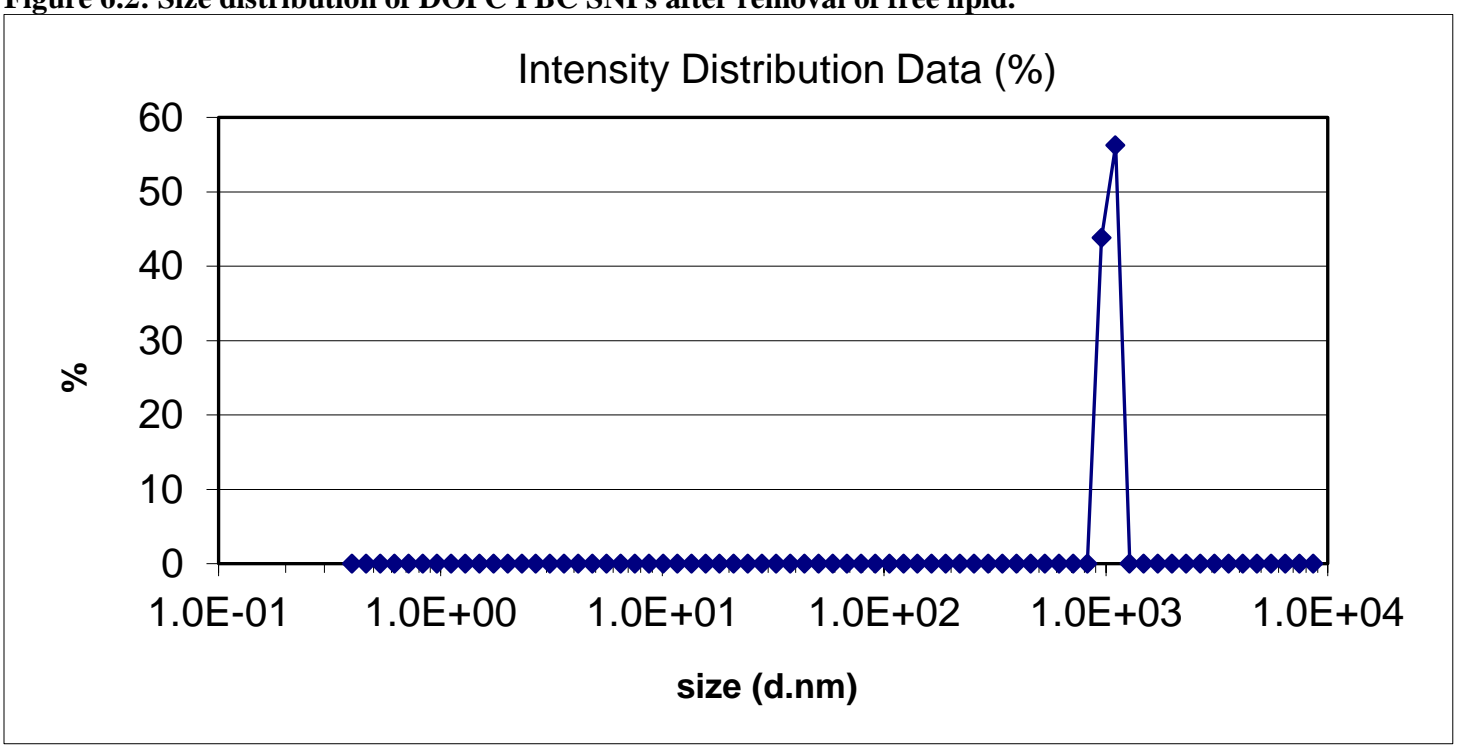


Figure 6.3: Size distribution of DPPC PBC SNPs after removal of free lipid.

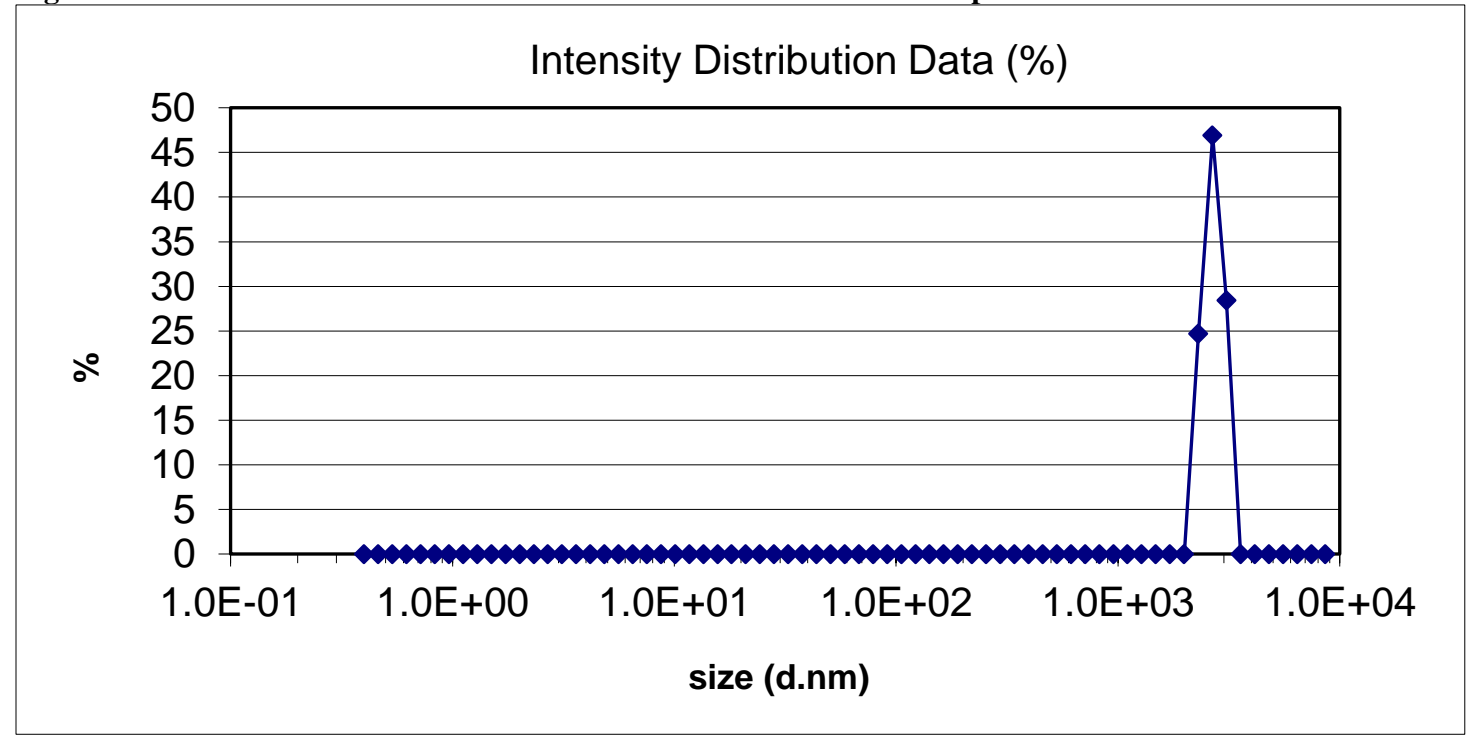

Figure 6.4: Size distribution of non-adsorbed DOPC (liposome form) and DOPC PBC SNP in the supernatant after centrifugation step for the removal of free lipid.

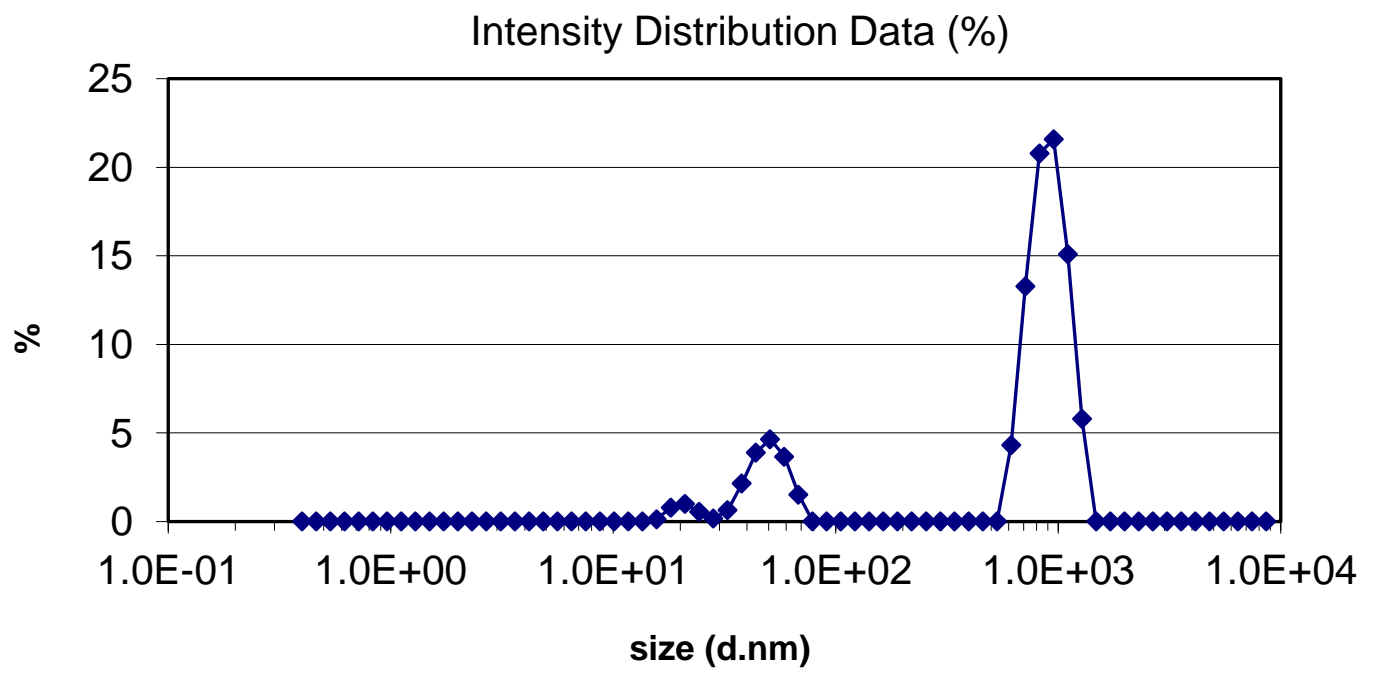


Figure 6.5: Size distribution of non-adsorbed DPPC (liposome form) and DPPC PBC SNP in the supernatant after centrifugation step for the removal of free lipid.

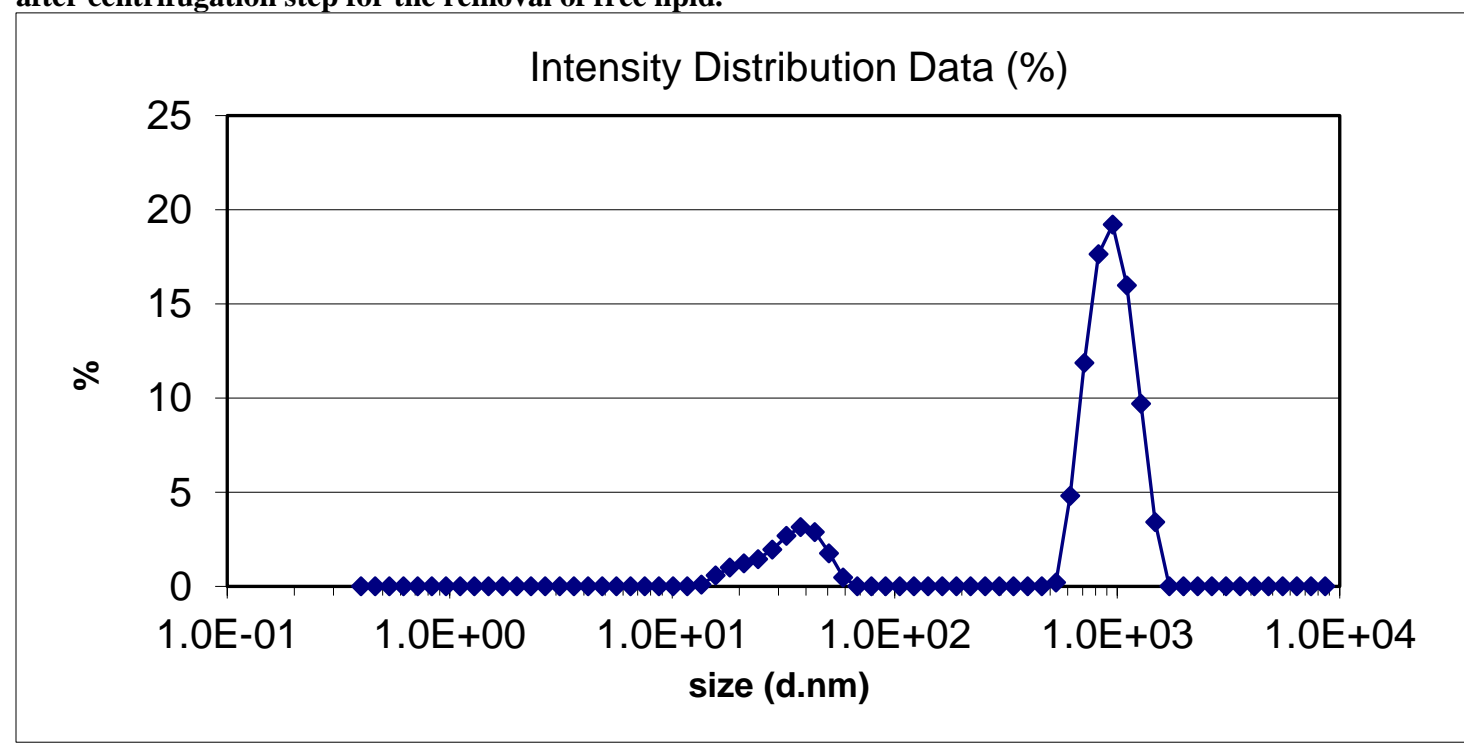

Figure 6.6: Size (DLS output) of non-surface modified silica particles (particles as received) in deionized water, $\mathrm{pH}=6.5$.

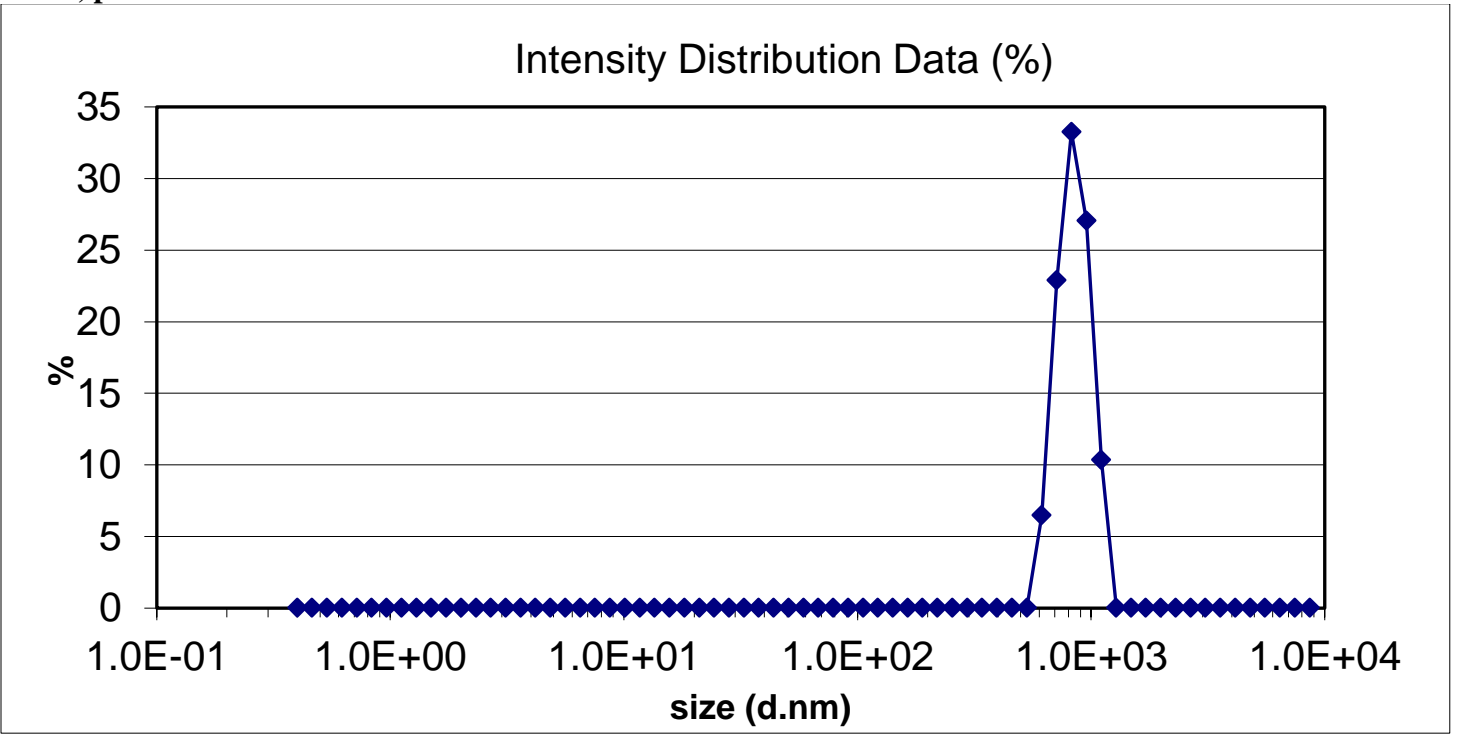




\subsubsection{Performance of lipid-coated silica particles}

Figure 6.7: Stability of crude oil - DI water emulsion stabilized with DOPC liposomes (0.1 wt\% equivalent DOPC; $7.52 \mu$ Mol w.r.t aqueous phase).

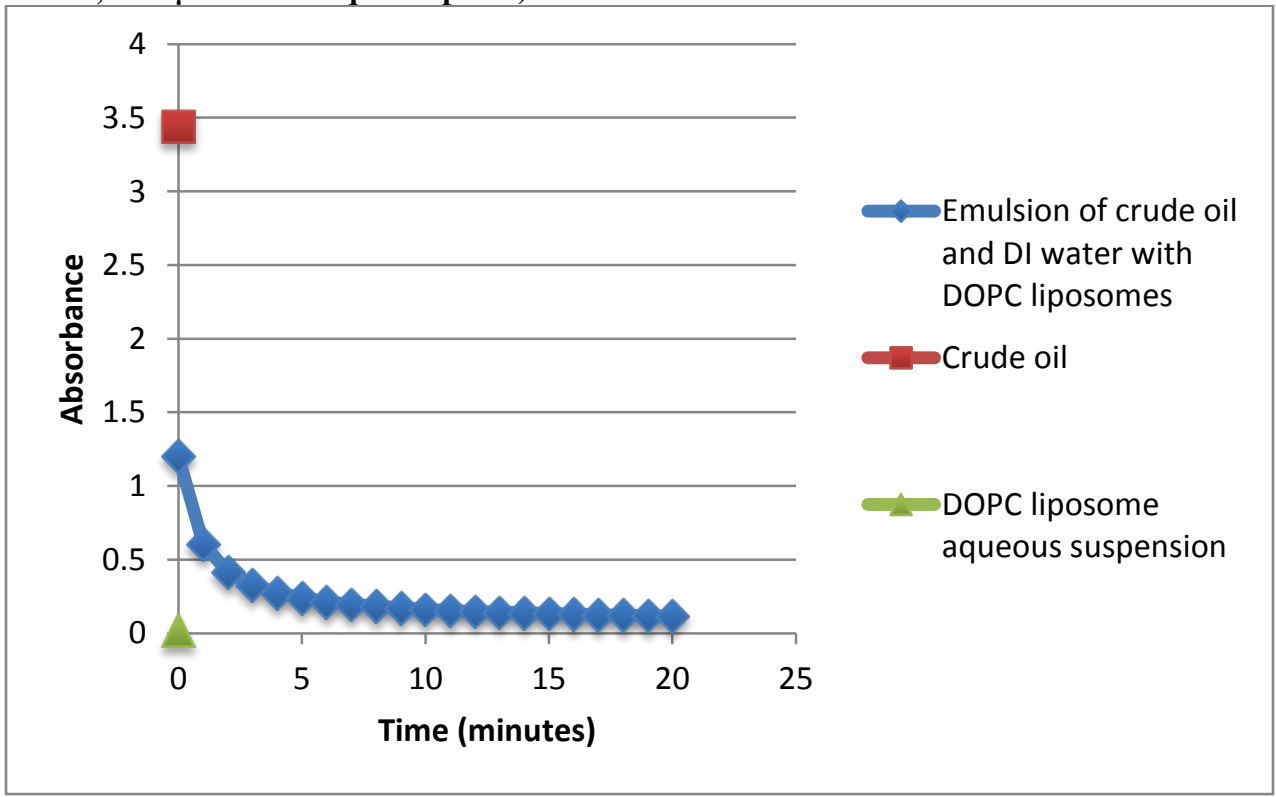

Figure 6.8: Stability of crude oil - DI water emulsion stabilized with DPPC liposomes (0.1 wt\% equivalent; $7.52 \mu \mathrm{Mol}$ w.r.t. aqueous phase).

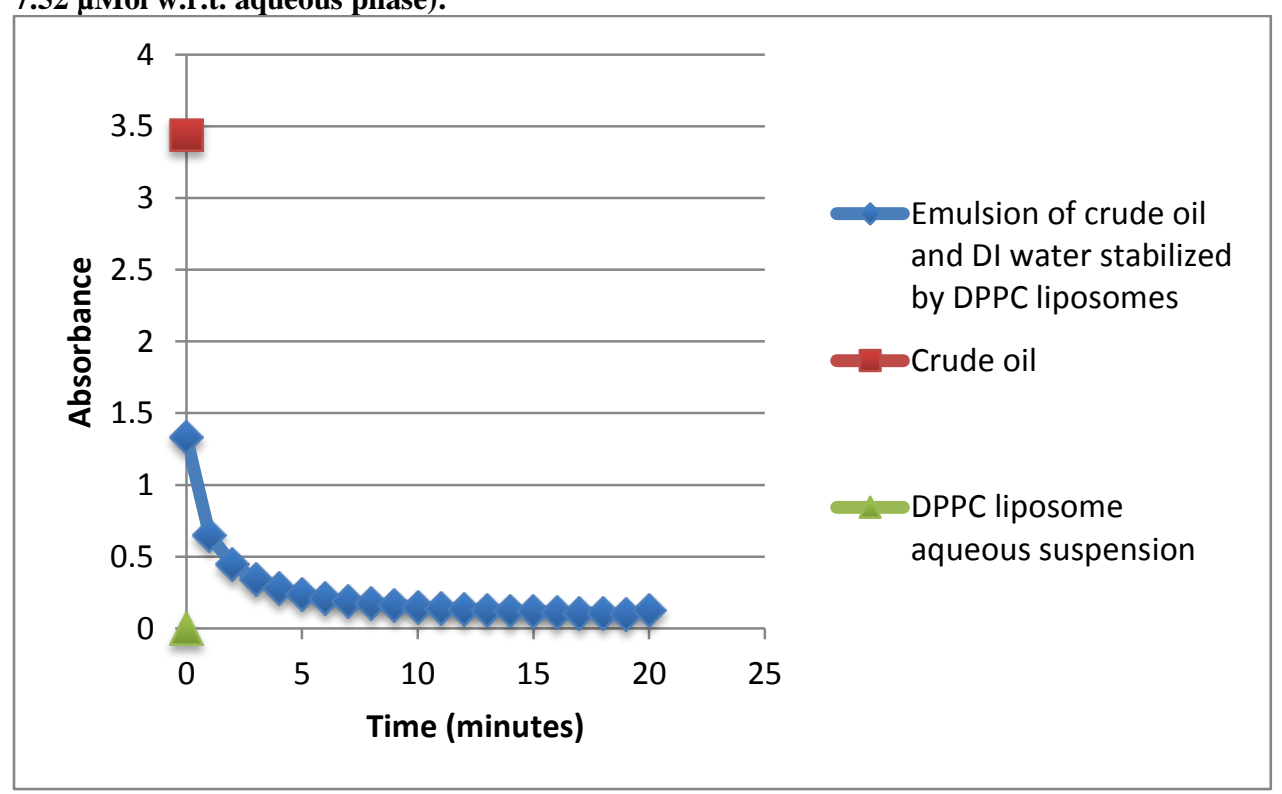


Figure 6.9: Stability of crude oil - DI water emulsion stabilized with SNP (0.1 wt\%).

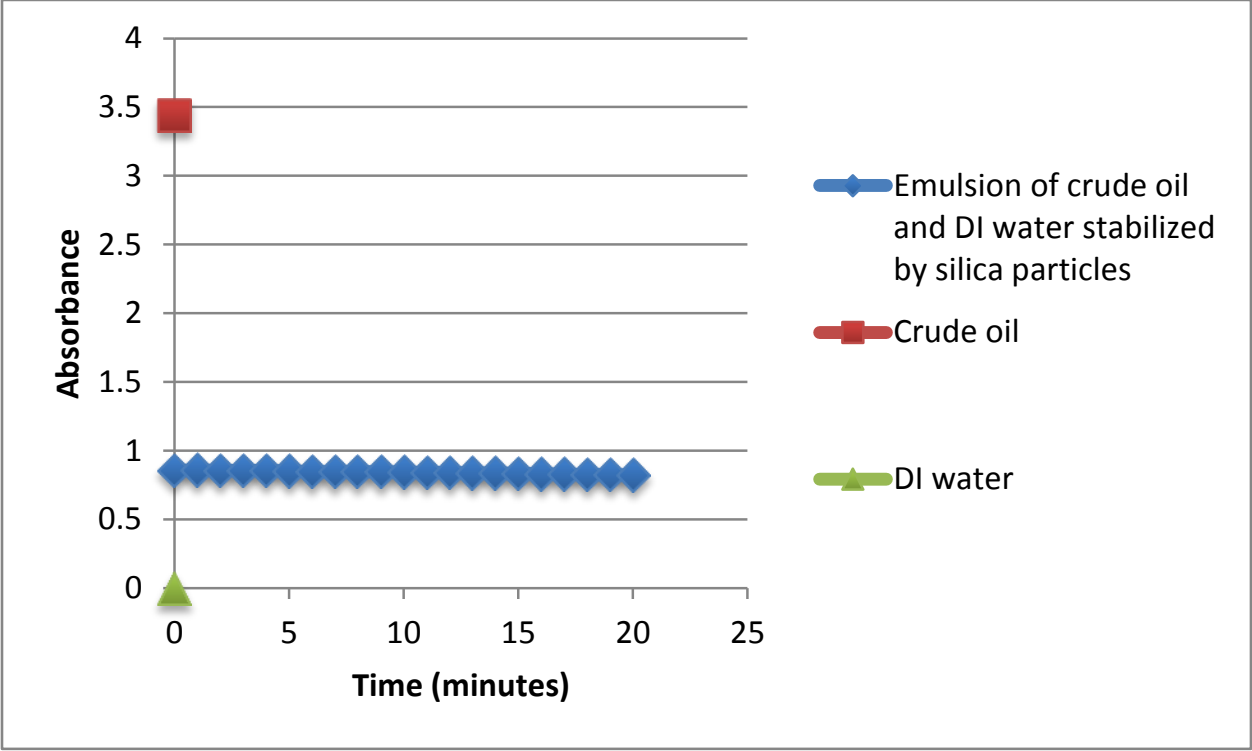

Figure 6.10: Cryo-SEM image of octane in DI water droplets stabilized by SNPs only (1 wt \%). $10 \mu \mathrm{m}$ scale bar. Magnification $15.17 \mathrm{kX}$.

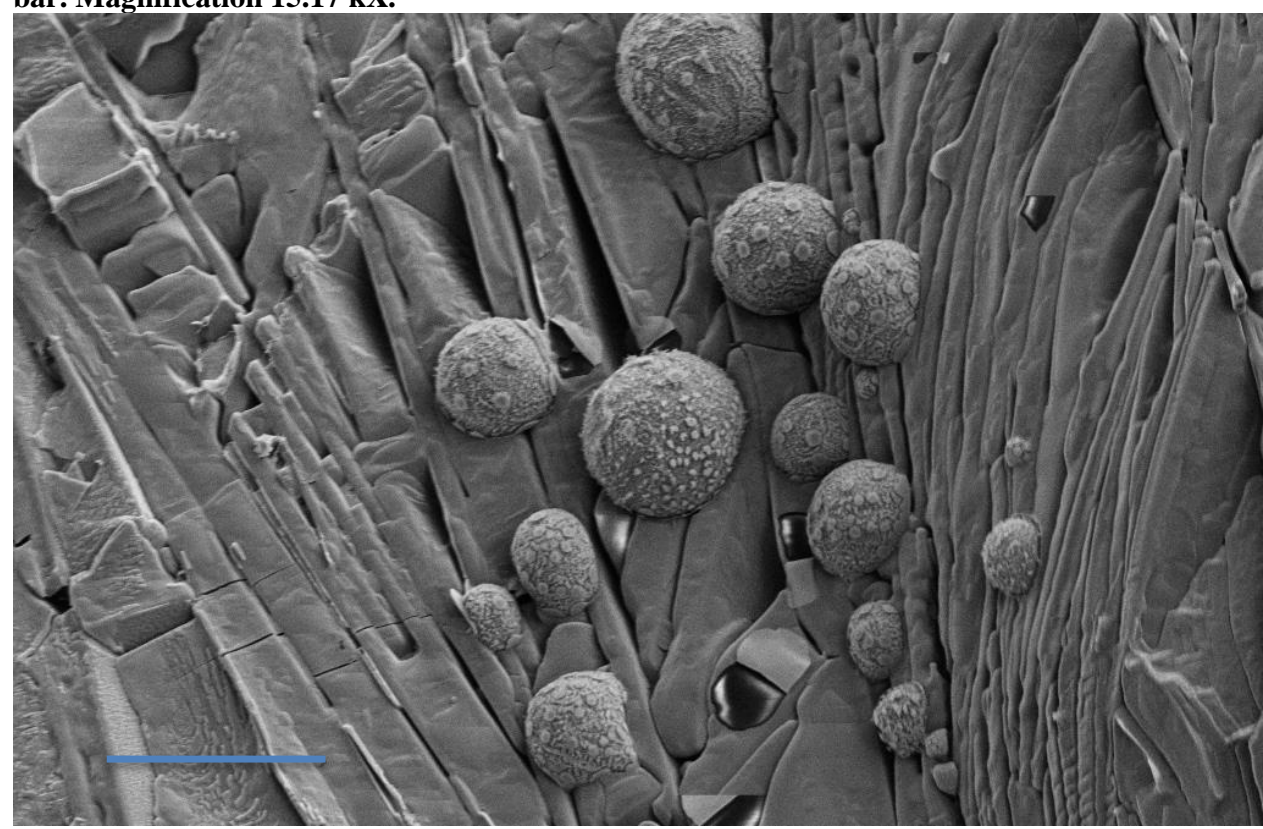


Figure 6.11: Stability of crude oil - DI water emulsion stabilized with DPPC PBC SNP (0.1 wt\%).

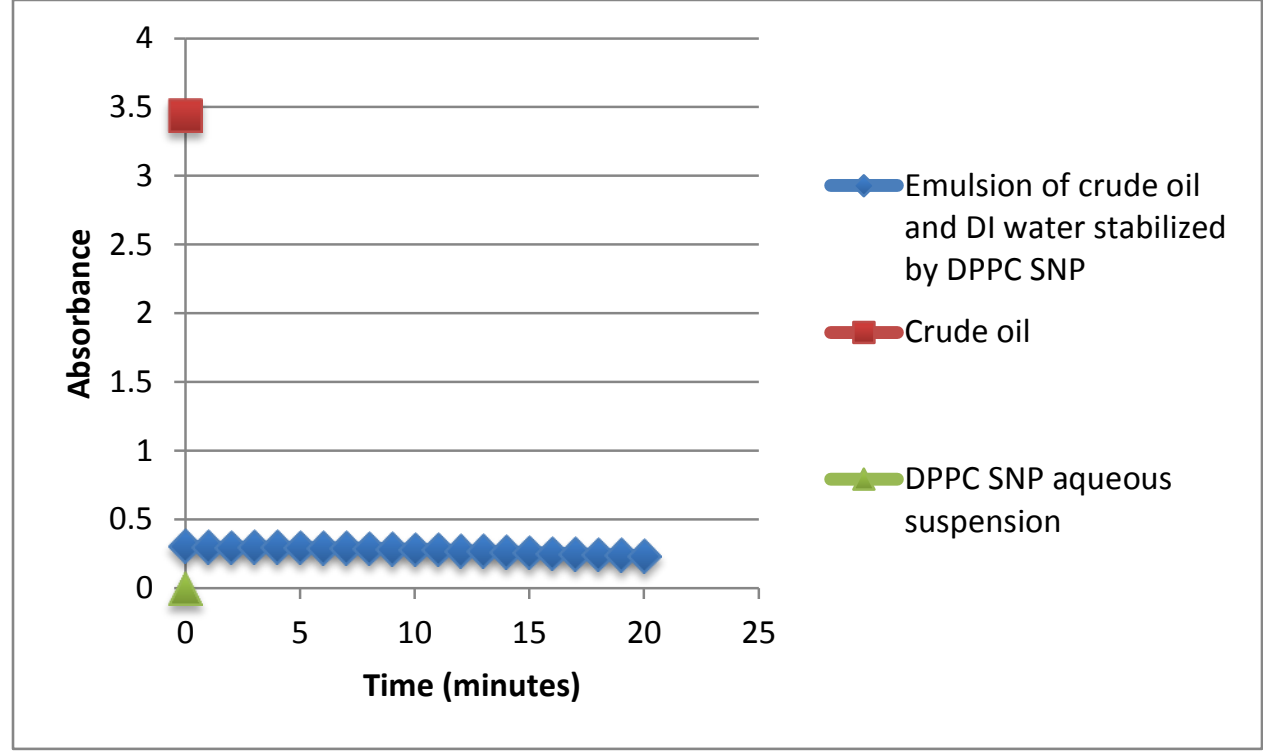

Figure 6.12: Stability of crude oil - DI water emulsion stabilized with DPPC PBC SNP (0.1 wt\%).

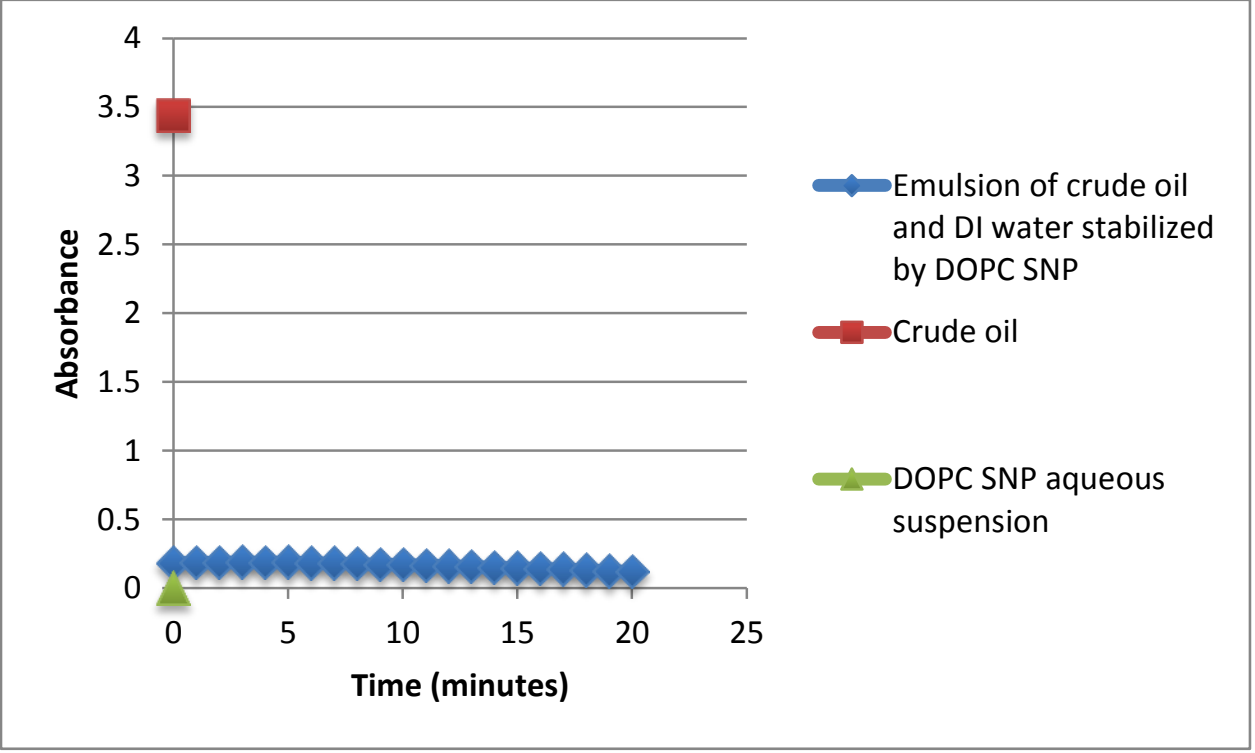


Table 6.1: Emulsification of octane and DI water by DPPC PBC SNP at various particle concentrations w.r.t the aqueous phase. No oil-phase dye (Sudan IV) used.

\begin{tabular}{|c|c|c|c|c|}
\hline $\begin{array}{l}\text { Description } \\
\text { of emulsion }\end{array}$ & $\begin{array}{l}\text { Immediately } \\
\text { after vortex }\end{array}$ & $\begin{array}{l}24 \text { hours } \\
\text { after vortex }\end{array}$ & $\begin{array}{l}72 \text { hours } \\
\text { after vortex }\end{array}$ & $\begin{array}{l}\text { Characterization of } \\
\text { emulsion }\end{array}$ \\
\hline $\begin{array}{l}\text { DPPC SNP } \\
0.05 \mathrm{wt} \%\end{array}$ & & & & $\begin{array}{l}\text { Emulsion in the water } \\
\text { phase. Emulsion dissipated } \\
\text { within the observed time } \\
\text { frame. Sedimentation was } \\
\text { observed. }\end{array}$ \\
\hline $\begin{array}{l}\text { DPPC SNP } \\
0.1 \mathrm{wt} \%\end{array}$ & & & & $\begin{array}{l}\text { Emulsion in the water } \\
\text { phase. Emulsion dissipated } \\
\text { within the observed time } \\
\text { frame. Sedimentation was } \\
\text { observed. }\end{array}$ \\
\hline $\begin{array}{l}\text { DPPC SNP } \\
1 \mathrm{wt} \%\end{array}$ & & & & $\begin{array}{l}\text { Emulsion in the water } \\
\text { phase. Emulsion was } \\
\text { reduced substantially } \\
\text { within the observed time } \\
\text { frame. Sedimentation of } \\
\text { particles and of the oil } \\
\text { droplets was observed. }\end{array}$ \\
\hline
\end{tabular}




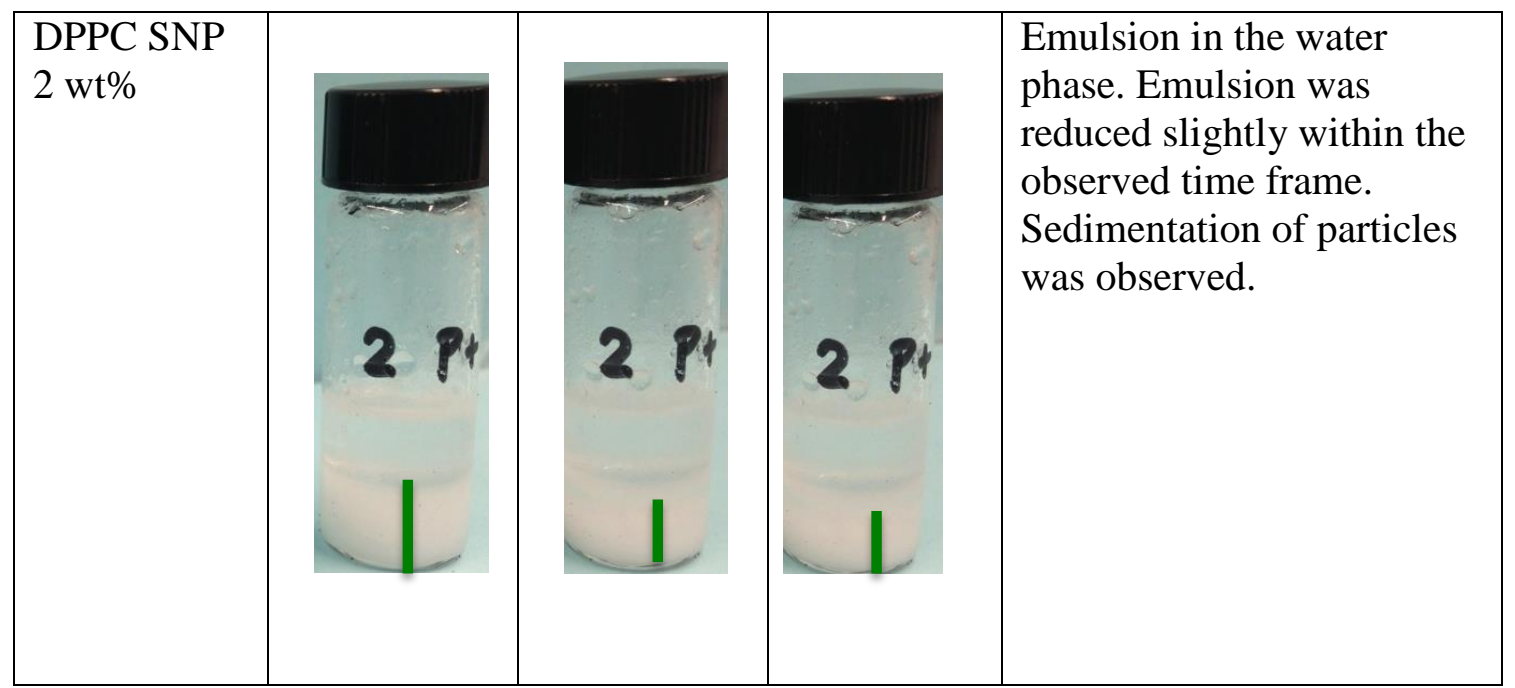

Table 6.2: Emulsification of octane and DI water by DOPC PBC SNPs at various particle concentrations w.r.t the aqueous phase. No oil-phase dye (Sudan IV) used.

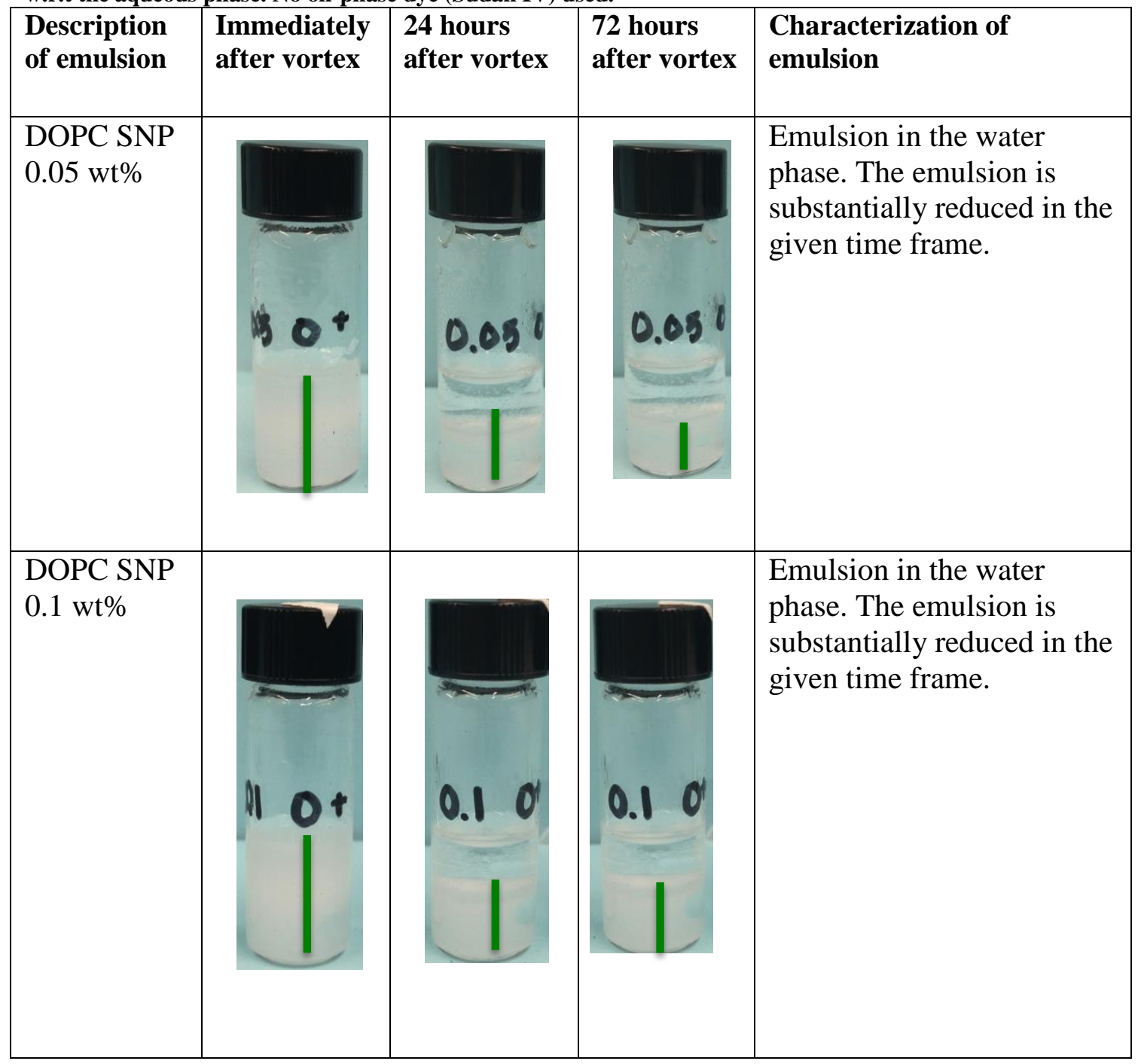




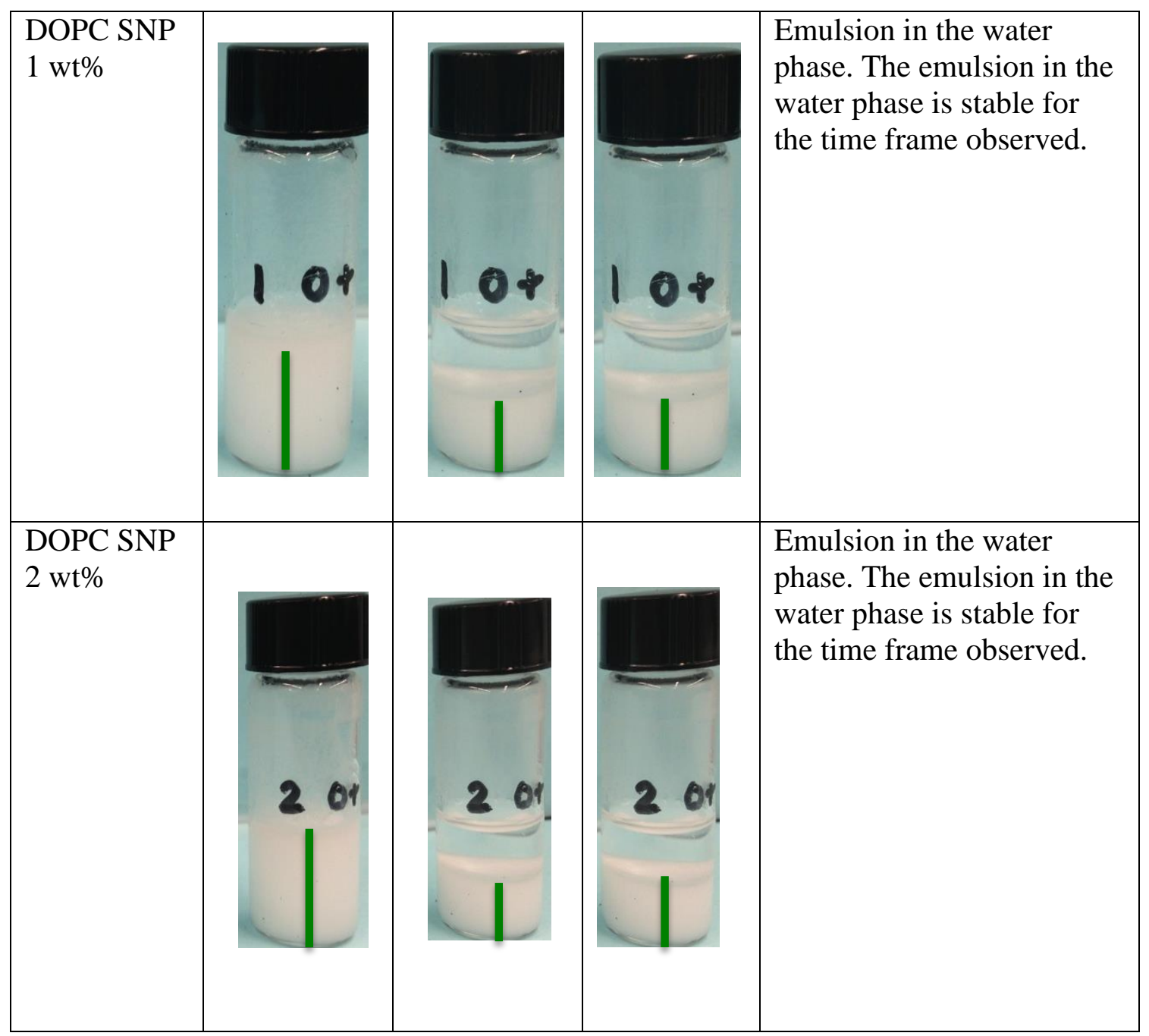


Table 6.3: Emulsification of octane and DI water by DPPC liposomes. No oil-phase dye (Sudan IV) used.

\begin{tabular}{|c|c|c|c|c|}
\hline $\begin{array}{l}\text { Description } \\
\text { of emulsion }\end{array}$ & $\begin{array}{l}\text { Immediately } \\
\text { after vortex }\end{array}$ & $\begin{array}{l}24 \text { hours } \\
\text { after vortex }\end{array}$ & $\begin{array}{l}72 \text { hours } \\
\text { after vortex }\end{array}$ & $\begin{array}{l}\text { Characterization of } \\
\text { emulsion }\end{array}$ \\
\hline $\begin{array}{l}\text { DPPC, } 0.05 \\
\text { wt } \% \\
\text { equivalent }\end{array}$ & \multirow[b]{2}{*}{18} & \multirow[b]{2}{*}{9,0} & \multirow[b]{2}{*}{9.0} & \multirow[t]{2}{*}{ No emulsion visible. } \\
\hline & & & & \\
\hline $\begin{array}{l}\text { DPPC, } \\
0.1 \mathrm{wt} \% \\
\text { equivalent }\end{array}$ & \multirow[b]{2}{*}{$0.1 P$} & \multirow[b]{2}{*}{0.1} & \multirow[b]{2}{*}{0.11} & \multirow[t]{2}{*}{ No visible emulsion. } \\
\hline & & & & \\
\hline $\begin{array}{l}\text { DPPC, } \\
1 \mathrm{wt} \% \\
\text { equivalent }\end{array}$ & $1 P$ & IP & IP & $\begin{array}{l}\text { Emulsion in the water } \\
\text { phase visible. Coalescence } \\
\text { observed within the given } \\
\text { time frame. }\end{array}$ \\
\hline \multirow[t]{3}{*}{\begin{tabular}{|l|} 
DPPC, \\
$2 \mathrm{wt} \%$ \\
equivalent
\end{tabular}} & & & & \multirow[t]{3}{*}{$\begin{array}{l}\text { Emulsion in the water } \\
\text { phase visible. Coalescence } \\
\text { observed within the given } \\
\text { time frame. }\end{array}$} \\
\hline & $p^{\prime}$ & $2 \%$ & $2 P$ & \\
\hline & & I & & \\
\hline
\end{tabular}


Table 6.4: Emulsification of octane and DI water by DOPC liposomes. No oil-phase dye used.

\begin{tabular}{|c|c|c|c|c|}
\hline $\begin{array}{l}\text { Description } \\
\text { of emulsion }\end{array}$ & $\begin{array}{l}\text { Immediately } \\
\text { after vortex }\end{array}$ & $\begin{array}{l}24 \text { hours } \\
\text { after vortex }\end{array}$ & $\begin{array}{l}72 \text { hours } \\
\text { after vortex }\end{array}$ & Characterization of emulsion \\
\hline $\begin{array}{l}\text { DOPC, } 0.05 \\
\text { wt\% } \\
\text { equivalent }\end{array}$ & 0.050 & 0.050 & 0.05 & $\begin{array}{l}\text { Some water droplets } \\
\text { observed in the oil phase. } \\
\text { No visible emulsion phase. }\end{array}$ \\
\hline $\begin{array}{l}\text { DOPC, } \\
0.1 \mathrm{wt} \% \\
\text { equivalent }\end{array}$ & 0.911 & 0.811 & & $\begin{array}{l}\text { Some water droplets } \\
\text { observed in the oil phase. } \\
\text { Emulsion in the water phase } \\
\text { visible. }\end{array}$ \\
\hline $\begin{array}{l}\text { DOPC, } \\
1 \mathrm{wt} \% \\
\text { equivalent }\end{array}$ & & & & $\begin{array}{l}\text { Emulsion in the water } \\
\text { phase. }\end{array}$ \\
\hline & 10 & 10 & & \\
\hline & & & & \\
\hline
\end{tabular}




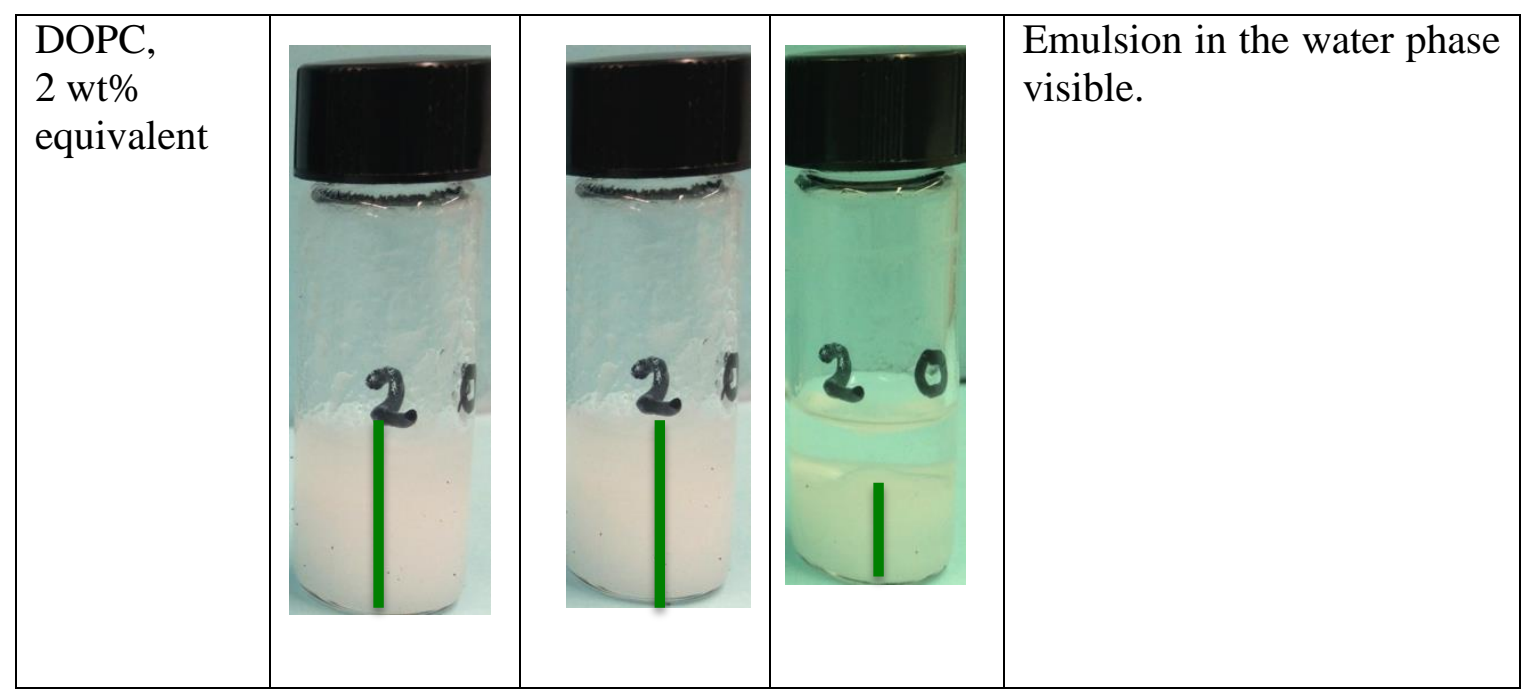


Table 6.5: Emulsification of octane and DI water by SNPs. No oil-phase dye used.

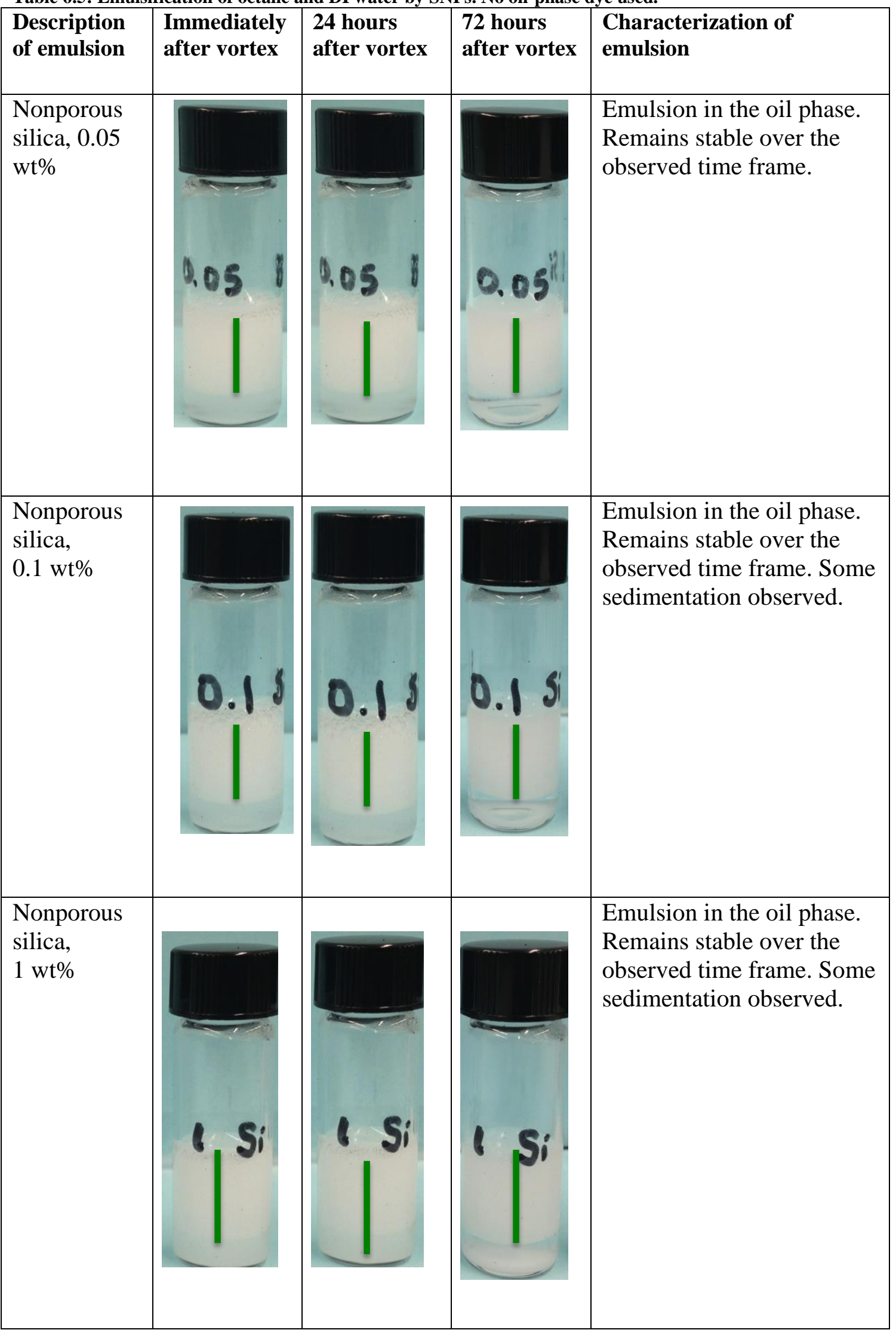




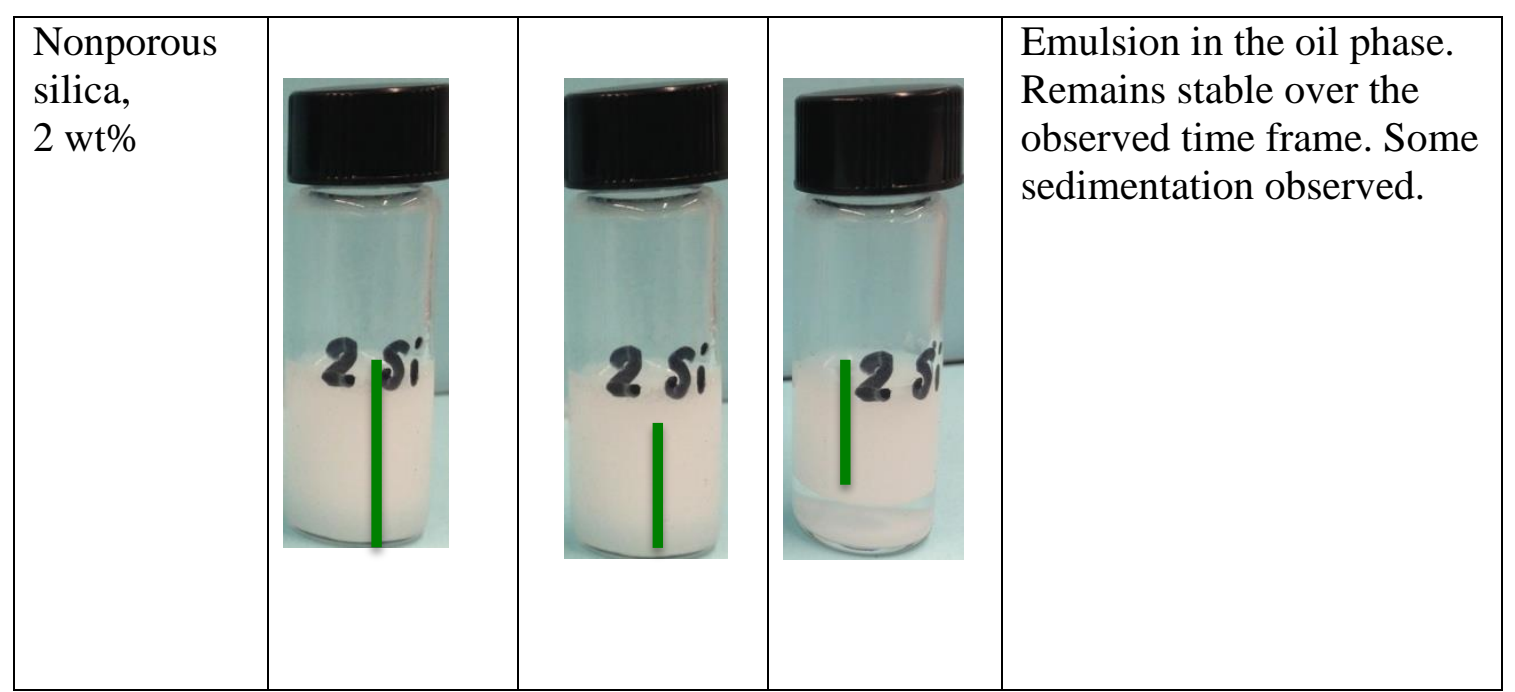


Table 6.6: Emulsification of octane and DI water by DOPC PBC SNPs at various particle concentrations w.r.t the aqueous phase. Oil-phase dye (Sudan IV) used.

\begin{tabular}{|c|c|c|c|}
\hline $\begin{array}{l}\text { Description } \\
\text { of emulsion }\end{array}$ & $\begin{array}{l}\text { Immediatel } \\
\text { y after } \\
\text { vortex }\end{array}$ & $\begin{array}{l}72 \text { hours } \\
\text { later }\end{array}$ & Characterization of emulsion \\
\hline $\begin{array}{l}\text { DOPC SNP } \\
0.1 \mathrm{wt} \%\end{array}$ & & & Emulsion in the water phase. \\
\hline $\begin{array}{l}\text { DOPC SNP } \\
1 \mathrm{wt} \%\end{array}$ & & & $\begin{array}{l}\text { Emulsion in the water phase. } \\
\text { Sedimentation observed. }\end{array}$ \\
\hline $\begin{array}{l}\text { DOPC SNP } \\
2 \mathrm{wt} \%\end{array}$ & & & Emulsion in the water phase \\
\hline
\end{tabular}


Table 6.7: Emulsification of octane and DI water by DPPC PBC SNPs at various particle concentrations w.r.t. the aqueous phase. Oil-phase dye (Sudan IV) used.

\begin{tabular}{|c|c|c|c|}
\hline $\begin{array}{l}\text { Description } \\
\text { of emulsion }\end{array}$ & $\begin{array}{l}\text { Immediatel } \\
\text { y after } \\
\text { vortex }\end{array}$ & $\begin{array}{l}72 \text { hours } \\
\text { later }\end{array}$ & $\begin{array}{l}\text { Characterization of } \\
\text { emulsion }\end{array}$ \\
\hline $\begin{array}{l}\text { DPPC SNP } \\
0.1 \mathrm{wt} \%\end{array}$ & & & $\begin{array}{l}\text { No visible emulsion. Some } \\
\text { oil droplets in the water } \\
\text { phase and sedimentation } \\
\text { observed. }\end{array}$ \\
\hline $\begin{array}{l}\text { DPPC SNP } \\
1 \mathrm{wt} \%\end{array}$ & & & $\begin{array}{l}\text { Rapid emulsion } \\
\text { destabilization observed. } \\
\text { Significant oil mineral } \\
\text { aggregate sedimentation } \\
\text { observed. }\end{array}$ \\
\hline $\begin{array}{l}\text { DPPC SNP } \\
2 \mathrm{wt} \%\end{array}$ & & & $\begin{array}{l}\text { Rapid emulsion } \\
\text { destabilization observed. } \\
\text { Significant oil mineral } \\
\text { aggregate sedimentation } \\
\text { observed. }\end{array}$ \\
\hline
\end{tabular}


Table 6.8: Emulsification of octane and DI water by DPPC liposomes at various concentrations w.r.t. the aqueous phase. Oil-phase dye (Sudan IV) used. No removal of free lipid.

\begin{tabular}{|c|c|c|c|}
\hline $\begin{array}{l}\text { Description } \\
\text { of emulsion }\end{array}$ & $\begin{array}{l}\text { Immediatel } \\
\text { y after } \\
\text { vortex }\end{array}$ & $\begin{array}{l}72 \text { hours } \\
\text { later }\end{array}$ & $\begin{array}{l}\text { Characterization of } \\
\text { emulsion }\end{array}$ \\
\hline $\begin{array}{l}\text { DPPC } \\
0.1 \mathrm{wt} \% \\
\text { equivalent }\end{array}$ & & & $\begin{array}{l}\text { No visible emulsion. Some } \\
\text { oil droplets in the water } \\
\text { phase observed. }\end{array}$ \\
\hline $\begin{array}{l}\text { DPPC } \\
1 \mathrm{wt} \% \\
\text { equivalent }\end{array}$ & & & Emulsion in the oil phase. \\
\hline $\begin{array}{l}\text { DPPC } \\
2 \mathrm{wt} \%\end{array}$ & & & $\begin{array}{l}\text { Emulsion observed primarily } \\
\text { in the oil phase but also in } \\
\text { the water phase. }\end{array}$ \\
\hline
\end{tabular}


Table 6.9: Emulsification of octane and DI water by DOPC liposomes at various concentrations w.r.t. the aqueous phase. Oil-phase dye (Sudan IV) used. No removal of free lipid.

\begin{tabular}{|c|c|c|c|}
\hline $\begin{array}{l}\text { Description } \\
\text { of emulsion }\end{array}$ & $\begin{array}{l}\text { Immediately } \\
\text { after vortex }\end{array}$ & $\begin{array}{l}72 \text { hours } \\
\text { later }\end{array}$ & $\begin{array}{l}\text { Characterization of } \\
\text { emulsion }\end{array}$ \\
\hline $\begin{array}{l}\text { DOPC } \\
0.1 \mathrm{wt} \% \\
\text { equivalent }\end{array}$ & & & $\begin{array}{l}\text { Emulsion in the oil phase. } \\
\text { Some oil sedimentation } \\
\text { observed. }\end{array}$ \\
\hline $\begin{array}{l}\text { DOPC } \\
1 \mathrm{wt} \% \\
\text { equivalent }\end{array}$ & & & $\begin{array}{l}\text { Emulsion in the oil phase. } \\
\text { Coalescence observed in } \\
\text { the given time frame. }\end{array}$ \\
\hline $\begin{array}{l}\text { DOPC } \\
2 \mathrm{wt} \%\end{array}$ & & & $\begin{array}{l}\text { Emulsion in the oil phase. } \\
\text { Coalescence observed in } \\
\text { the given time frame. } \\
\text { Sedimented oil droplets } \\
\text { observed. }\end{array}$ \\
\hline
\end{tabular}


Table 6.10: Emulsification of octane and DI water by SNPs. Oil-phase dye (Sudan IV) used.

\begin{tabular}{|c|c|c|c|}
\hline $\begin{array}{l}\text { Description } \\
\text { of emulsion }\end{array}$ & $\begin{array}{l}\text { Immediatel } \\
\text { y after } \\
\text { vortex }\end{array}$ & $\begin{array}{l}72 \text { hours } \\
\text { later }\end{array}$ & $\begin{array}{l}\text { Characterization of } \\
\text { emulsion }\end{array}$ \\
\hline $\begin{array}{l}\text { Nonporous } \\
\text { silica } \\
0.1 \mathrm{wt} \%\end{array}$ & & & $\begin{array}{l}\text { No visible emulsion } \\
\text { observed. Sedimentation of } \\
\text { silica particles observed. }\end{array}$ \\
\hline $\begin{array}{l}\text { Nonporous } \\
\text { silica } \\
1 \mathrm{wt} \%\end{array}$ & & & $\begin{array}{l}\text { Emulsion in the water phase } \\
\text { observed. Significant } \\
\text { sedimentation of silica } \\
\text { particles and some oil } \\
\text { droplets observed. }\end{array}$ \\
\hline $\begin{array}{l}\text { Nonporous } \\
\text { silica } \\
2 \mathrm{wt} \%\end{array}$ & & & $\begin{array}{l}\text { Emulsion in the water phase } \\
\text { observed. Significant } \\
\text { sedimentation of silica } \\
\text { particles and some oil } \\
\text { droplets observed. }\end{array}$ \\
\hline
\end{tabular}


Table 6.11: Emulsification of octane and DI water with low concentrations of DPPC and DOPC PBC SNPS. No free lipid removal step.

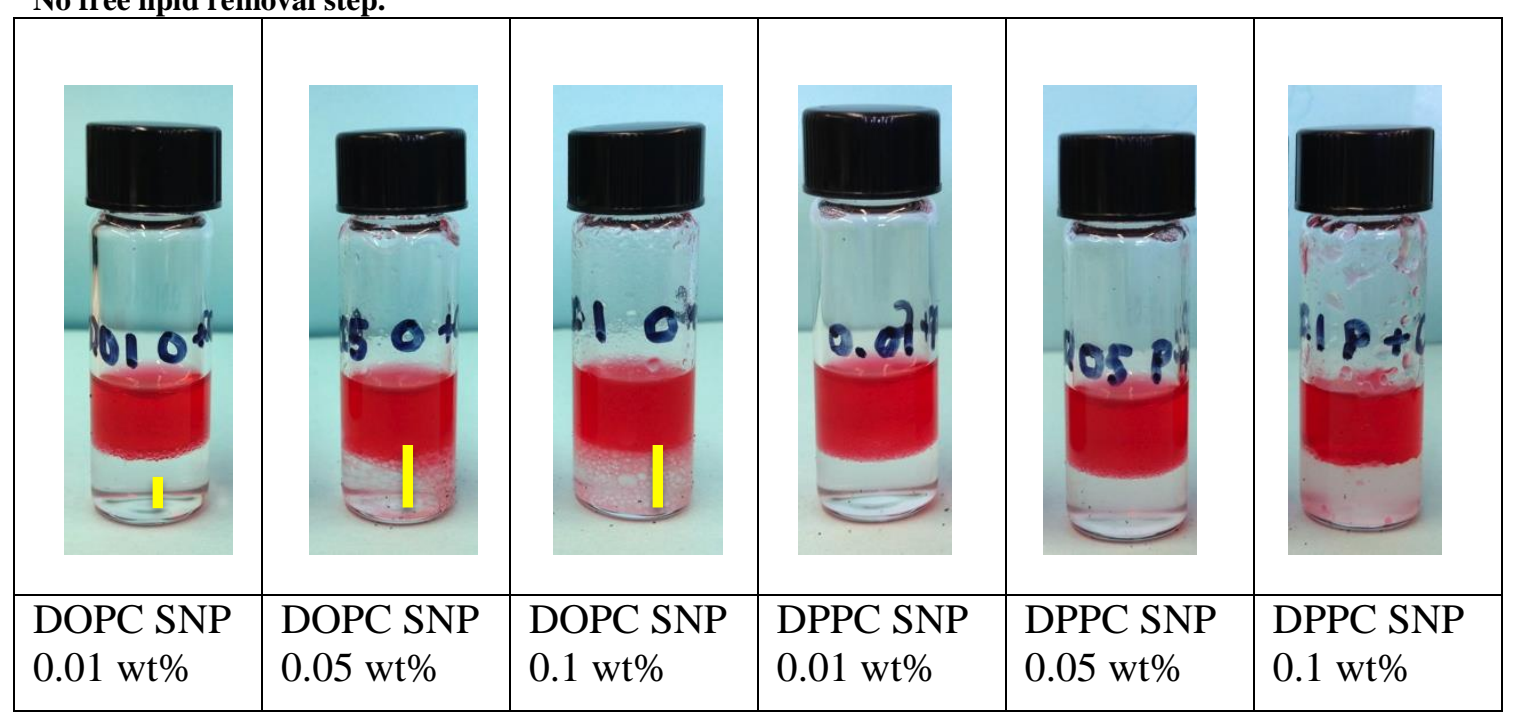

\subsection{Lipid bilayer-coated silica particles}

Figure 6.13: Stability of crude oil - DI water emulsion stabilized with DPPC BC SNP (0.1 wt\%).

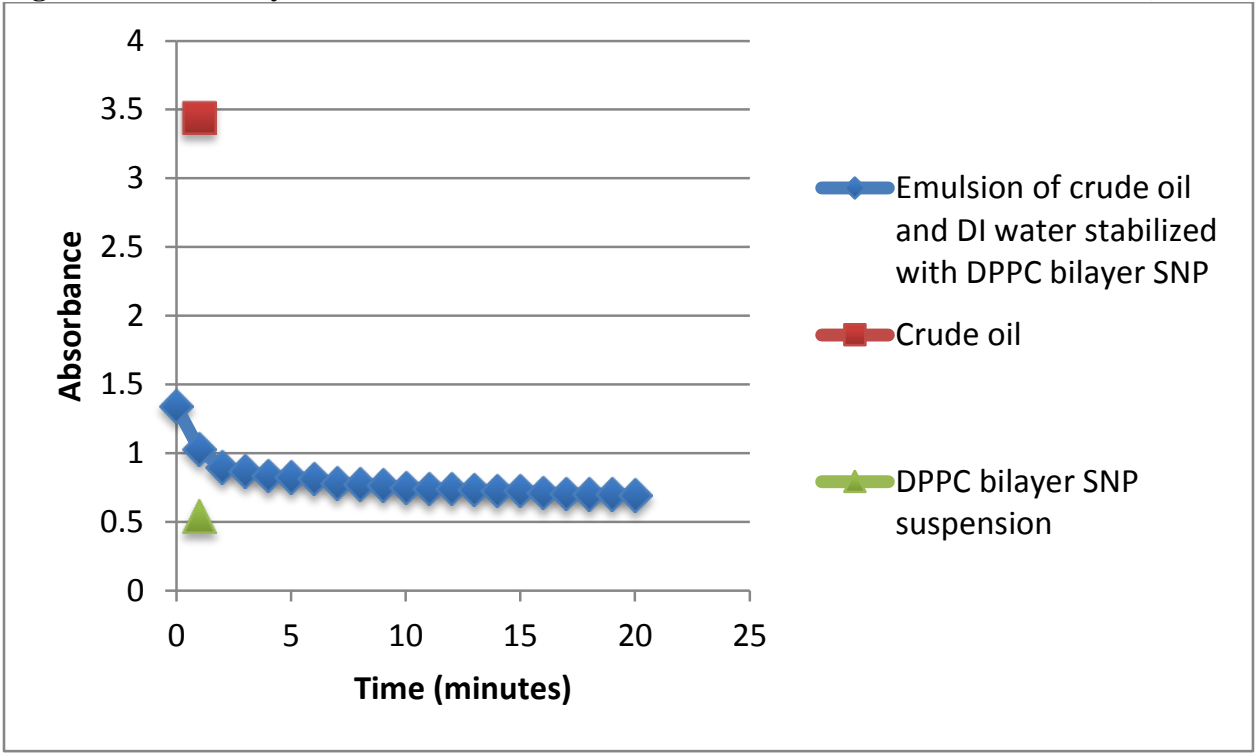


Figure 6.14: Stability of crude oil - DI water emulsion stabilized with DOPC BC SNP (0.1 wt\%).

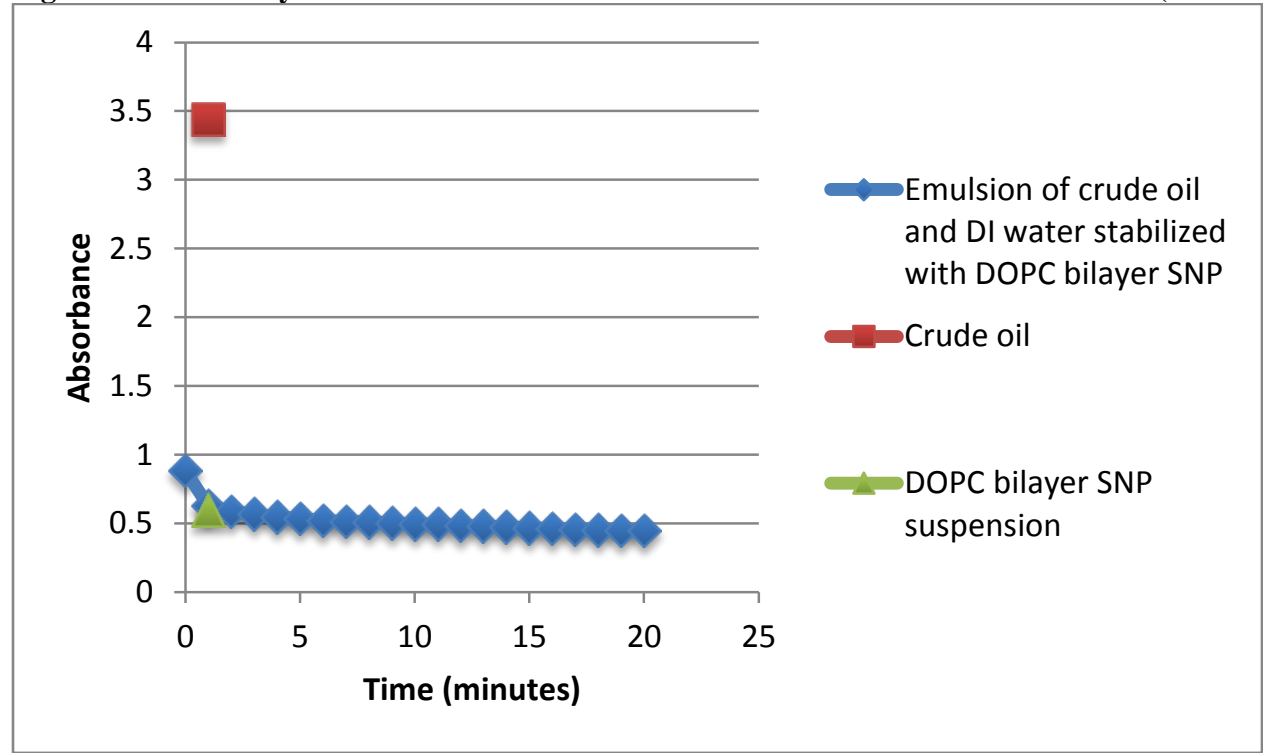

Figure 6.15: Stability of crude oil - DI water emulsion stabilized with SNPs as received $(0.1 \mathrm{wt} \%)$.

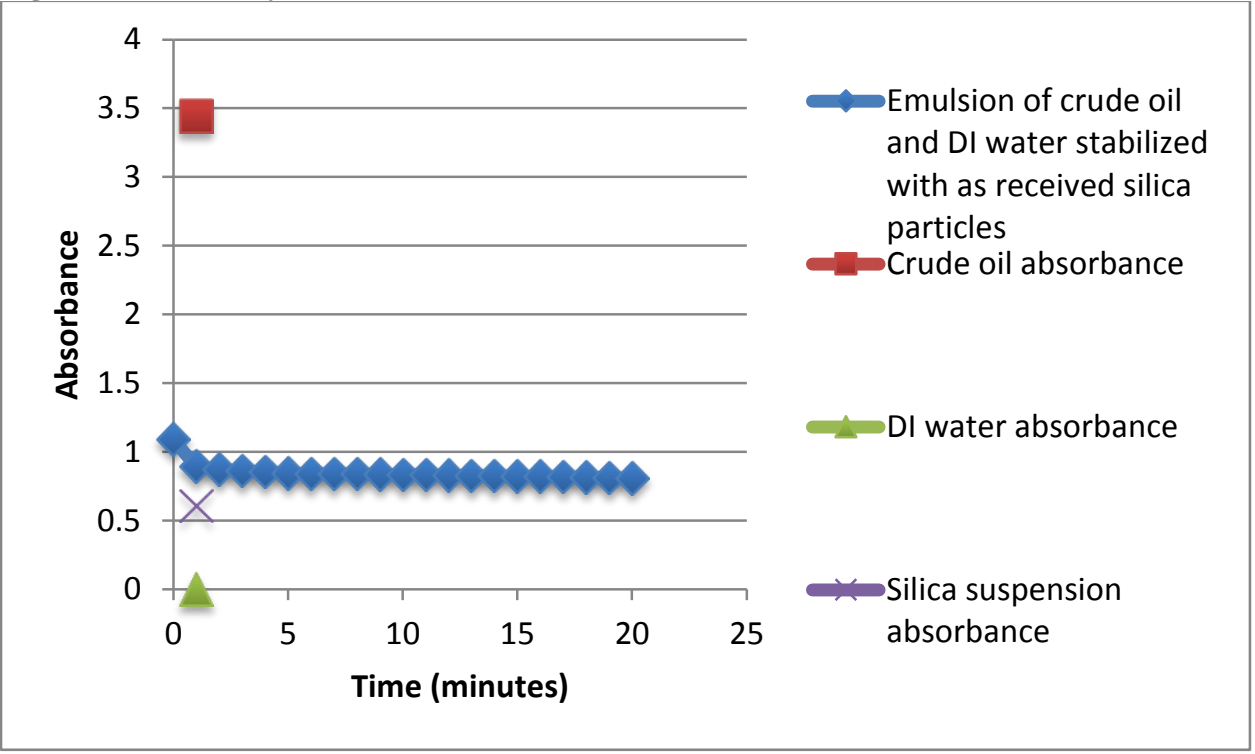




\subsection{Lipid monolayer-coated silica particles (MC SNPs)}

\subsubsection{Characterization of MC SNPs}

Figure 6.16: Size distribution of hydrophilic silica particles in toluene before grafting of silane groups (DLS output).

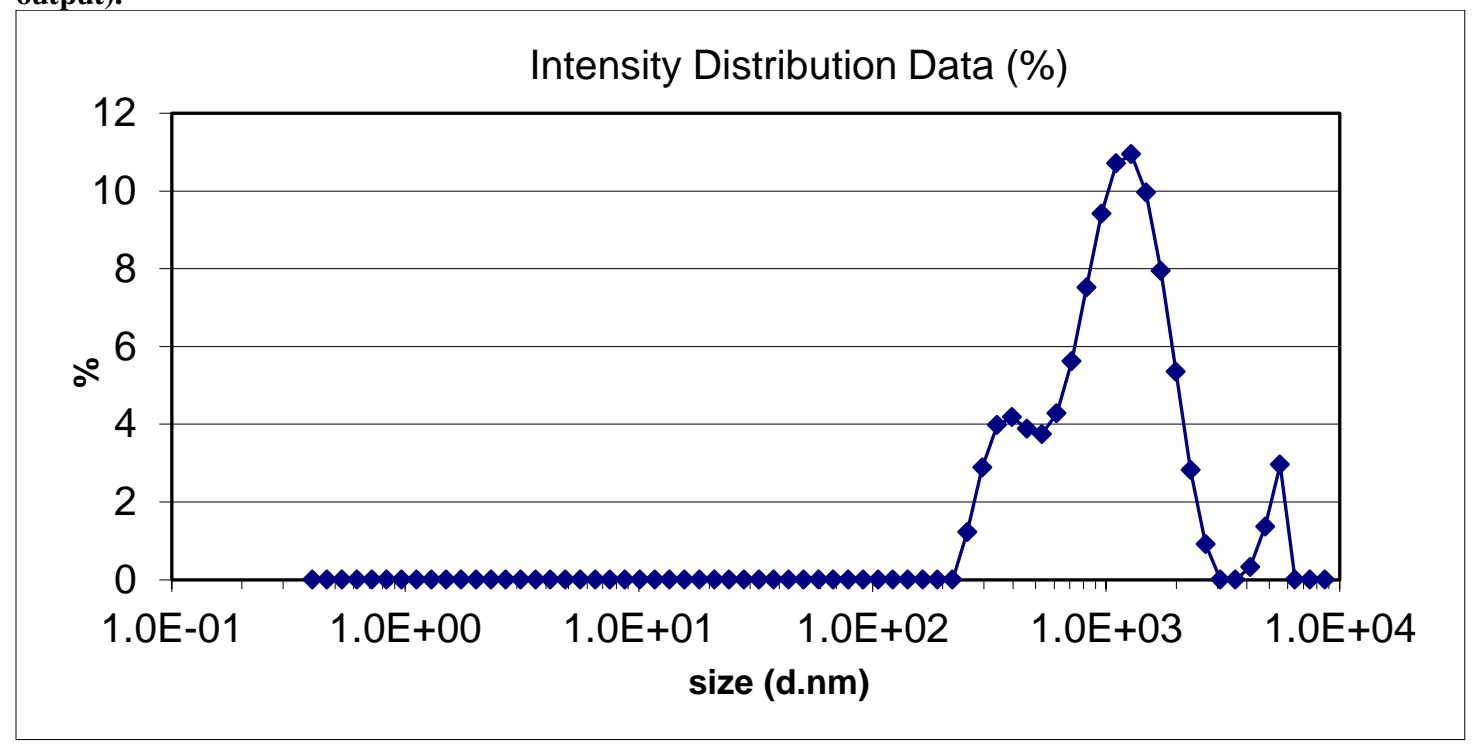

Figure 6.17: Size distribution of hydrophobic silica particles in toluene before adsorption of lipid.

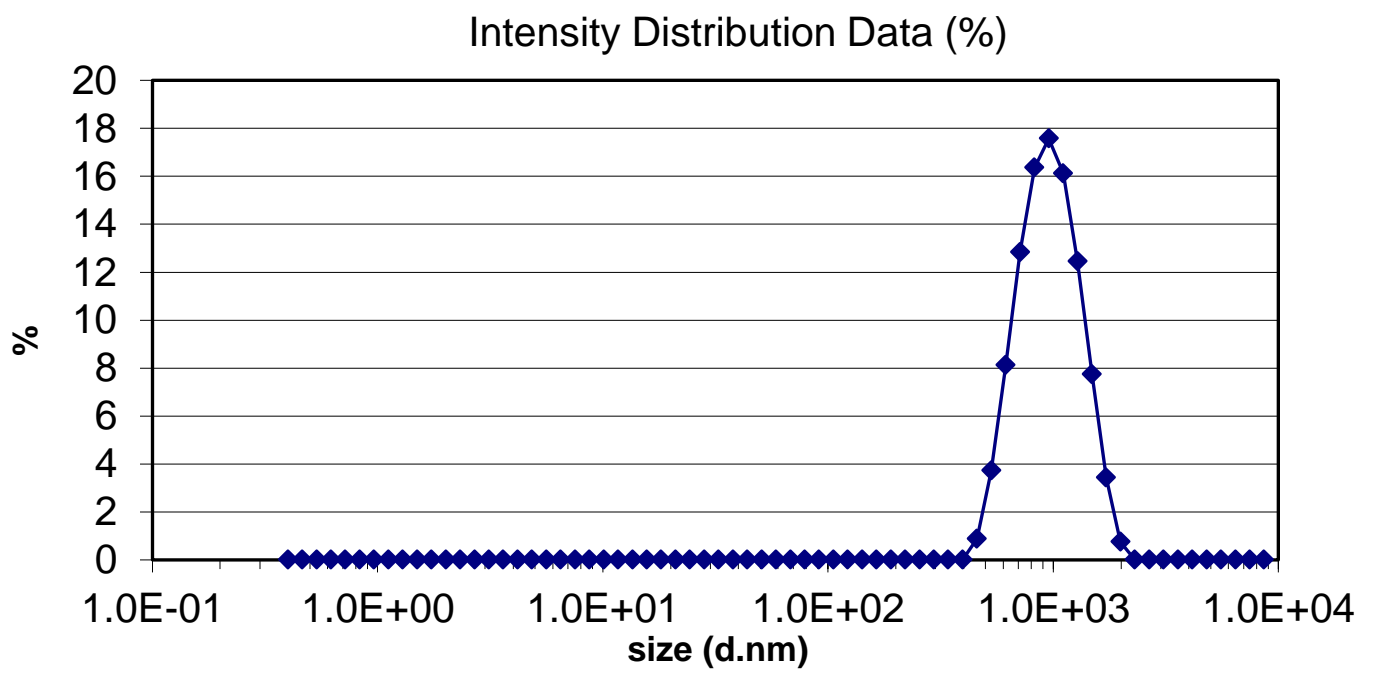


Figure 6.18: Size distribution of DOPC liposomes before adsorption to hydrophobic silica particles.

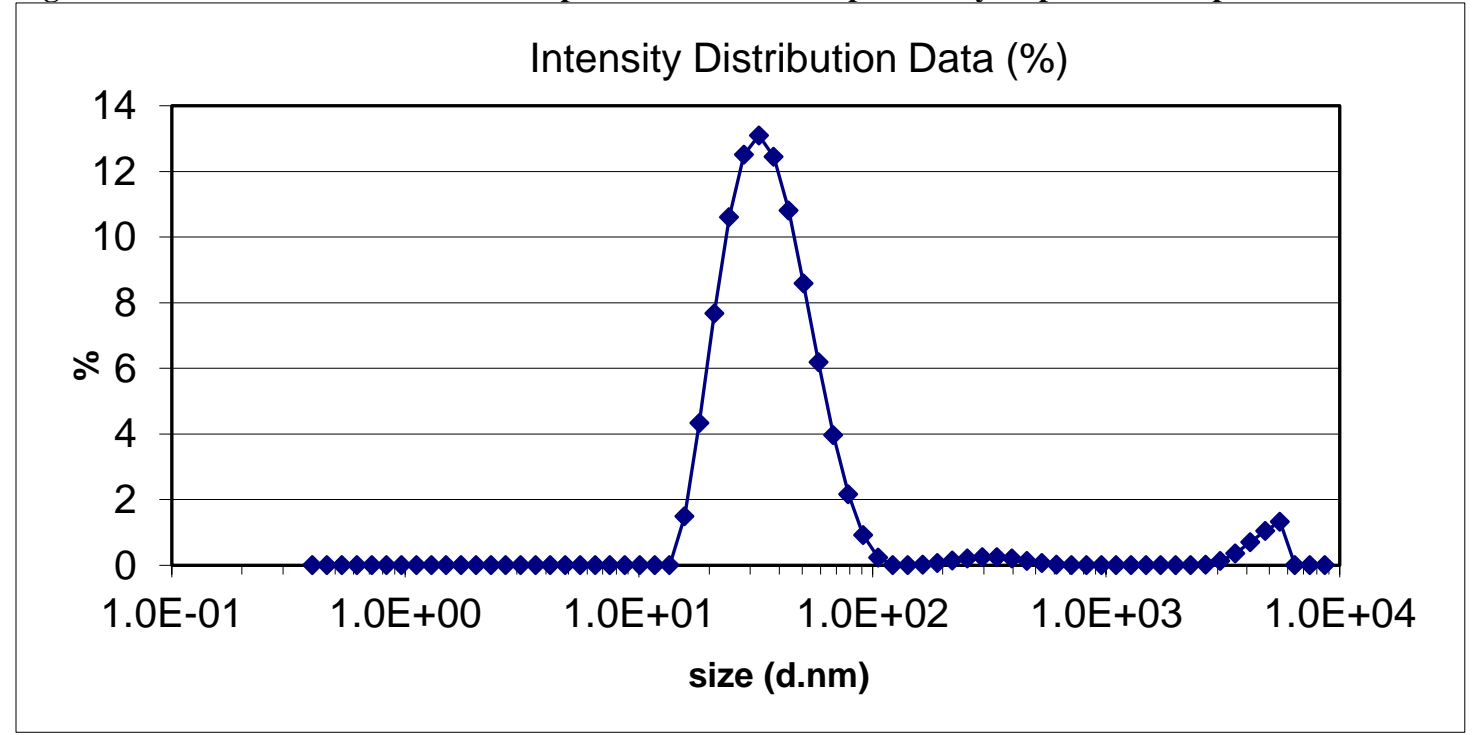

Figure 6.19: Size distribution of DOPC MC SNPs in DI water.

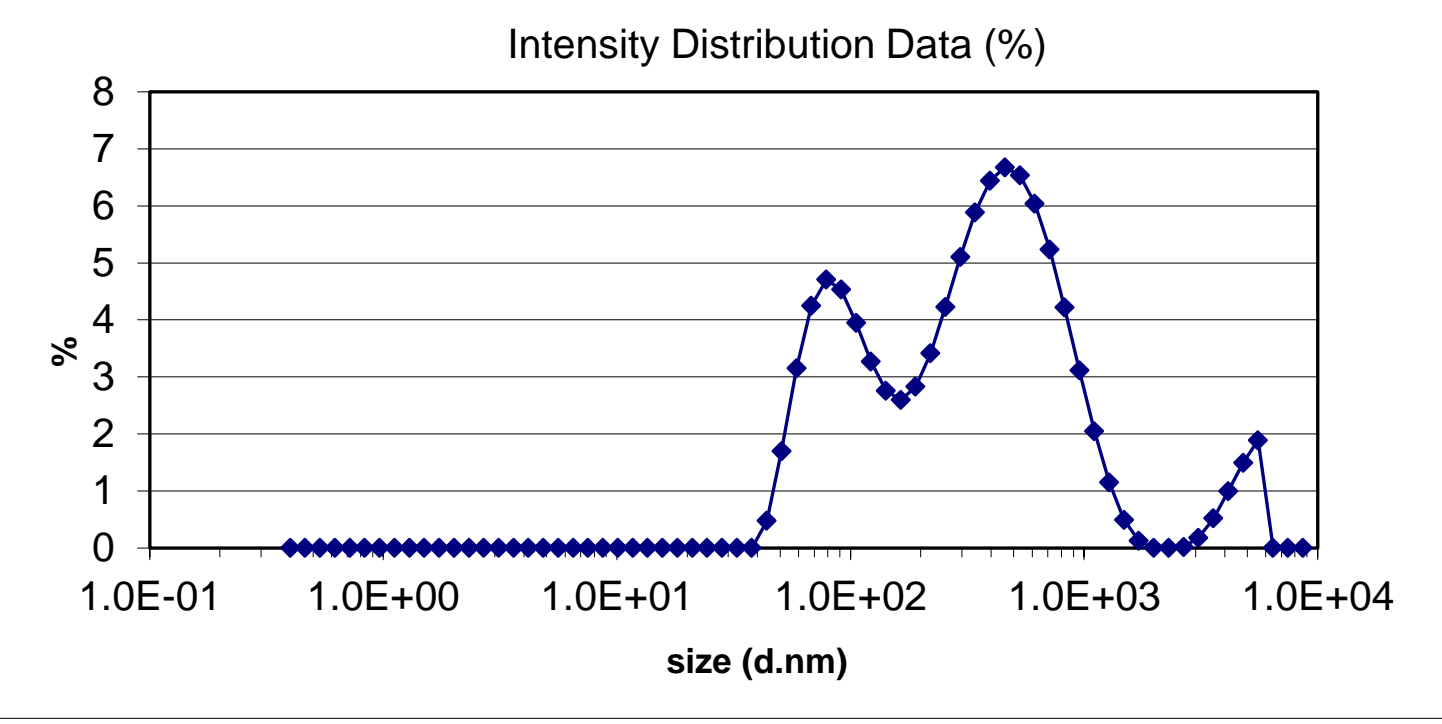


Figure 6.20 Size distribution of DPPC MC SNPs in DI water.

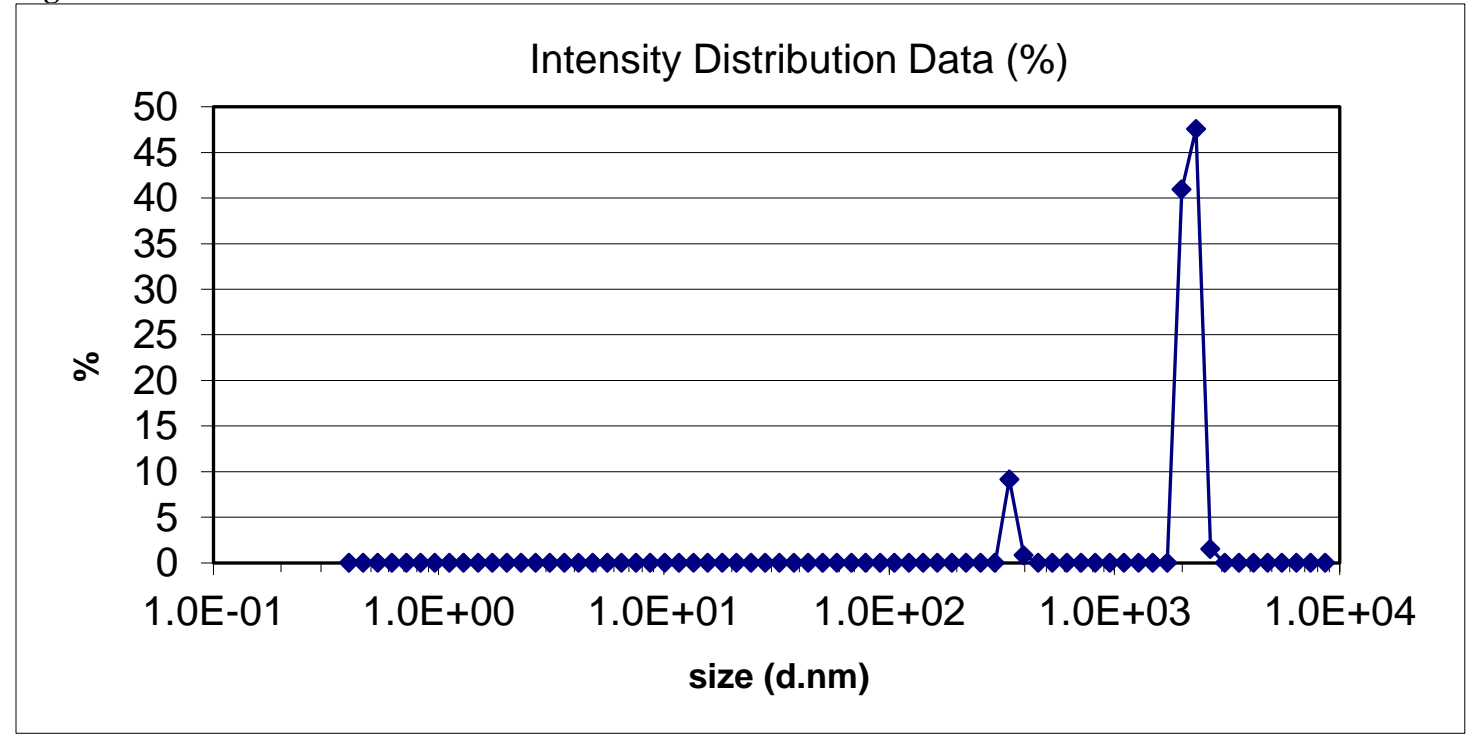




\subsubsection{Performance of MC SNPs}

Figure 6.21: Stability of crude oil - DI water emulsion stabilized with DPPC MC SNPs (0.1 wt\%).

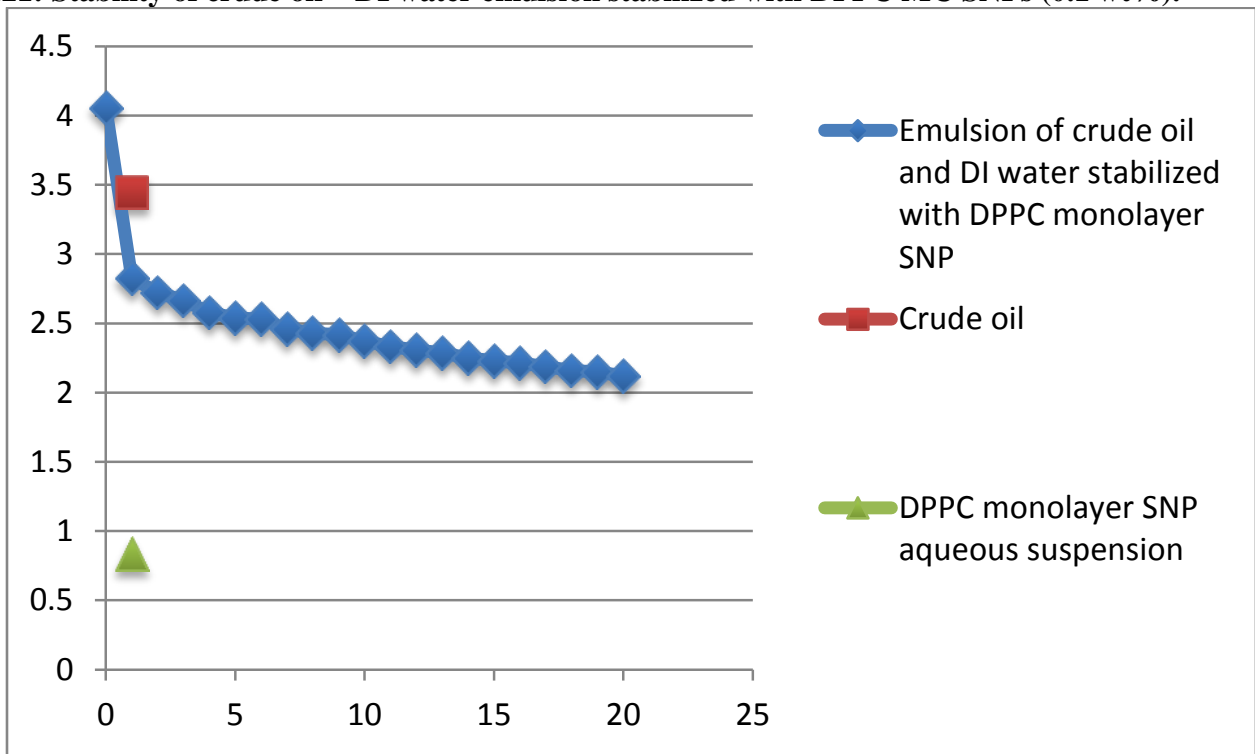

Figure 6.22: Stability of crude oil - DI water emulsion stabilized with DOPC MC SNPs (0.1 wt\%).

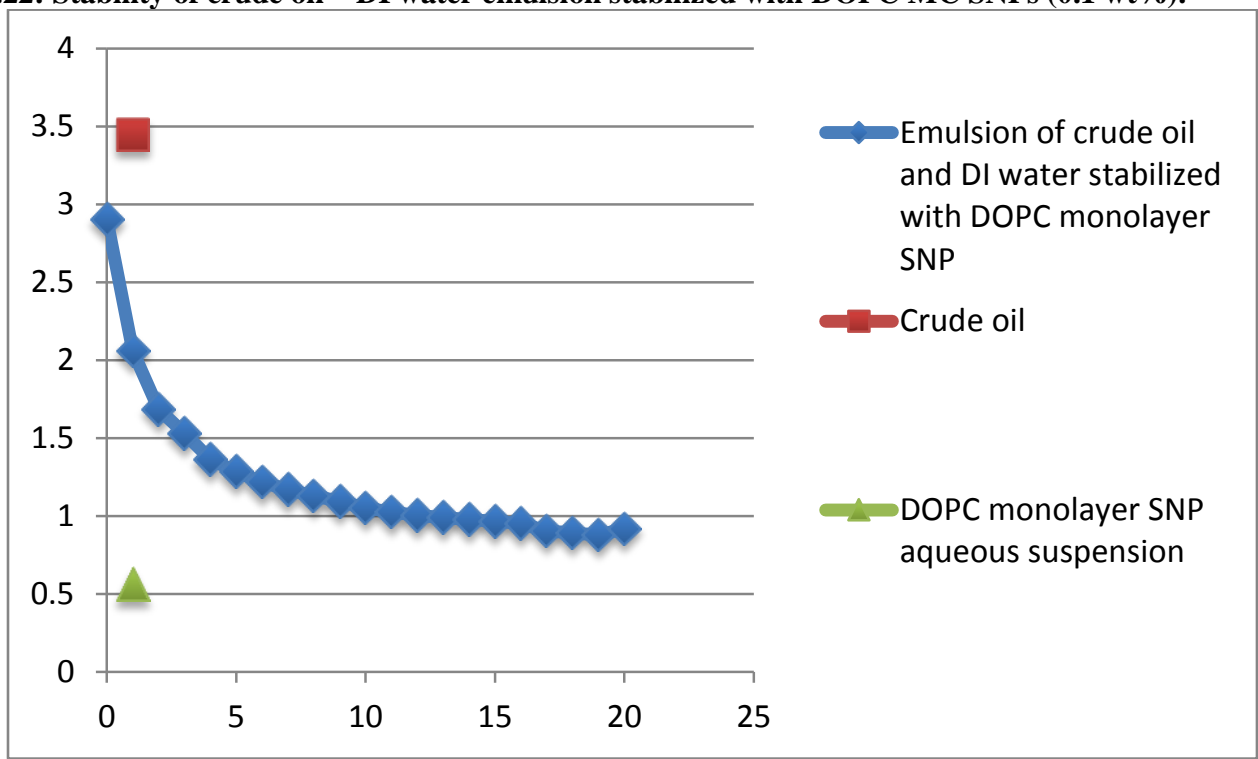




\section{BIBLIOGRAPHY}

Alaska Department of Environmental Conservation. (1993). The Exxon Valdez Oil Spill: Final Report State of Alaska Response. State of Alaska, Department of Environmental Conservation, Office of the Commissioner, Juneau.

Aveyard, R., Binks, B.P. \& Clint, J.H. (2003). Emulsions stabilised solely by colloidal particles. Advances in Colloid and Interface Science 100-102: 503-546.

Bayerl, T.M. \& Bloom, M. (1990). Physical properties of single phospholipid bilayers adsorbed to micro glass beads. A new vesicular model system studied by $2 \mathrm{H}-$ nuclear magnetic resonance. Biophysical journal 58(2): 357-62.

Binks, B.P. \& Lumsdon, S.O. (2000). Influence of Particle Wettability on the Type and Stability of Surfactant-Free Emulsions. Langmuir 16(23): 8622-8631.

BP. (2014). BP Global: Gulf of Mexico Restoration. Retrieved June 11, 2014, from http://www.bp.com/en/global/corporate/gulf-of-mexico-restoration.html.

Bragg, J., Prince, R., Harner, E. \& Atlas, R. (1994). Effectiveness of bioremediation for the Exxon Valdez oil spill. Nature 368: 413-418.

Chevalier, Y. \& Bolzinger, M.-A. (2013). Emulsions stabilized with solid nanoparticles: Pickering emulsions. Colloids and Surfaces A: Physicochemical and Engineering Aspects 439: 23-34.

Chibowski, E., Szcześ, A. \& Hołysz, L. (2010). Changes of zeta potential and particles size of silica caused by DPPC adsorption and enzyme phospholipase A2 presence. Adsorption 16(4-5): 305-312.

EPA. (2011). Composition of Crude OIl and Refined Products. Dallas, Texas. Retrieved from http://www.epa.gov/region6/6en/xp/longhorn_nepa_documents/lppapp6a.pdf

EPA. (2014). Oil Spill Response Techniques. Retrieved June 12, 2014, from http://www.epa.gov/osweroe1/content/learning/oiltech.htm.

Filler, D.M., Snape, I. \& Barnes, D.L. (eds.). (2008). Bioremediation of Petroleum Hydrocarbons in Cold Regions. Cambridge: Cambridge University Press.

Franklin, C.L. \& Warner, L.J. (2011). The Role and Regulation of Dispersants in Oil Spill Response. Natural Resources \& Environment 26(2): 26-29.

Frelichowska, J., Bolzinger, M.-A. \& Chevalier, Y. (2009). Pickering emulsions with bare silica. Colloids and Surfaces A: Physicochemical and Engineering Aspects 343(1-3): 70-74. 
George-Ares, a \& Clark, J.R. (2000). Aquatic toxicity of two Corexit dispersants. Chemosphere 40(8): 897-906.

Gong, Y., Zhao, X., Cai, Z., O’Reilly, S.E., Hao, X. \& Zhao, D. (2014). A review of oil, dispersed oil and sediment interactions in the aquatic environment: Influence on the fate, transport and remediation of oil spills. Marine Pollution Bulletin 79(1-2): 16-33.

González, J., Figueiras, F.G., Aranguren-Gassis, M., Crespo, B.G., Fernández, E., Morán, X. a. G. \& Nieto-Cid, M. (2009). Effect of a simulated oil spill on natural assemblages of marine phytoplankton enclosed in microcosms. Estuarine, Coastal and Shelf Science 83(3): 265-276.

Goodbody-Gringley, G., Wetzel, D.L., Gillon, D., Pulster, E., Miller, A. \& Ritchie, K.B. (2013). Toxicity of Deepwater Horizon source oil and the chemical dispersant, Corexit ${ }^{\circledR}$ 9500, to coral larvae. PloS one 8(1): 78-85.

Gruner, S.M., Tate, M.W., Kirk, G.L., So, P.T.C., Turner, D.C. \& Keane, D.T. (1988). X-ray Diffraction Study of the Polymorphic Behavior of N-Methylated Dioleoylphosphatidylethanolamine. Biochemistry (1984): 2853-2866.

Gupta, A., Sender, M., Fields, S. \& Bothun, G. (2014). Phase and sedimentation behavior of oil (octane) dispersions in the presence of model mineral aggregates. Accepted to Marine Pollution Bulletin.

Hazen, T. (2011). The Gulf Oil Spill - Where Did All the Oil Go? Retrieved June 22, 2014, http://energyseminar.stanford.edu/node/315.

He, Y., Wu, F., Sun, X., Li, R., Guo, Y., Li, C., ... Gao, J. (2013). Factors that affect Pickering emulsions stabilized by graphene oxide. ACS applied materials \& interfaces 5(11): 4843-55.

Hemmer, M.J., Barron, M.G. \& Greene, R.M. (2011). Comparative toxicity of eight oil dispersants, Louisiana sweet crude oil (LSC), and chemically dispersed LSC to two aquatic test species. Environmental toxicology and chemistry/SETAC 30(10): 2244-52.

Hemmer, M.J., Barron, Mace, G. \& Greene, R.M. (2010). Comparative Toxicity of Eight Oil Dispersant Products on Two Gulf of Mexico Aquatic Test Species. USEPA Dispersant Toxicity Testing.

Howarth, R.W. (1988). Nutrient Limitation of Net Primary Production in Marine Ecosystems. Annual Review of Ecology and Systematics 19: 89-110. 
Howarth, R.W. \& Marino, R. (2006). Nitrogen as the limiting nutrient for eutrophication in coastal marine ecosystems: Evolving views over three decades. Limnology and Oceanography 51: 364-376.

Kujawinski, E.B., Kido Soule, M.C., Valentine, D.L., Boysen, A.K., Longnecker, K. \& Redmond, M.C. (2011). Fate of dispersants associated with the deepwater horizon oil spill. Environmental science \& technology 45(4): 1298-306.

Leonenko, Z. V, Finot, E., Ma, H., Dahms, T.E.S. \& Cramb, D.T. (2004). Investigation of temperature-induced phase transitions in DOPC and DPPC phospholipid bilayers using temperature-controlled scanning force microscopy. Biophysical journal 86(6): 3783-93.

Lessard, R.R. \& Demarco, G. (2000). The Significance of Oil Spill Dispersants. Spill Science \& Technology Bulletin 6(1): 59-68.

Li, Z., Kepkay, P., Lee, K., King, T., Boufadel, M.C. \& Venosa, A.D. (2007). Effects of chemical dispersants and mineral fines on crude oil dispersion in a wave tank under breaking waves. Marine pollution bulletin 54(7): 983-93.

Liang, H.-N. \& Tang, C. (2014). Pea protein exhibits a novel Pickering stabilization for oil-in-water emulsions at $\mathrm{pH}$ 3.0. LWT - Food Science and Technology 58(2): 463-469.

Lide, D.R. \& Haynes, W.M. (2010). CRC Handbook of Chemistry (90th ed.). Taylor and Francis Group: New York.

Liu, J., Stace-Naughton, A., Jiang, X. \& Brinker, C.J. (2009). Porous nanoparticle supported lipid bilayers (protocells) as delivery vehicles. Journal of the American Chemical Society 131(4): 1354-5.

MacDonald, R.C., Ashley, G.W., Shida, M.M., Rakhmanova, V. a., Tarahovsky, Y.S., Pantazatos, D.P., ... McIntosh, T.J. (1999). Physical and Biological Properties of Cationic Triesters of Phosphatidylcholine. Biophysical Journal 77(5): 26122629.

Mager, M.D. \& Melosh, N. a. (2007). Lipid bilayer deposition and patterning via air bubble collapse. Langmuir. 23(18): 9369-77.

Marsh, D. (1990). CRC Handbook of Lipid Bilayer. Boston: CRC Press Inc.

Malvern Instruments (2014a) An Introduction to Dynamic Light Scattering in 30 Minutes. Zetasizer Nano Series. Worcester, UK: Malvern Instruments Worldwide. 
Malvern Instruments (2014b) An Introduction to Zeta Potential in 30 Minutes. Zetasizer Nano Series. Worcester, UK: Malvern Instruments Worldwide.

Mayer, L.A., Boufadel, M.C., Brenner, J., Carne, R.S., Cooper, C.K. \& Deming, J.W. (2013). An Ecosystem Services Approach to Assessing the Impacts of the Deepwater Horizon Oil Spill in the Gulf of Mexico. Report Brief. Washington, D.C.: National Academy of Sciences.

Melle, S., Lask, M. \& Fuller, G.G. (2005). Pickering emulsions with controllable stability. Langmuir 21: 2158-62.

Michel, J. \& Hayes, M.O. (1999). Weathering Patterns of Oil Residues Eight Years after the Exxon Valdez Oil Spill. Marine Pollution Bulletin 38(10): 855-863.

Mornet, S., Lambert, O., Duguet, E. \& Brisson, A. (2005). The formation of supported lipid bilayers on silica nanoparticles revealed by cryoelectron microscopy. Nano letters 5(2): 281-5.

Nalco (2014). Corexit Components. Retrieved June 12, 2014, http://www.nalcoesllc.com/nes/1602.htm

NG. (2011). Oil-Eating Bacteria Engineered. National Geographic. Retrieved June 12, 2014, from http://video.nationalgeographic.com/video/news/nsf-oilsomasundaran-vin

NRC. (1989). Using Oil Spill Dispersants on the Sea. Washington, D.C.: National Academy Press.

NRC. (2005). Oil Spill Dispersants: Efficacy and Effects. Washington, D.C.: National Academies Press.

Paytan, A. \& McLaughlin, K. (2007). The oceanic phosphorus cycle. Chemical reviews 107(2): 563-76.

Pickering, S.U. (1907). Emulsions. J. Chem. Soc. 91: 2001-2021.

Place, B.J., Perkins, M.J., Sinclair, E., Barsamian, A.L., Blakemore, P.R. \& Field, J. a. (2014). Trace analysis of surfactants in Corexit oil dispersant formulations and seawater. Deep Sea Research Part II: Topical Studies in Oceanography (Tween 80): $1-9$.

Reddy, C.M., Arey, J.S., Seewald, J.S., Sylva, S.P., Lemkau, K.L., Nelson, R.K., ... Camilli, R. (2012). Composition and fate of gas and oil released to the water column during the Deepwater Horizon oil spill. Proceedings of the National Academy of Sciences of the United States of America 109(50): 20229-34. 
Rial, D., Radović, J.R., Bayona, J.M., Macrae, K., Thomas, K. V \& Beiras, R. (2013). Effects of simulated weathering on the toxicity of selected crude oils and their components to sea urchin embryos. Journal of hazardous materials 260: 67-73.

Rogers, J.R. \& Bennett, P.C. (2004). Mineral stimulation of subsurface microorganisms: release of limiting nutrients from silicates. Chemical Geology 203(1-2): 91-108.

Röling, W.F.M., Milner, M.G., Jones, D.M., Lee, K., Daniel, F., Swannell, R.J.P., ... Head, I.M. (2002). Robust Hydrocarbon Degradation and Dynamics of Bacterial Communities during Nutrient-Enhanced Oil Spill Bioremediation Robust Hydrocarbon Degradation and Dynamics of Bacterial Communities during Nutrient-Enhanced Oil Spill Bioremediation. Applied and Environmental Microbiology 68(11): 5537-5548.

Saha, A., Nikova, A., Venkataraman, P., John, V.T. \& Bose, A. (2013). Oil Emulsification Using Surface-Tunable Carbon Black Particles. ACS Applied Materials \& Interfaces. 5: 3094-3100.

Smith, S. V. (1984). Phosphorus versus nitrogen limitation. Limnol. Oceanogr. 29(6): 1149-60.

Tamm, L.K. \& McConnell, H.M. (1985). Supported phospholipid bilayers. Biophysical journal 47(1): 105-13.

Tuck, D.M. (1999). Discussion of Paper: National Ground Water Association. Ground Water 37(4).

Torchilin, V. and V. Weissig. Liposomes: A practical approach, $2^{\text {nd }}$ edition. Oxford University Press, Boston, 2003.

UMD (2003). Piranha Standard Operating Procedure. http://www.lamp.umd.edu/Sop/Piranha_SOP.htm

Wang, W., Zheng, Y. \& Lee, K. (2013). Chemical dispersion of oil with mineral fines in a low temperature environment. Marine pollution bulletin 72(1): 205-12.

Wang, Z.-J. \& Deserno, M. (2010). Systematic implicit solvent coarse-graining of bilayer membranes: lipid and phase transferability of the force field. New journal of physics 12(9): 1-32.

Yang, S.-Z., Jin, H.-J., Wei, Z., He, R.-X., Ji, Y.-J., Li, X.-M. \& Yu, S.-P. (2009). Bioremediation of Oil Spills in Cold Environments: A Review. Pedosphere 19(3): 371-381. 
Zahed, M.A., Aziz, H.A., Isa, M.H., Mohajeri, L., Mohajeri, S. \& Kutty, S.R.M. (2011). Kinetic modeling and half life study on bioremediation of crude oil dispersed by Corexit 9500. Journal of hazardous materials 185(2-3): 1027-31.

Zhao, J., Wu, J., Heberle, F. a, Mills, T.T., Klawitter, P., Huang, G., ... Feigenson, G.W. (2007). Phase studies of model biomembranes: complex behavior of DSPC/DOPC/cholesterol. Biochimica et biophysica acta 1768(11): 2764-76. 